\title{
Motivation, Empowerment, and Cognitive Style in a Community of Practice
}

\section{A case study of a community garden group}

\author{
Simon Tegg \\ $9 / 27 / 2010$
}

ENVI 593

THESIS

Abstract:

Social work and Participatory GIS researchers have focused on the social empowerment of disadvantaged groups while neglecting psychological aspects of empowerment. Social empowerment generally refers to an increase in political or economic power for the disadvantaged. Psychological empowerment generally refers to internal, motivational processes. Community development projects must often balance the two, and the diverse needs, interests, and ideologies of practitioners and participants. It is proposed that two psychological theories can explain how psychological empowerment occurs and varies. These theories are the Empathiser-Sytemiser theory of cognitive style (Baron-Cohen et al., 2005), and Self-Determination theory (Deci and Ryan, 2000). The links between these theories and the implications for empowerment are explored through a case study of a community gardening group and community mapping in Wellington, New Zealand. The thesis argues that empowerment-oriented efforts are especially valuable during economic decline and transition. 
Acknowledgements:

I would like to thank the following people who have provided support and advice throughout this project, without which it would not have been possible. First and foremost the research participants and other members of Kai o Te Aro for donating their time and providing many of the insights. My supervisor Mairead de Roiste for keeping the project on track, and providing advice that greatly improved the result. My family, for their love, support, and encouragement.

In addition, the following people generously contributed in many various ways: Phillip Barker, Charles Barrie, Marianne Bevan, Stuart Corbett, Shamina Bikha, Heidi Clark, Raven Cretny, Zack Dorner, Monica Evans, Julie Anne Genter, Hannah MacKintosh, Emma Moon, Andrew Morrison, Aaron Packhard, Richie Singleton, Rebeka Whale, and the GIS staff at Wellington City Council. 


\section{Contents}

$1 \quad$ INTRODUCTION ..................................................................................... 1

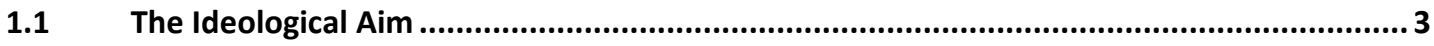

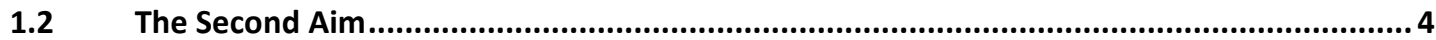

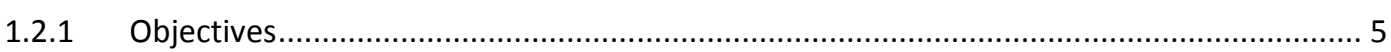

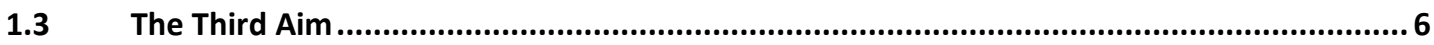

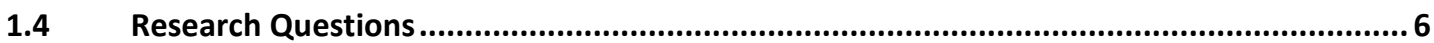

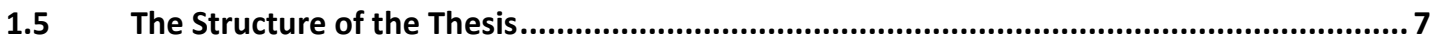

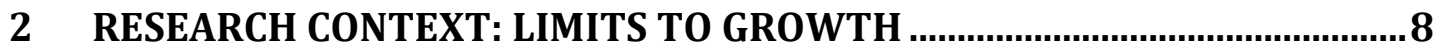

2.1 The Ideology of Sustainable Development ........................................................ 10

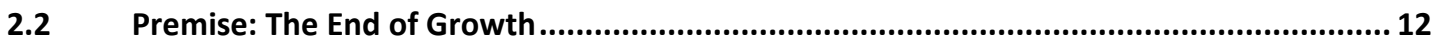

2.2.1 Orthodox Growth Theory: Methodology and Assumptions ........................................ 13

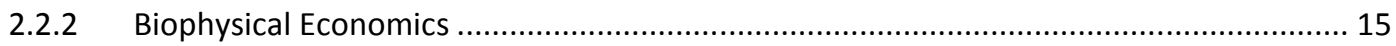

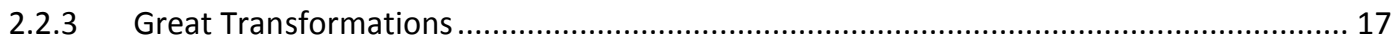

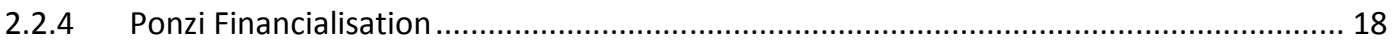

2.2.5 Deindustrialisation: Fossil Fuel Depletion .................................................................. 26

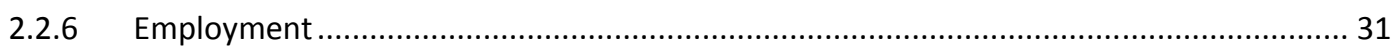

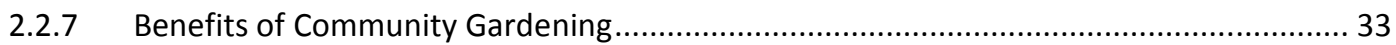

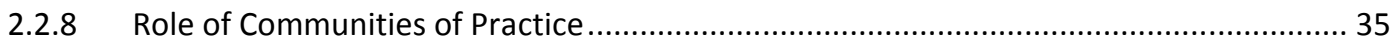

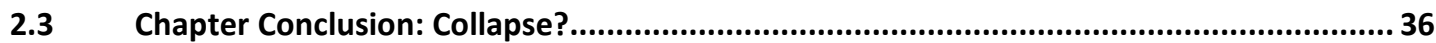




\section{THE PSYCHOLOGY OF EMPOWERMENT AND PARTICIPATORY}

GEOGRAPHIC INFORMATION SYSTEMS ...................................................... 40

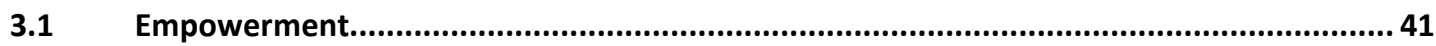

3.2 Participatory Geographic Information Systems (PGIS) .......................................... 42

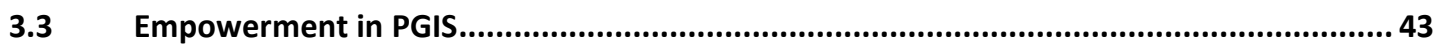

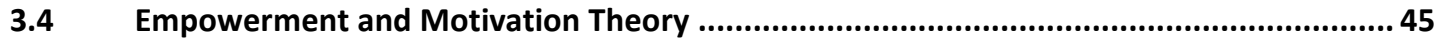

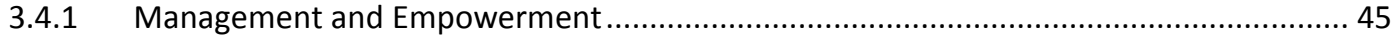

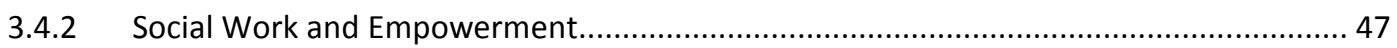

Intrinsic Motivation and Self-Determination (SD) Theory ........................................... 47

3.4.4 Psychological Empowerment Model Summary ...................................................... 52

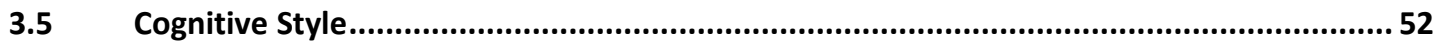

3.5.1 Empathiser-Systemiser Theory of Cognitive Style .................................................. 53

3.6 Application of Motivation and Cognitive Style to Communities of Practice and PGIS ....... 54

4 `METHODOLOGY................................................................................................. 56

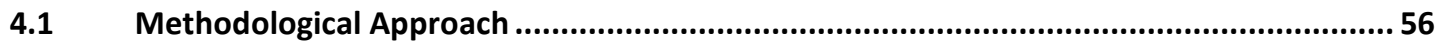

4.1.1 The Problems of Rationalist Research..................................................................... 56

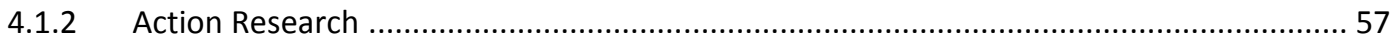

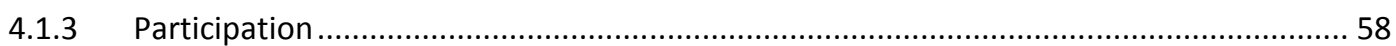

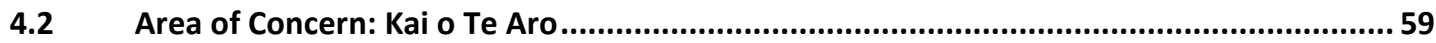

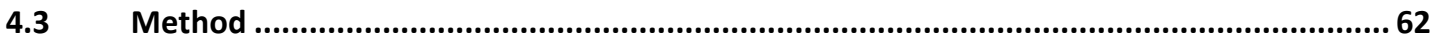

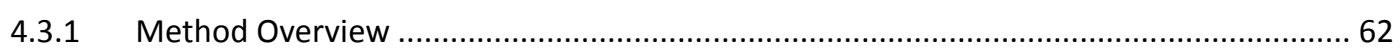

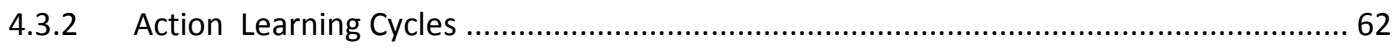

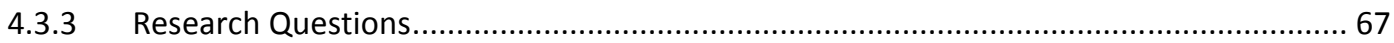

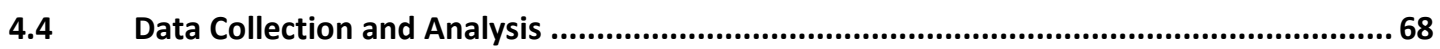

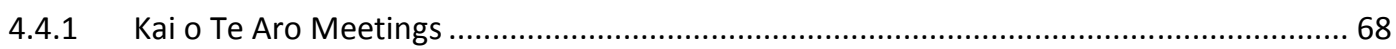

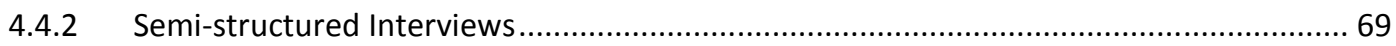

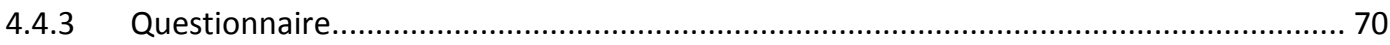

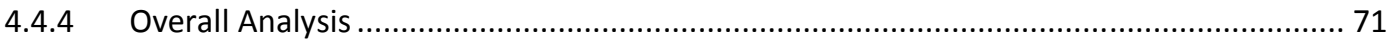




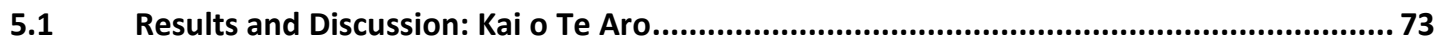

5.1.1 Empathiser-Systemiser Cognitive Style Questionnaires ........................................... 73

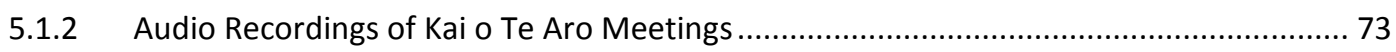

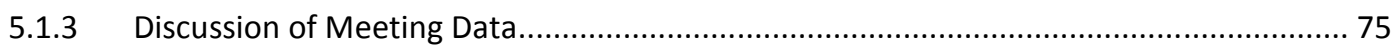

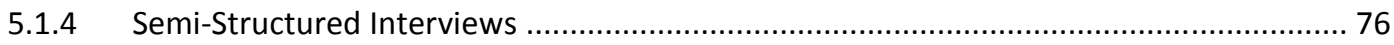

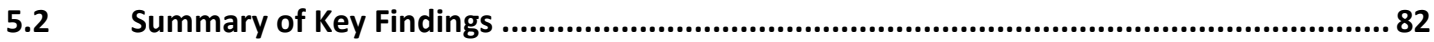

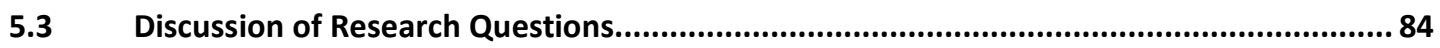

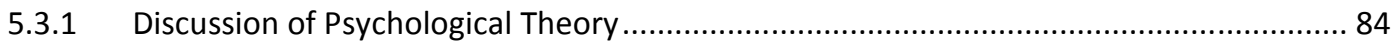

5.3.2 Discussion of Empowerment Theory and Practice....................................................... 85

5.3.3 Discussion of Ideology, Environmentalism and Social Change ................................... 92

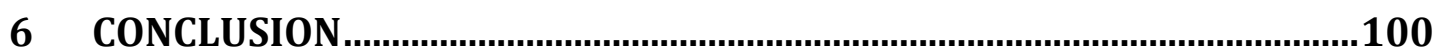

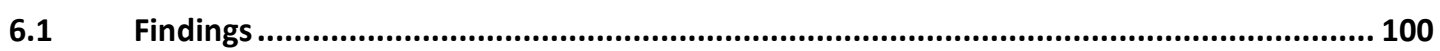

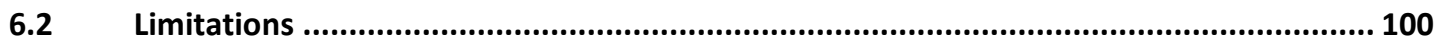

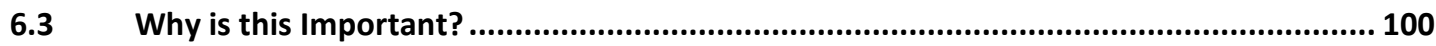

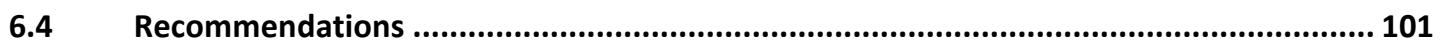

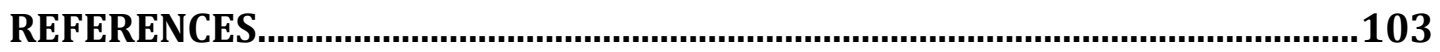

ACRONYMS ...........................................................................................................120

APPENDIX A: SEMI-STRUCTURED INTERVIEW OUTLINE ............................121 
APPENDIX B : SYSTEMISER QUOTIENT AND EMPATHISER QUOTIENT

QUESTIONNAIRE.

APPENDIX C: COPY OF PARTICIPANT INFORMATION SHEET

.134

APPENDIX D: ETHICS APPROVAL.

137 


\section{Figures, Tables and Maps}

Figure 2-A. Increase in Unemployment Rate: Selected Countries 2007-2010

(International Monetary Fund - International Labor Organisation, 2010)

Figure 2-B. Domestic Banking Credit/GDP and Financial Crises : Amplitude of the Boom Phase of the Cycle, Advanced Economies, 1997-2010

(Reinhart and Reinhart, 2010, 28)

Figure 2-C. Private Debt to GDP Ratios: Australia and USA (1860-2010)

(Keen, 2009a, 4) .....

Figure 2-D. USA Deleveraging During the Great Depression

(Keen, 2009b, 28).

Figure 2-E. New Zealand Debt Deleveraging.

Figure 2-F. Australian Debt to GDP Ratios, by Sector, 1975-2009

(Keen, 2009c, 21)

Figure 2-G. New Zealand Debt to GDP Ratios, by Sector, 1990-2010. 25

Figure 2-H. Debt to GDP Ratios, Selected Countries: 1990 - Q2 2009

(Roxburgh et al., 2010, 7).

Figure 2-I. Historical Oil Demand and Future Supply Projection of the Industry Task Force on Peak Oil on Energy Security in Million Barrels per Day (Mb/d)

(Industry Task Force on Peak Oil and Energy Security, 2010). 27

Figure 2-J. Static and Dynamic Fossil Fuel Projections by Fuel Type

(Mohr, 2010, 161). 29

Figure 2-K. Composition of the World's Energy Supply in 2006 30

Figure 2-L. Debasement of the Silver Denarius (Tainter, 2000, 21) ................................... 38

Table 3-A. Approximate Correspondence between PGIS Empowerment Frameworks ........ 44

Figure 3-B. Thomas and Velthouse's $(1990,670)$ Model of Empowerment Processes......... 46

Table 3-C. The External-Internal Motivation Continuum (Deci and Ryan, 2000, 237) ......... 49

Table 3-D. Potential Correspondence between Empowerment Models and Self Determination Theory. 52

Figure 4-A. The Learning Cycle (Kolb, 1973, 2) 57 


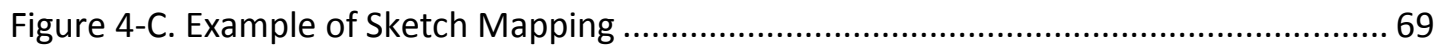

Figure 5-A. Frequency of Competence- and Relatedness-Satisfying Speech Acts in Kai o Te Aro Meetings (March - May, 2010) ......................................................................... 75

Figure 5-B. Raw Incidences of Reported Motivation Constructs in the Semi-structured Interview Data: Intrinsic vs. Extrinsic

Figure 5-C. Distribution of Participant Motivation Constructs in Semi-structured Interviews

Figure 5-D. Prevalence of Reported Extrinsic Motivation vs. Overall Motivations in Semistructured Interviews.

Figure 5-E. Motivation Construction. 86

Figure 5-F. Four Layers of Empowerment. 90 
[This page left blank\} 


\title{
1 Introduction
}

\author{
"Power without love is reckless and abusive, and love without power is sentimental \\ and anaemic." \\ $\sim$ Martin Luther King, Jr.
}

Adam Kahane writes in Power and Love $(2010,150)$ how change-makers often face a dilemma in choosing between the two forces of the book's title. In Kahane's sense, power refers to a drive for self-realisation, while love refers to a drive for unity. For community development practitioners, a power-based approach might involve advocating for more resources, while a love-based approach might focus on connecting community members together. The opening quote from King (1967) highlights the dilemma of the choice between these approaches. The downside of the power-focused approach comes when the powerful push back, or when power corrupts the newly powerful. The downside of the love-focused approach comes when the community connects, but achieves little of tangible benefit. In Power and Love, Kahane tells of his journey to reconcile the two approaches in diverse fields.

Community development practitioners have developed a variety of methods for the 'empowerment' of communities, but the use of the term empowerment demonstrates the power/love dilemma. Sometimes empowerment refers to process or outcome where the community gains political or economic power ('social empowerment') (Carr, 2003); and sometimes empowerment refers to internal psychological, or motivational process ('psychological empowerment') that occurs when the subject connects with a social group or a sense of purpose (Conger and Kanungo, 1988).

Arguably, empowerment methods are more relevant than ever. Industrial society faces the prospects of abrupt energy shortages (Hall et al., 2008); rising sea levels (Allison et al., 2009); more frequent extreme weather (ibid.); and financial meltdown (Keen, 2009c). A combination of which could lead to societal collapse (Beddoe et al., 2009; Homer-Dixon, 2006). If governments fail to mitigate these risks, and there 
are many reasons to believe they will not (Hassan, 2008; Tainter, 2000), then communities will have to adapt as best they can. Community development projects are a potential focus for adaptation efforts.

Community gardens are a focus for community development in line with the love/unity approach. Community gardens provide a venue for different types learning, community cohesion, and activism (Saldivar-Tanaka and Krasny, 2004), but rely on volunteer efforts and motivation for sustained success. Arguably, community gardens provide a valuable safeguard for botanical knowledge development and informal economic activity in an uncertain economic climate.

Participatory Geographic Information Systems (PGIS) is another method in the tradition of the power/social empowerment school. Geographic Information Systems (GIS) combines the advanced analytical, storage and visual display capabilities of computers with geographic information (GI). Institutions have used powerful GIS capabilities to analyse, manipulate and communicate GI (Jankowski, 2009). Some scholars have raised concerns about the institutional use of GIS (Pickles, 1995a). GIS users require advanced training and often expensive software. In response, scholars have developed a 'GIS and Society' discourse that critiques the institutional use of GIS and advocates its use by disadvantaged and non-specialist groups (Craig et al., 2002b). One strand of this research has been the use of GIS for participatory development objectives, or 'Participatory Geographic Information Systems' (PGIS) (Rambaldi et al., 2004). PGIS practitioners have attempted to socially empower the disadvantaged through the collaborative construction of GIS by non-specialists and GIS professionals working together (Craig and Elwood, 1999).

Gardeners often have geographical concerns. Geographic knowledge influences the selection and design of garden sites and their productivity. PGIS has potential uses as a geographic knowledge management and empowerment tool and similar methods have been used with community gardeners (Doyle and Krasny, 2003).

Perhaps reflecting Kahane's dilemma, empowerment methods have had mixed success. Lacking unity, communities have sometimes failed to make the best use out PGIS tools (Esnard, 2007) and the PGIS projects have not always had positive gender equity outcomes (McCall and Minang, 2005). Lacking power, community 
gardens often face insecure tenure arrangements (Saldivar-Tanaka and Krasny, 2004). The would-be empowerment practitioner may be tempted to combine approaches as they see fit. But as this thesis argues, Kahane's dilemma is not just about a choice of methods but is part of the psychology of project participants. Echoing the power/love dichotomy, people have different psychological needs (Deci and Ryan, 1985); have differing motivations for participating in group activities (Ryan and Deci, 2000); and understand the world in different ways (Baron-Cohen et al., 2005). Empowerment practitioners may benefit from an awareness of participants', and their own, cognitive variation and motivations.

The research follows a community garden group, Kai o Te Aro (KTA), of which the researcher is a member. Mapping activities were introduced in line with PGIS techniques, to investigate the influence of cognitive style has on the motivation for different activities and how participants construct and sustain motivation for involvement. The thesis explores links between psychology, empowerment, and societal predicaments as applied to community garden groups. In recent decades environmental studies has focused on theoretical knowledge to inform policy. The current study recognises the limitations of that approach and the ideologies that underlie it. Accordingly, the research has three aims: an ideological aim to justify the action research methodology and community focus within environmental studies; a theoretical aim to explore the potential links between two psychological theories, and a practical aim to apply psychological empowerment frameworks to community development practice.

\subsection{The Ideological Aim}

The ideological aim is to justify the research focus on community gardens and empowerment in the context of environmental studies, and the global transition to low-gain energy resources. In recent decades, environmental studies has become dominated by an 'eco-managerialist' ideology (Luke, 1999, 2009). Ecomanagerialists believe that humanity has the capacities to substantially solve environmental problems and transition industrial society to sustainability. Ecomanagerialists primarily advocate state-centralised or market-based instruments to 
solve problems (ibid.). From an eco-managerial perspective, empowerment and community gardening can appear as peripheral concerns, or at worst, distractions from the central concern of institutional transformation (e.g. Steffen, 2009). There is tension between eco-managerial environmentalists on one side, and those who argue for subsidiarity and localism on the other. The opposing sides of this debate often have different perspectives on industrial society's future. The former believing that humanity can preserve the status quo with minor modifications or transition the status quo to a sustainable society through planning (Hopwood et al., 2005; Scott, 1998), whilst the latter minority believe that industrial society will more likely suffer the same fate as past complex societies and collapse (Homer-Dixon, 2006). A subset of the latter minority believes that humans do not have the capacities to change this broad context (Greer, 2008). The thesis defends the latter viewpoint arguing against the assumptions that underpin the dominant views and the political and research agenda that follows from them.

\subsection{The Second Aim}

The second aim is to explore the links between the Self-Determination (SD) theory of motivation and the Empathiser-Systemiser (E-S) theory of cognitive style. E-S theory describes tendencies to be primarily driven to either, understand and respond appropriately to people ('empathising'); understand abstract systems and determine the rules that govern them ('systemising'); or an equal tendency to both empathise and systemise ('balanced'). Researchers have found that these tendencies vary amongst populations (Baron-Cohen et al., 2005).

In Self-Determination (SD) theory, the satisfaction of psychological needs plays a role in motivation and determines a large degree of human well-being (Deci and Ryan, 2000). SD theory describes three innate psychological needs that underlie intrinsic motivation: self-determination (autonomous action), competence (perceived self-efficacy), and relatedness (social connections with others).

It seems plausible that E-S and SD theories are linked. One's cognitive style could reflect variation in the degree of innate need, where a tendency to empathise would reflect a greater than average need for relatedness, and a tendency to systemise would reflect a greater than average need for competence. 
PGIS projects involve both empathising and systemising activities to varying degrees. Researchers have not yet linked SD and E-S theories. This study investigates whether E-S cognitive style can influence subject's motivation, psychological empowerment and the effectiveness of various activities in a community development project.

\subsubsection{Objectives}

Under the third aim the research has the following objectives:

1. Determine the motivations of participants for participating in group and gardening-related activities and test against the suitability of SD theory. Motivations may be extrinsic/ideological or intrinsic. Intrinsic motivations could include competence satisfying activities such as increasing knowledge or relatedness satisfying activities such as forming friendships.

2. Determine the E-S cognitive style of research participants.

3. Explore the potential links between E-S and SD theories and whether E-S cognitive style influences participant motivation and psychological empowerment through different empowerment practices.

4. Introduce mapping activities to the participating community gardening group of which the researcher is already a member. Mapping has potential knowledge management value for gardening groups and the literature links map usage to systemising (Baron-Cohen, 2002), and group processes to empathising (Baron-Cohen et al., 2005). 


\subsection{The Third Aim}

The third aim is to clarify the role of ideology, motivation, and psychological empowerment in a manner useful to PGIS and community development practitioners. Different disciplines have focused variously on motivation, psychological empowerment, and social empowerment without necessarily clarifying the relationships between these concepts. Motivation is the energetic force that drives behaviour, primarily studied by psychologists (Deci and Ryan, 1985). Management scholars usually regard psychological empowerment a motivational construct for improving task performance (Thomas and Velthouse, 1990). Development practitioners often attempt to empower disadvantaged groups, that is, to aid them in their power struggles (social empowerment), arguably a process dependent on motivation. The researcher reflects on insights generated during the research process and the application of SD theory to empowerment practice.

Theories of empowerment have variously drawn on the same or similar concepts, but the literature contains a confusion of different terminologies. Those working with disadvantaged groups such as PGIS researchers have tended to emphasise social empowerment without making the psychological aspects clear.

\subsection{Research Questions}

1. Can E-S theory explain any differences in the intrinsic motivation of KTA members?

Complementary Questions:

1(a) What activities related to community gardening activities do research participants find motivating?

1(b) What cognitive styles do participants have?

1(c) Do participants find mapping activities intrinsically motivating? 
2. What relevance does ideology and intrinsic motivation have to (a), the participation and motivation of research participants for KTA activities; (b), empowerment theory and practice; and (c), broader theories of social change?

\subsection{The Structure of the Thesis}

The thesis structure divides into chapters as follows. Following from the ideological aim, Chapter Two places empowerment-oriented research in the context of fossil fuel depletion and justifies the research focus on community garden groups. Chapter Three contains as literature review of empowerment, motivation, and PGIS. Chapter Four sets out the methodological approach, describes the case study research process, the collected data, and methods of analysis methodology used. Chapter Five presents, and discusses the results of this study in reference to the research questions. Finally Chapter Six draws overall conclusions and makes reccomendations. 


\title{
2 \\ Research Context: Limits to Growth
}

\author{
“Unemployment is Capitalism's way of getting you to plant a garden” \\ Orson Scott Card
}

\begin{abstract}
“...the most seductive theory of all is that what we are experiencing now is nothing less than a movement back towards an informal economy after a briefflirtation of 200 years or so with a formal one."

$\sim$ Victor Keegan
\end{abstract}

This chapter describes the relevance of community gardens to current energyeconomic crises and the discipline of environmental studies. It will attempt to reframe the research context away from the eco-managerial 'sustainable development' paradigm that dominates environmental studies (Luke, 2009). This reframing serves three intertwined purposes: first, in line with the ideological aim, the chapter defends a minority 'limits to growth' paradigm as relevant for understanding current contexts; second, in line with the second research question, the chapter familiarises the reader with a limits to growth ideology, an ideology that could potentially motivate subjects to participate in community gardens; and third, in line with a transparency required by the action-research methodology, the chapter makes the ideological motivations of the researcher clear.

The chapter's arguments can be summarised as follows. The recent era of expanding material prosperity was fuelled by fossil fuels, and is now nearing its end with the depletion of those fuels. The direct implications for many people will be widespread unemployment. Community gardens can help mitigate the social, economic, and political impacts of widespread unemployment. The influence of the ideologies of progressive liberalism and rationalism partially explains the neglect of resource scarcity in public discourse. 
These arguments are based on two heterodox perspectives on economic growth. In one of the heterodox perspectives biophysical economics, economic growth is dependent on energy and resource flows (Ayres et al., 2007; Cleveland et al., 1984). A view distinct from orthodox economics which views economic growth as ultimately dependent on human ingenuity (Mokyr et al., 2005). From a biophysical economics perspective, a near-term contraction of energy supply and continuing declines in resource quality, as forecasted by a number of researchers (Aleklett et al., 2009; Campbell and Laherrere, 1998; Imam et al., 2004; Mohr, 2010), is likely to force household income, and labour market participation into decline (Hall et al., 2008). A second heterodox perspective, that of Post-Keynesian (PK) economics, views the recent Global Financial Crisis (GFC) as the start of a global debt deleveraging cycle of similar magnitude and consequence as that which caused the Great Depression of the 1930's. In the PK view, debt de-leveraging will continue to painfully reorder the economies of industrialised countries away from discretionary goods, undercutting employment for many years (Grauwe, 2009; Keen, 2009a, c; Keen, 2009d; Reinhart and Rogoff, 2009). A view that is distinct from orthodox economics, which views the GFC as a rare but serious interruption in a continuing programme of rising prosperity (International Monetary Fund, 2010). Accordingly, the combined unemployment effects of resource depletion and debt deleveraging make diverting surplus household labour to food production beneficial (Carson, 2010).

A limiting factor is the gardening skill of householders. Cheap and convenient agroindustrial food has weakened gardening and culinary knowledge in industrialised countries (McClintlock, 2008). Community gardens provide a ready means to upskill gardeners (Krasny and Tidball, 2009).

Most immediately, we can expect the end of economic growth to be accompanied by mental health problems and political turbulence. At the macro-scale, long-term shifts from relative material abundance to relative poverty has historically coincided with societal decline or collapse (Costanza et al., 2008; Diamond, 2005; Odum and Odum, 2006). The community resilience benefits of community gardens could also mitigate mental health, social inequity and potential societal collapse complications. 


\subsection{The Ideology of Sustainable Development}

In the 1970's when energy prices were high, arguments for and against limits to growth were widely debated (Day and Hall, 2009); often centred around the report of the same name (Meadows et al., 1972). With a fall in energy prices during the 1980's and vocal misrepresentations of the key arguments, this debate has subsided (Day and Hall, 2009). Following the publication of the influential Our Common Future (Brundtland and Khalid, 1987), 'Sustainable development', became the main paradigm for environmental research and debate. The sustainable development concept proposes that conditions should improve in a manner that does not impact the conditions of future generations (Brown Weiss, 1992-1993). The dominant ecomanagerial strand of sustainable development does not address the potential for a near-term end of economic growth, instead proposing that the 'quality' of growth should change (Hopwood et al., 2005). A web-search in September 2010 of Google Scholar for articles containing the term "limits to growth" reveals about 13,000 results published in the last 10 years. A similar search for articles with the term "sustainable development" gives 525,000 results. It would be easy to conclude that scholarly consensus has dismissed limits to growth arguments on merits. However, this study takes the less comforting tack. This chapter argues that the dominant ideologies of progressive liberalism and rationalism underpin the relative disregard of resource scarcity and the political choice to focus on large-scale schemes.

Liberalism maintains that justice is the supreme political virtue and frames political action as accelerating a universal end to injustice and suffering. The liberal doctrine of progress assures liberals that progressive political actions form part of a grand unfolding historical narrative with a future superior to the present (Gray, 2007).

Progressive environmentalism claims a 'sustainable future' as the end. To achieve a sustainable future, future generations are to be included in a fundamental rights framework (Brown Weiss, 1992-1993), and pro-environmental values are to be evangelised (Oskamp, 2000). Reflecting an apocalyptic strand of Western thought, a variant sees looming environmental disasters and/or resource shortages as catalysts to transform society and usher in the desired future (Gray, 2007; Hopwood et al., 
2005). Environmental progressives assume that an environmental ethic can triumph and allow a just, sustainable society to take hold (e.g. Raskin, 2000).

Rationalism maintains that knowledge is acquired through abstract human reasoning, devaluing the practical knowledge acquired through direct experience (Oakeshott, 1994). Environmental rationalists ${ }^{1}$ attempt to devise techno-institutional fixes for environmental and resource problems, typically involving state- or market-based prescriptions (Luke, 2009).

The rationalist perspective makes three assumptions among others: first, the assumption of order, that an underlying relationship between cause and effect exists, can be discovered, and can inform an ideal practice; second, the assumption of rational choice, that decision-makers will make rational decisions when the consequences are made clear; and third, the assumption of institutional capability, that the institutions that implement fixes are fully capable of controlling outcomes (Bonaiuti, 2010; Holling and Meffe, 1996; Kurtz and Snowden, 2003; Thomas, 1998).

The assumption of progress is a statement of faith (Gray, 2007), while rationalist assumptions are sometimes but not always true (Kurtz and Snowden, 2003).

The universal aspirations of progressivism require powerful institutions to implement solutions, while the precepts of rationalism assure the eco-managerialist that these institutions can solve the issue at hand. Following from these influences, the ecomanagerialist believes that industrial society can reform its way to sustainability and focuses their efforts on the sustainable development political project: government and market regulations, advanced technological development, and pro-environmental value evangelisation (Hopwood et al., 2005).

Environmental psychologists have reasoned that pro-environmental behaviour follows from pro-environmental attitudes and social norms (Ajzen, 1991; Stern et al., 1999), as opposed to a rationalistic approach that emphasises the transfer of knowledge to change behaviour (Barr and Gilg, 2006). For example, Rudningen (2009) identifies an ideology concerned with peak oil and climate change as a motivator for pro-environmental behaviour amongst 'transition towns' community groups. The 'behaviour change' approach attempts to foster pro-environmental

\footnotetext{
${ }^{1}$ AKA 'Ecological Modernisation' , 'Rational Ecologicalism', and 'Eco-managerialism'
} 
behaviour through a variety of psychologically informed environmental education techniques, notably, 'community-based social marketing' (McKenzie-Mohr and Smith, 1999; Oskamp, 2000). While these approaches appear to turn away from the rational choice assumption, Ferreira (2007) argues that the environmental education field has unnecessarily adopted the utopian goal of societal transformation. A goal consistent with a progressive worldview (Gray, 2007). Following from Question 2, this study will address the relevance of such ideologies for psychological empowerment and motivation.

\subsection{Premise: The End of Growth}

Included in the main variants of sustainable development is an assumption that economic growth is not threatened by resource depletion in the near term (Hopwood et al. 2005) One's estimation of the prospects for economic growth underlies views on the effectiveness of a variety of political choices and ultimately the choice to focus on small-scale, local projects such as community gardens or large-scale international agreements. If one sees the GFC as rare interlude in advancing economic prosperity, then one could argue that the resumption of economic growth will solve a variety of welfare problems (Acemoglu, 2007), and potentially a number of political and environmental problems (Helliwell, 1994; Stern et al., 1996). If one accepts the premise of continued growth, discussion shifts to the techno-institutional fixes for transitioning to a sustainable future. If however, one views the GFC as the beginning of the end of global aggregate economic growth, such as in the standard scenario projected by the authors of the 1972 report Limits to Growth (Meadows et al., 1972), then the former discussions take on a surreal quality. The risk of a nearterm end of economic growth, largely absent from public discussions, casts doubt on the capacities of mainstream institutions to anticipate risks and solve problems. If one takes this risk seriously, then means of maintaining basic wellbeing, such as the research focus of this study, becomes a more relevant concern.

The following sections examine the methodology and assumptions that underlie claims by mainstream economists that economic growth does not suffer fundamental limits. An alternative, biophysical economics perspective is presented and applied to the socioeconomic transitions of the past and the energy transition currently 
underway. Complicating this energy transition, the global economy is still unstable following the GFC of 2008. A PK economics perspective on the GFC as the beginning of an extended period of debt de-leveraging bust, that follows a credit funded boom is also presented.

\subsubsection{Orthodox Growth Theory: Methodology and Assumptions}

'Deductivism' (Lawson, 1996) forms the methodological basis for the knowledge claims of orthodox growth theory. Deductivism assumes that the phenomenon in question occurs in a closed system and posits laws that predict event regularities. Closed systems exhibit lawful behaviour of the type "whenever event (or state of affairs) $x$ then event (or state of affairs) $y^{\prime \prime}$ (ibid., 407). The reader will note the deductivism appears to be the methodological cognate of systemising, as systemising is the drive to derive laws that govern event regularities from (assumedly) closed systems.

Using a deductivist approach, orthodox economic theory attempts to explain increases in economic output through the 'aggregate production function', a mathematical law traditionally containing two factors of production: Labour (e.g. total hours worked) and Capital (e.g. the value of all machinery and infrastructure utilised in the economy); and a catch-all residual 'Technical Change' (usually conceptualised as learning and/or technological progress). Technical Change does not have a real world proxy and is measured as a change in the ratio between inputs (Labour and Capital) and economic output (Gross Domestic Product (GDP)). By definition, Technical Change is the remaining residual growth after the growth accounted for by increases in Labour and Capital. Orthodox growth theorists have observed that increases in economic output had occurred concurrently with increases in workers, capital, and knowledge. The aggregate production function represents the economy as a closed system and describes a law that an aggregate increase in labour, capital and knowledge will result in growth economic output (Warr and Ayres, 2006).

Both the methodological approach of the aggregate production function and the assumptions made to utilize it are problematic. Concerning methodology, Lawson (1995) argues that closed systems are only found in astronomy and well controlled 
experiments. Economic systems intrinsically include the behaviour of unlawfully behaving humans (Baron-Cohen et al., 2005), and extrinsically receive imperfectly substitutable resources and ecosystem services from the environment (Cleveland et al., 1984). Accordingly, from Lawson's critical realist perspective an economic system cannot achieve closure and a deductivist approach is therefore inappropriate. Concerning the assumptions made, econometricians have run statistical regressions to determine the relationship between social factors, such as schooling, the residual unaccounted for growth represented by Technical Change and economic output with mixed results. No comprehensive set of factors or relationships has emerged that can explain Technical Change or growth over long periods (Easterly and Levine, 2001; Li and Ayres, 2008). According to the main variation of orthodox growth theory the contribution of Labour to growth will slow with slowing population growth. So too will the contribution of capital investment to growth slow, as the economy becomes saturated with capital (Ayres and van den Bergh, 2005). Assuming no fundamental limits to technological progress and that all factors are perfectly substitutable, economists propose that economic growth will continue indefinitely (e.g. Simon, 1981).

Other scholars dispute that economy is a closed system and that all factors are perfectly substitutable (Ayres, 2007; Daly, 1980, 1997). Indeed, 19 ${ }^{\text {th }}$ century classical economists traditionally used Land (and by implication natural resources), Labour, and Capital as the factors of production. Czech (2009) argues that economists dropped Land as a production factor as a result of a political backlash against the prospect of land taxes. According to Czech (ibid.) wealthy land barons backed the 'Chicago school' of economics which developed much of what was to become orthodox $20^{\text {th }}$ Century economics. By promoting the idea that land was not essential to wealth generation, the Chicago school countered arguments for land taxes to the advantage of their benefactors. 
Mainstream economic agencies such as the International Monetary Fund issue forecasts that the world economy will return to strong growth over the next few years (International Monetary Fund, 2010). Ultimately these forecasts rely on the orthodox growth theory outlined above, along with an assumption that productivity will improve because it has usually done so in the recent past (Massi, 1997). These assumptions do not constitute a sound basis for confidence in global economic growth, or that unemployment will return to recent levels (Figure 2-A).

Figure 2-A

Increase in Unemployment Rate: Selected Countries 2007-2010

(International Monetary Fund - International Labor Organisation, 2010)

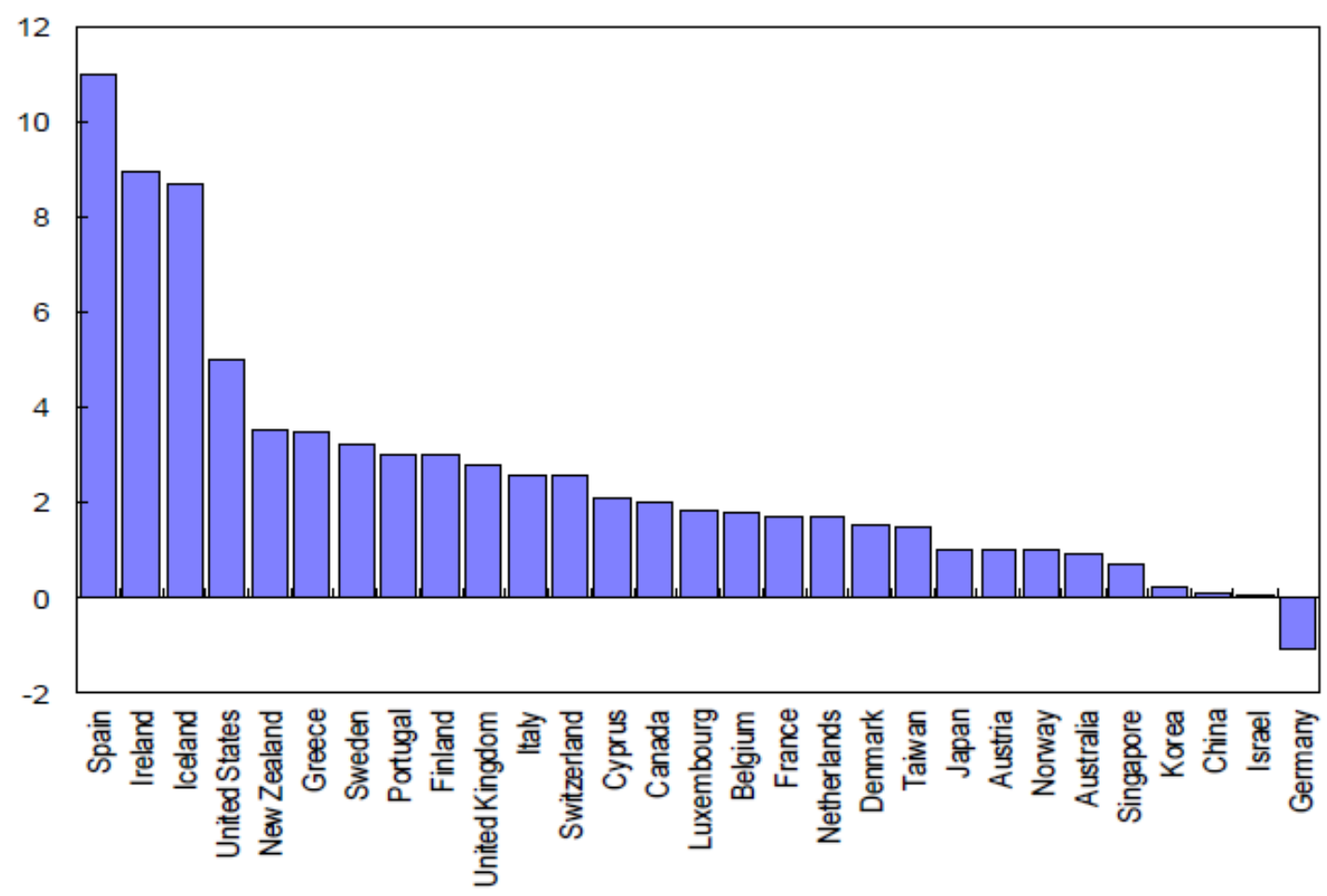

\subsubsection{Biophysical Economics}

Biophysical economics accounts for the role of natural resources in economic output, arguing that material wealth depends upon the throughput rate, energy quality ${ }^{2}$, and

\footnotetext{
${ }^{2}$ Energy Return On Invested (EROI) is one of the main metrics for assessing the quality of an energy process. It describes the amount of energy spent acquiring the useful energy delivered to society Hall, C., Balogh, S. and Murphy, D. 2009: What is the Minimum EROI that a Sustainable Society Must Have? Energies 2, 25-47.
} 
efficiency of energy transformations (Ayres and van den Bergh, 2005; Ayres and Warr, 2005; Cleveland and Costanza, 2008). The biophysical economics position is in broad agreement with a number of scholars in a variety of disciplines (Cleveland et al., 1984; Cottrell, 1955; Gagnon, 2008; Georgescu-Roegen, 1975; Haberl, 2001; Illich, 1974; Meadows et al., 1972; Odum, 1988; Reynolds, 1998; Sorrell, 2010; Stern and Cleveland, 2004; Tainter et al., 2003; White, 1943). Biophysical economics attempts to reconcile economics with the physical sciences. In doing so, biophysical economists make direct use of concepts from physics to delineate economic production as a mechanical work process that uses energy to transform materials into physical goods or provide services through operating devices (Cleveland et al., 1984). Following thermodynamic laws, mechanical work transforms energy from high to low grade (Reynolds, 1994), whilst the material flows of production disperse minerals as waste. For energy resources 'grade' ${ }^{3}$ refers to the ability to perform useful work and is related to the resource's physical qualities. For example, manufacturing steel combusts energy dense coal, transforming the coal's chemical energy into low grade (high entropy) waste heat. In the biophysical view, the finite nature of high grade fossil fuels poses a problem for long-term exponential growth.

Biophysical economists attribute the extraordinary increases in labour productivity and economic growth to increasing throughput and quality of energy resources, and improving energy efficiency (Ayres and van den Bergh, 2005; Cleveland, 2008; Cleveland et al., 1984). Increased labour productivity permitted a large scale shift in employment away from agriculture to manufacturing and services (Ayres, 2006; Daly, 1980b). Labour freed from subsistence farming can produce ephemeral low energy intensity services. Mainstream economists have taken the growth of the service sector to represent the 'dematerialisation' of economic output, and therefore its independence from resource consumption. However, as Lawn (2001) points out, all services have a physical good component. Moreover, while energy availability may have little immediate impact on the micro-economics of service-providing businesses, at the macro-scale the value of a service depends on the willingness of consumers to pay for it. Hence, continuing growth in the monetary value of services

\footnotetext{
${ }^{3}$ More precisely 'exergy'.
} 
will depend on the net income of households once the costs of resource-intensive necessities (e.g. food, shelter, heating, cooling, essential mobility etc.) have been removed. In an economy where the costs of necessities rise faster than income must necessarily contract expenditure on discretionary purchases, and subsequently the economic sectors which produce them (Hall et al., 2008).

\subsubsection{Great Transformations}

In a biophysical economics perspective of economic history the global socioeconomic system has passed through at least two 'great transformations, ${ }^{4}$ which have altered society's energy metabolism: The agricultural and industrial revolutions (Keefer, 2005). A third transformation, financialisation, has altered class power relations in industrialised countries through debt-financing (Palley, 2007), a process which has culminated in the GFC (Keen, 2009c). Society has entered another transformation, debt-deleveraging -a reduction in debt-fuelled consumption as uncertainty leads debt-holders to switch from accumulating debt to paying down debt; and is about to enter a fourth: deindustrialisation -the depletion of high grade non-renewable energy resources and their substitution with low grade renewable energy, and human and animal labour. The two transformations will restructure the economy away from discretionary goods and services to necessities. This study argues that the resulting disruptions will likely decrease formal employment making food-gardening skills more valuable.

The first transformation, from hunter-gatherer societies to agrarian societies, began around ten thousand years ago. Neolithic farmers began cultivating storable grains, producing a small energy surplus and opening the way for limited labour specialisation and complex hierarchical societies (Diamond, 1987, 2005; Haberl, 2006; Haberl et al., 2009). In an agrarian society, biomass supplies the vast bulk of energy. Human and animal labour converts food and fodder, transforming the bulk of useful work endosomatically (within the organism), while combustion converts supplementary wood into heat and light exosomatically (outside of the organism) (Haberl, 2001).

\footnotetext{
${ }^{4}$ The domestication of fire by ancestral hominids could be considered a third great transformation.
} 
The second great transformation, from agrarian to industrial society, has occurred through the $18^{\text {th }}$ and $19^{\text {th }}$ Centuries and continues in many parts of the world. High grade coal replacing low grade wood and fuelled the steam-powered industrial revolution (Pomeranz, 2000). Tractors and combine harvesters replaced work performed by human or animal labour, dramatically improving output per person, but required increasing amounts of fuel. Innovation improved the efficiency of machines and appliances performing more useful work (Ayres et al., 2007). The twentieth century saw the almost complete substitution of endosomatic human and animal labour in the industrialising countries for fossil fuel-powered exosomatic energy transformation (Ayres and Warr, 2005; Keefer, 2005).

\subsubsection{Ponzi Financialisation}

A third transformation, the speculative financial leveraging of industrialised economies (hereafter: ponzi financialisation), does not concern societal metabolism but has allowed the financial classes to increase their share of wealth entitlements in industrialised countries at the expense of the other classes through private debt accumulation and housing and stock market bubbles (Brenner, 2009; Foster, 2008; Keen, 2009c; Palley, 2007). Orthodox economics holds to three assumptions that have obscured the importance of ponzi financialisation for understanding the GFC: first, that money is created by reserve banks and multiplied by the lending of private banks; second, that private debt accumulation is the rational behaviour of market participants based on accurate assessments of future economic prospects; and third, that the economy tends toward equilibrium, in other words, that economic metrics (GDP growth, unemployment rates etc.) will stabilise near historical values . An alternative PK theory of ponzi financialisation that rejects these assumptions, and interprets Keynes (1936) differently, has been developed by Fisher (1933), Moore (1979), Minsky (1992), and Keen (2009a,b) amongst others, with recent supportive empirical work by Reinhart and Rogoff (2009).

One of the roots of ponzi financialisation can be traced to invention of fractionalreserve lending. Beginning in 1694 with the Bank of England, banks gained the right to lend more money than was stored in reserve, vastly increasing the money supply, and freeing it from the supply of gold bullion (Quigley, 1979). Today, according to 
the PK perspective, money is created 'out of nothing' when a private bank issues a new loan (Daly, 1980a; Keen, 2009a, c), preceding the lending of central banks (Moore, 1979) ${ }^{5}$. In the PK perspective, along with interest rates, lending is therefore dependent on perceptions of economic prospects and the availability of credit-worthy borrowers rather than solely the actions of central banks. Efforts to re-start lending, such as the slashing of interest rates following the GFC, amount to 'pushing on a string' as these efforts only marginally impact broader market psychology (Keen, 2009a).

Reinhart and Rogoff (2009) detail numerous examples of financial bubbles and subsequent collapse over the last eight centuries. Periods of uncertainty and asset price deflation have regularly followed overconfidence and speculative lending as investors realise that they will not be able to on-sell the asset for greater return, and seek to cash-out of the market before everyone else. Despite a clear history of periods of overconfident euphoria, followed by a financial crisis (Galbraith, 1990), orthodox economics has been reluctant to incorporate psychological factors into macroeconomic theory (Akerlof, 2002).

In Perez's (2009) view, financial bubbles form through either the 'pull' of a major new technology, where investors become overconfident in the new technology's potential, or the 'push' of easy liquidity, where low interest rates and financial deregulation encourage asset price speculation. Most recently, internet technology stocks entered a bubble which burst in 2000; while arguably easy liquidity has encouraged speculation on house prices and a global housing bubble (ibid.). Financial bubbles misallocate investment away from productive enterprise into speculation, forcing the economy to painfully restructure once the bubble bursts. As asset-prices rise, asset holders believe they have become wealthier, spurring consumption. Much of the economy leverages off asset prices. Industries that provide discretionary goods and services, and those servicing the housing market, boom (Palley, 2007). Figure 2-B shows how the ratio between domestic banking credit and GDP in several countries in the lead up to the GFC.

\footnotetext{
${ }^{5}$ A perspective supported empirically by Kydland and Prescott Kydland, F.E. and Prescott, E.C. 1990: Business Cycles: Real facts and a monetary myth. Quarterly Review of the Federa Reserve Bank of Minneapolis 14, 3-18..
} 
Figure 2-B

Domestic Banking Credit/GDP and Financial Crises : Amplitude of the Boom Phase of the Cycle, Advanced Economies, 1997-2010

(Reinhart and Reinhart, 2010, 28)

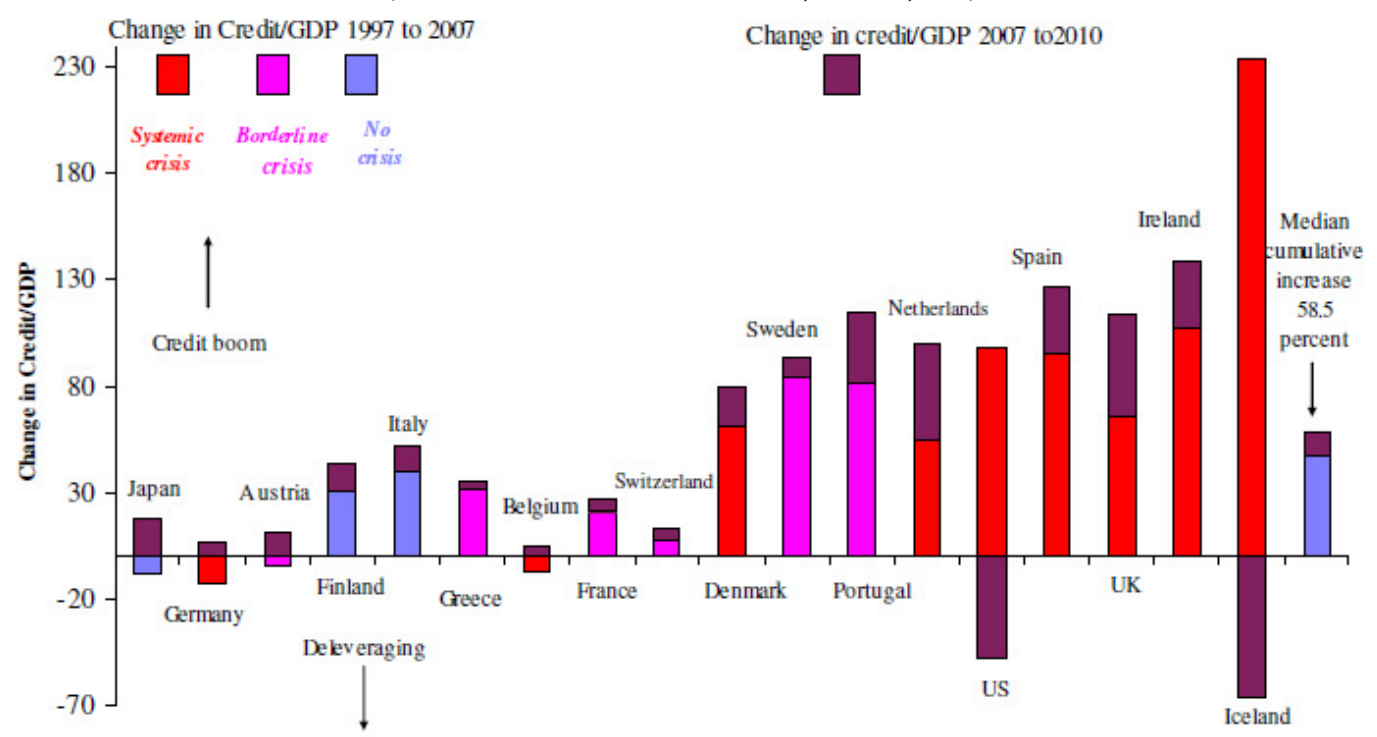

Figure 2-C

Private Debt to GDP Ratios: Australia and USA (1860-2010)

(Keen, 2009a, 4)

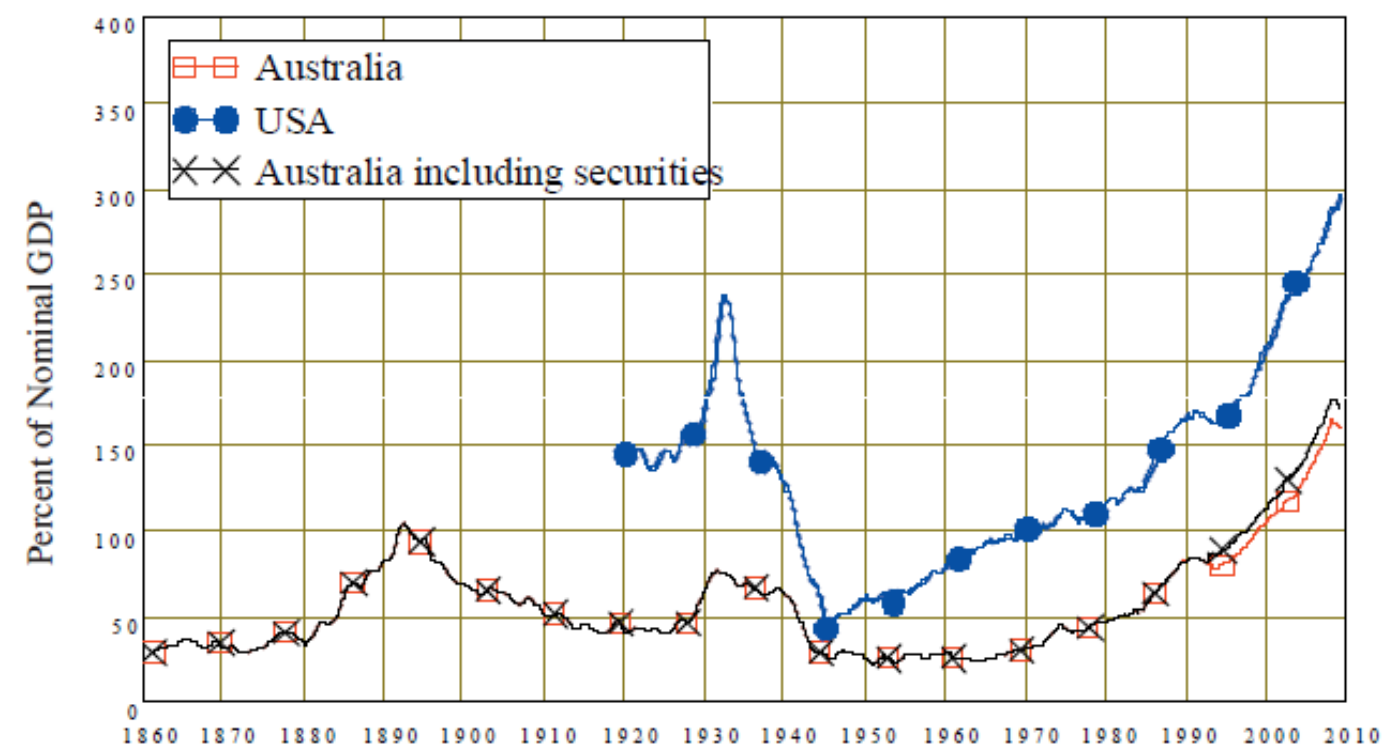

Eventually, the supply of those willing to enter debt-based speculation runs low, and the psychology of debtors switches from overconfidence to uncertainty. Whereas previously a debtor would spur aggregate demand by increasing debt to fund asset price speculation, consumption and investment; now the debtor becomes increasingly 
aware of the heightened risks of this approach and begins to pay down debt, reducing demand (Fisher, 1933; Grauwe, 2009; Keen, 2009d). In the present case, government action to restore confidence implies that debtors will resume increasing their debt to income ratios, a prospect that Keen (2009c) considers unlikely given their unprecedented magnitude. Aggregate debt levels in industrialised countries are now greater than they were before the Great Depression (see Figure 2-C for private debt in Australia and USA). Instead, the industrialised economies face the prospect of deleveraging. In the PK perspective aggregate demand is GDP plus the change in debt, an approach which recognises the transfers between asset markets with the productive economy (Keen, 2009d). Figure 2-D shows the correlation and lag between the debt financed proportion of aggregate demand and unemployment leading up to and during the Great Depression. In 1925, an increase in private debt was funding about $10 \%$ of aggregate demand. As debtors switched to from increasing debt to paying down debt aggregate demand fell, leading to an increase in unemployment (inverted on this chart) after an 18 month lag. 
Figure 2-D

USA Deleveraging During the Great Depression

(Keen, 2009b, 28)

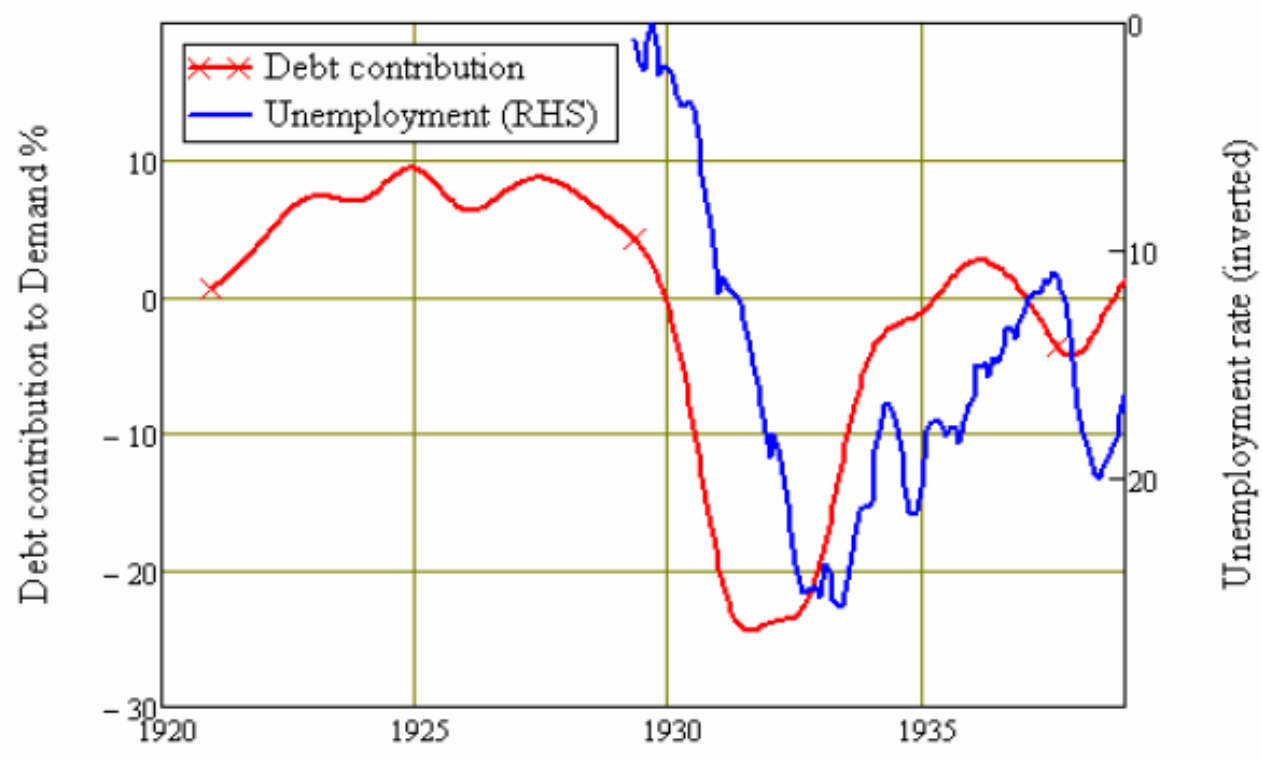

Figure 2-E

New Zealand Debt Deleveraging. Researcher's Calculations with Data from the Reserve Bank of New Zealand

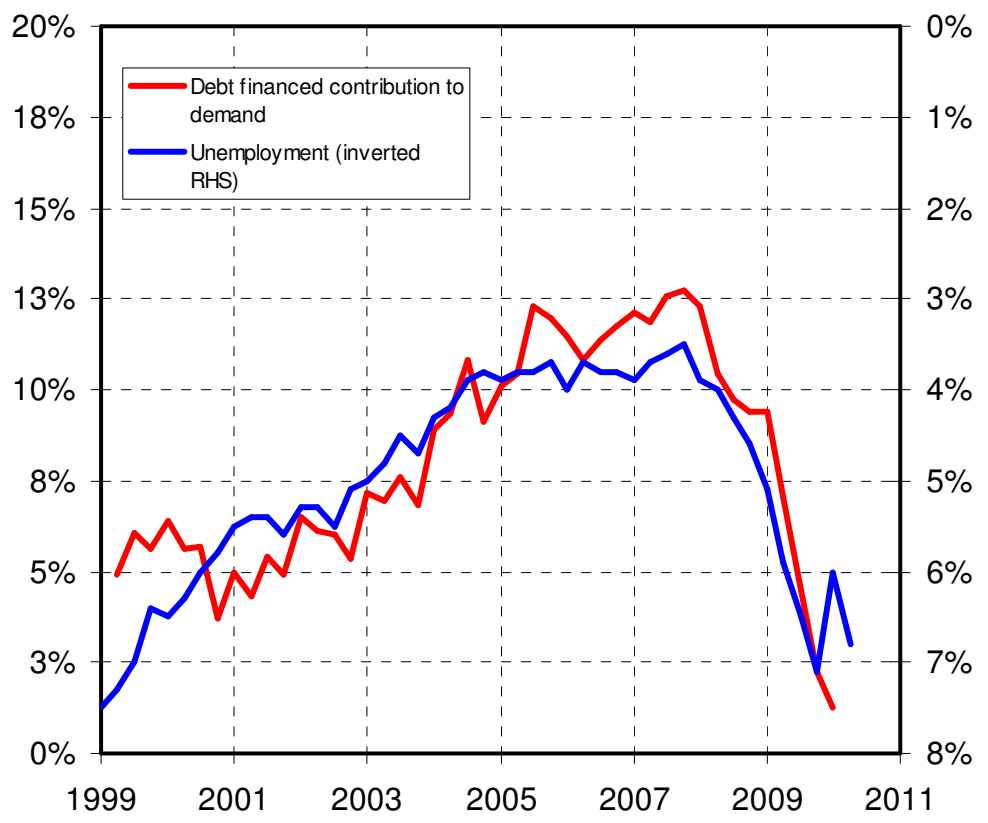


Figure 2-E repeats this exercise for New Zealand with available data from the Reserve Bank of New Zealand. The chart displays a high correlation between changes in debt levels and unemployment, representative of an economy dependent on debt-funded demand. ${ }^{6}$

From the equilibrium perspective of orthodox economic theory, debt repayments are merely a transfer from debtors to creditors that do not affect aggregate demand (Bernanke, 1995). This perspective assumes that equilibrium is a valid description of economic reality and ignores the debt-financed component of demand in a highly leveraged economy, and the potential dynamics of an economy in disequilibrium. As Keynes famously remarked when referring to the tendency of orthodox economics to focus on the hypothesised 'long run equilibrium':

"...But this long run is a misleading guide to current affairs. In the long run we are all dead. Economists set themselves too easy, too useless a task if in tempestuous seasons they can only tell us that when the storm is long past the ocean is flat again." (Keynes, 1923, 80)

In the PK perspective, economies contain inherent out-of-phase dynamics that can steer them away from historical experience. One such dynamic effect occurs when a speculative, debt fuelled asset bubble unwinds. As indebted households and businesses lose confidence they liquidate assets to pay down debt, leading to slumping asset prices and further uncertainty. Whereas in the orthodox perspective an increase in savings automatically flows through to increased investment, in the PK perspective, banks cannot find willing debtors and/or react to deteriorating conditions by freezing lending, constraining credit and investment. Without the boost supplied by increasing debt, demand falls, prompting businesses to lower prices, further lowering sales. To balance the books, businesses must shed jobs and employment falls. The economy enters a debt-deflationary spiral where falling asset prices, falling demand, and falling employment reinforce each other. (Fisher, 1933; Keen, 1997).

\footnotetext{
${ }^{6}$ Debt contribution to demand is calculated as $\Delta$ Private Debt divided by $\Delta$ Private Debt + GDP. It appears that the lag between debt de-leveraging and unemployment is less than 3 months but this cannot be discerned accurately with the quarterly data used.
} 
The GFC has initiated private sector debt-deleveraging in industrialised countries. Government stimulus spending has induced economic activity, but raised government debt-levels., Government debt increases are not generally large enough to offset private sector deleveraging and contribute to the overall debt picture (see Figures 2-F, 2-G and 2-H for the Australian, New Zealand, and other examples) (Keen, 2009a, c).

Figure 2-F

Australian Debt to GDP Ratios, by Sector, 1975-2009

(Keen, 2009c, 21)

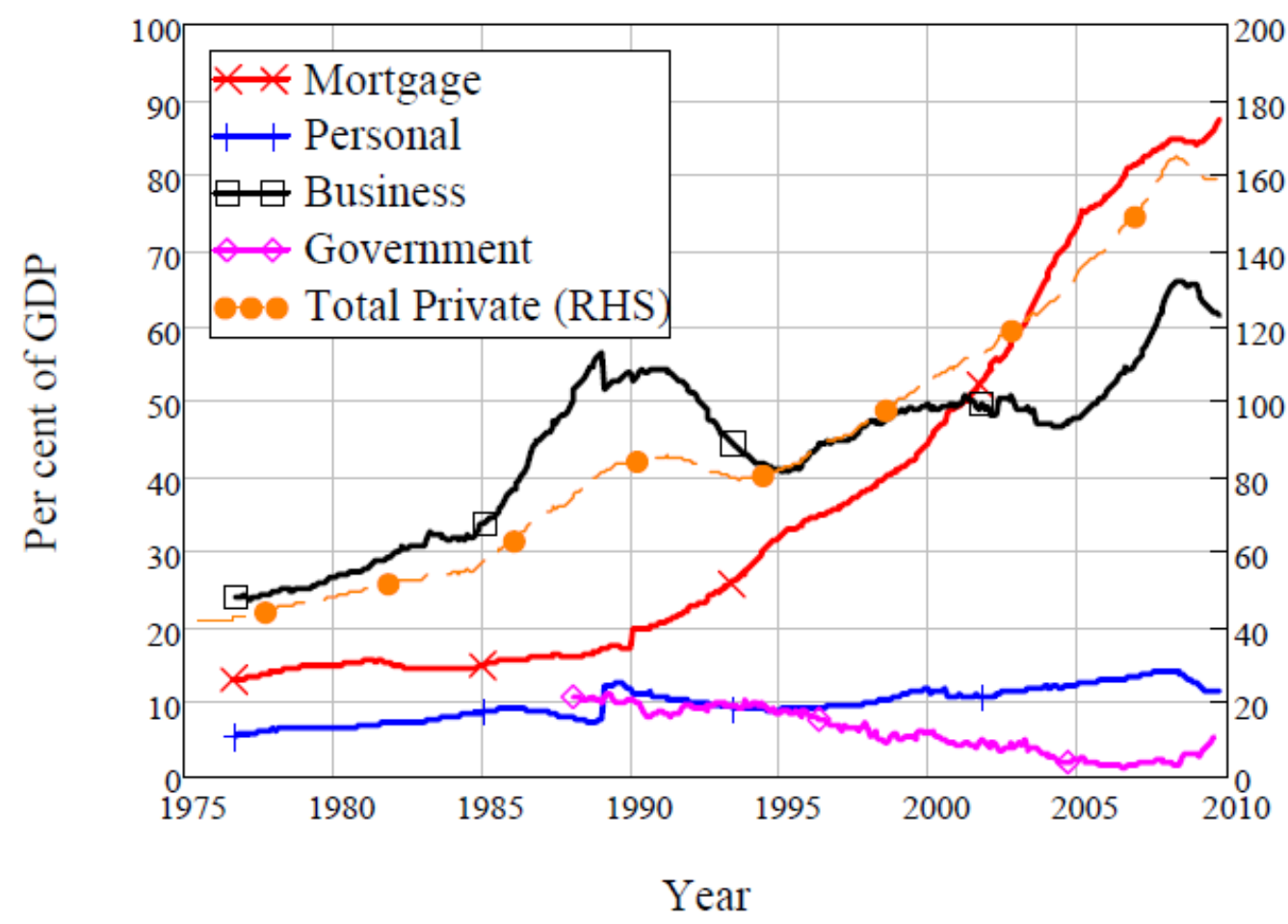


Figure 2-G

New Zealand Debt to GDP Ratios, by Sector, 1990-2010

(Researcher's calculations with data from the Reserve Bank of NZ )

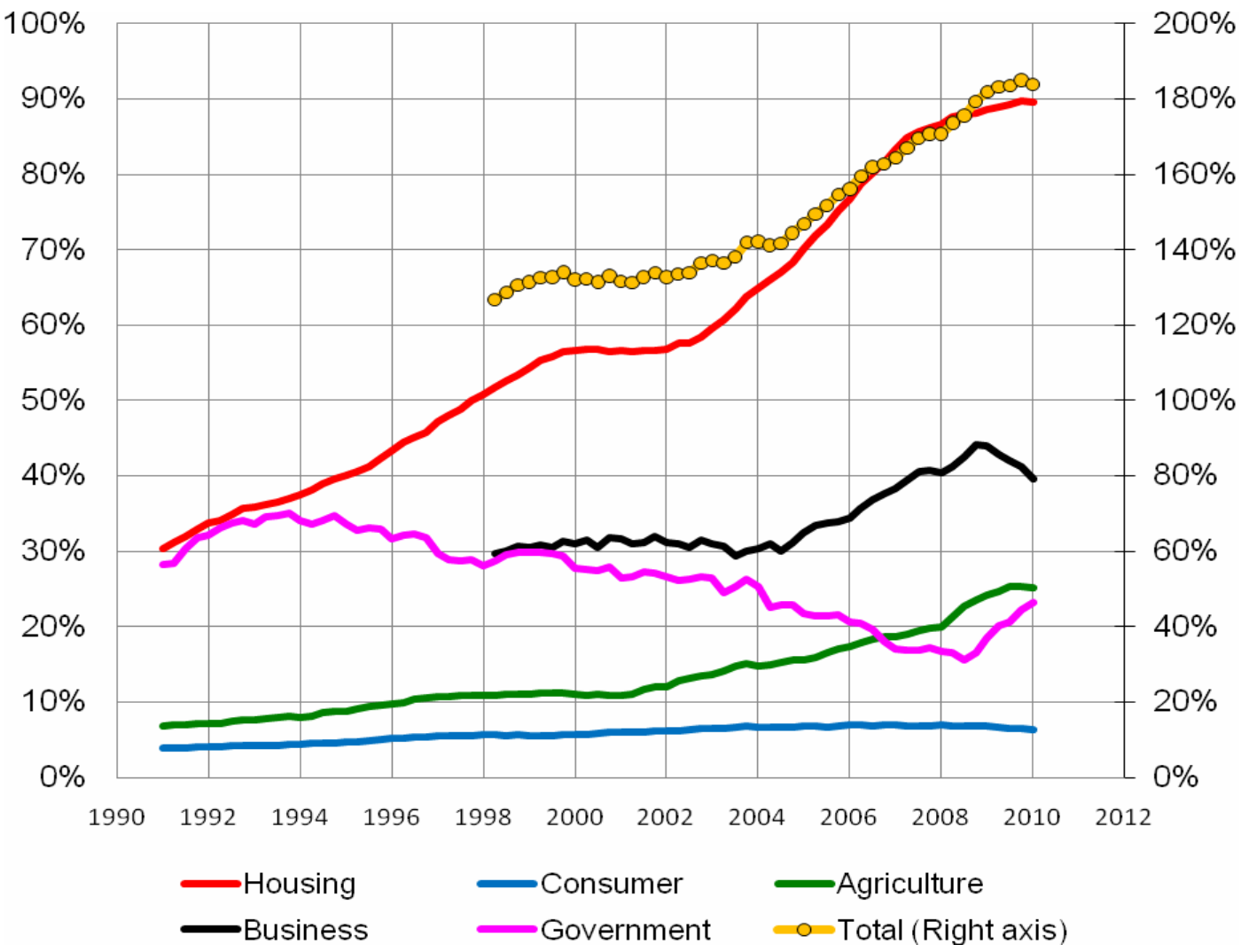

Figure 2-H

Debt to GDP Ratios, Selected Countries: 1990 - Q2 2009

(Roxburgh et al., 2010, 7)

Debt grew in most mature economies
Domestic private and public sector debt' ${ }^{1}$ by country
$\%$ of GDP


The economy requires sustained economic growth to pay back the accumulated debt plus interest. Globally, the market value of financial instruments exceeds that of the real economy by 3.5 times (Farrell et al., 2008). As we have seen with sub-prime mortgages, financial instruments can dramatically shed value when market expectations of the solvency and returns of the underlying assets change. The stability of the financial system ultimately depends on financial market expectations of the viability of growth in the global capitalist economy. Market expectations will not likely be met because a fifth and larger, process is underway that limits the growth of the productive economy: -fossil fuel depletion (Greco, 2009; Kunz, 2009; Sorrell, 2010).

\subsubsection{Deindustrialisation: Fossil Fuel Depletion}

Greer (2008) calls the shift away from fossil energy 'deindustrialisation'. As fossil fuels deplete, aggregate energy levels and economic output fall. Society is forced to substitute smaller scale fluctuating renewable energy sources and human and animal labour. From a short-term perspective, fossil fuels have the advantages of energy density, storability, ease of transportability, and explosive energy release making them highly useful for industrial economic activity (Giampietro, 2008; Reynolds, 1994, 1998). However, from a long-term perspective fossil fuels have a number of disadvantages, not to mention their contribution to climate change. These disadvantages include the peaking extraction profile of non-renewable resources. As the resource depletes the extraction rate initially rises with growing demand, then falls as scarcity (Bardi, 2005; Bently, 2009); and a tendency for society to use the best resources first leaving the lower grades for future development, a factor which limits energy quality ${ }^{7}$.

\footnotetext{
${ }^{7}$ See Hall et al. Hall, C., Powers, R. and Schoenberg, W. 2008: Peak Oil, EROI, Investments and the Economy in an Uncertain Future. Biofuels, Solar and Wind as Renewable Energy Systems, 109-132. for discussion of the 'best, first' principle and how efficiency improvements, are generally subject to the slow turnover of capital stock and high upfront costs
} 
Oil is the largest single source of the world's primary energy at approximately $35 \%$ (Energy Information Administration (EIA), 2006). Oil fuels approximately 95\% of the world's transport (International Energy Agency, 2006). A number of analysts expect the world's oil extraction rate to reach maximum and begin to decline in the 2005-20158 timeframe (Figure 2-I) (Campbell and Laherrere, 1998; Deffeyes, 2005; Industry Task Force on Peak Oil and Energy Security, 2010; Mohr, 2010)

Figure 2-I

Historical Oil Demand and Future Supply Projection of the Industry Task

Force on Peak Oil on Energy Security in Million Barrels per Day (Mb/d) (Industry Task Force on Peak Oil and Energy Security, 2010)

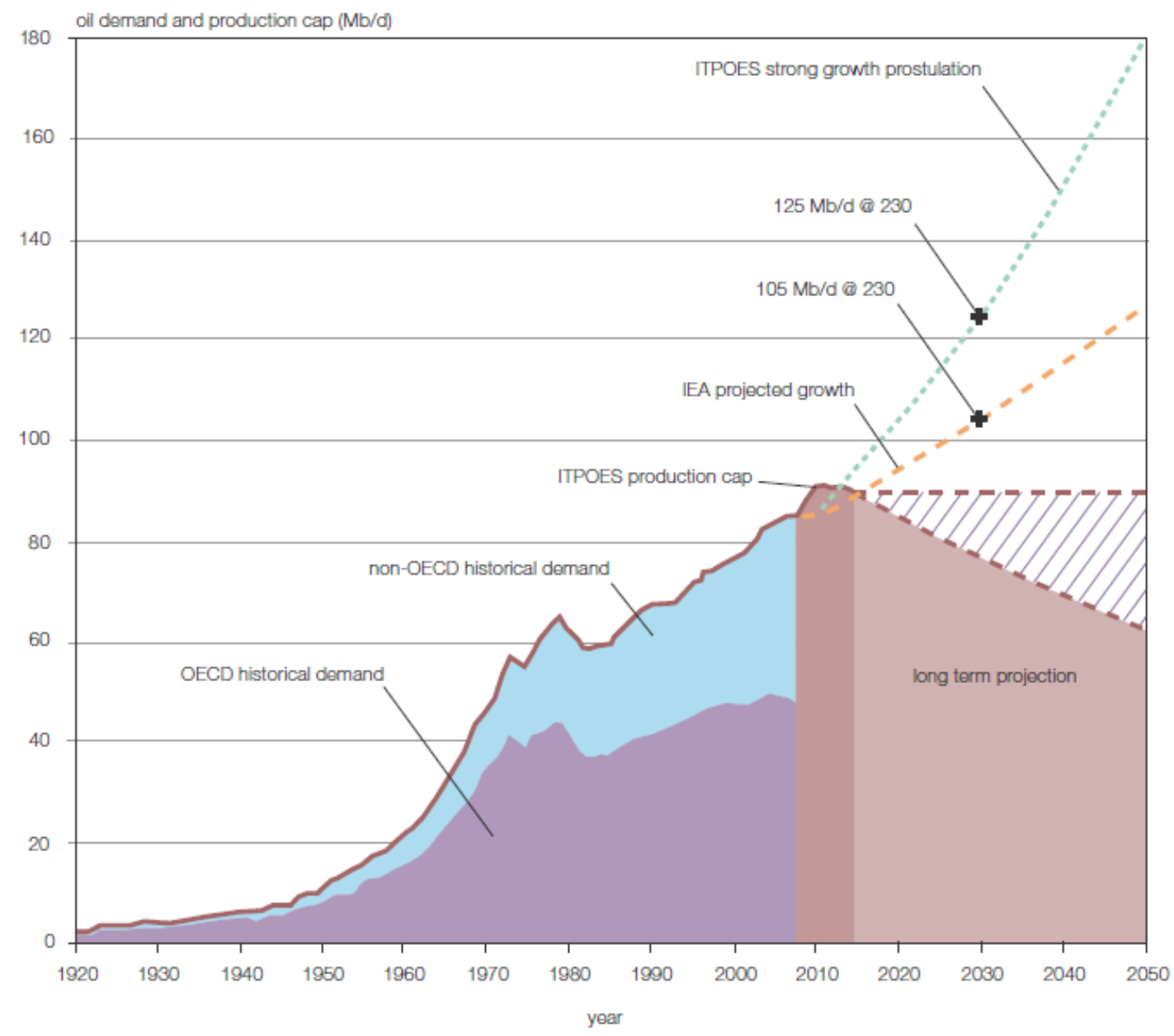

Other non-renewable resources also suffer extraction rate constraints over the medium to long term. For example, coal (Mohr and Evans, 2009; Zittel and Schindler, 2007); natural gas (Imam et al., 2004; Mohr and Evans, 2007); uranium

\footnotetext{
${ }^{8}$ Oil extraction has been flat since 2005 but definitions of 'oil', which may include other analogous liquids, and low data confidence make dating peak oil ambiguous.
} 
(Pearce, 2008); and various important minerals (Mudd and Ward, 2008), including the agriculturally essential phosphorous (Cordell et al., 2009)

Renewable energy sources are growing rapidly but do so from a low base. To maintain increases in aggregate energy supply and make up for diminishing quality alternatives must grow faster than fossil fuels decline. Mohr $(2010,150)$ forecasts total fossil fuel supply to peak between 2012 and 2029 at 433 - 581 exajoules per year (EJ/year) and decline about 3-5 EJ/year to 2050 in the central cases (Figure 2-J). 


\section{Figure 2-J}

Static and Dynamic Fossil Fuel Projections by Fuel Type

(Mohr, 2010, 161)
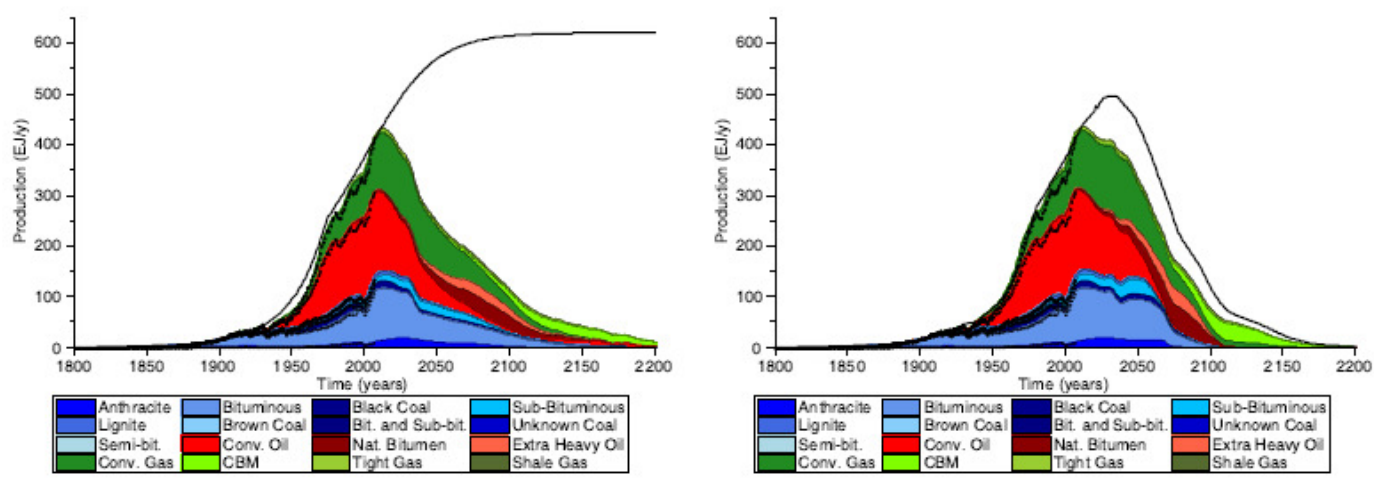

A CASE 1 STATIC

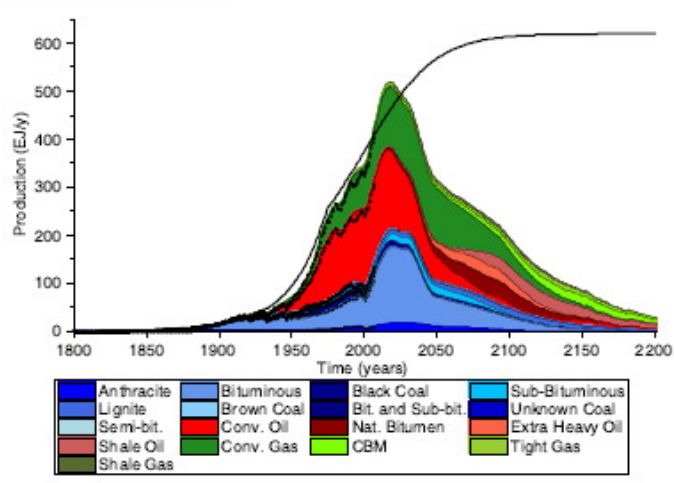

B CASE 1 DYNAMIC

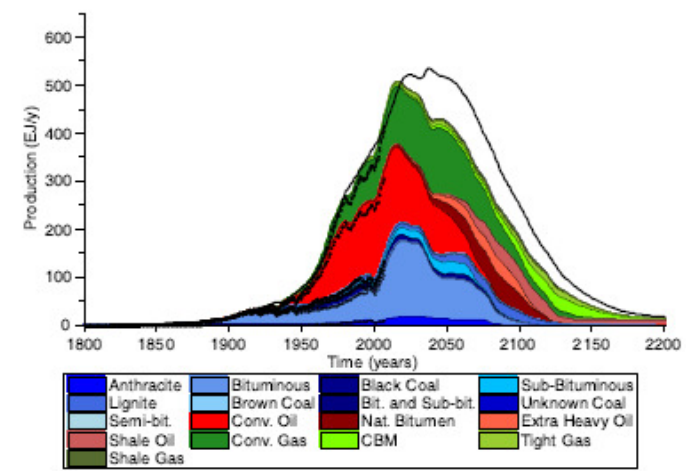

C CASE 2 STATIC

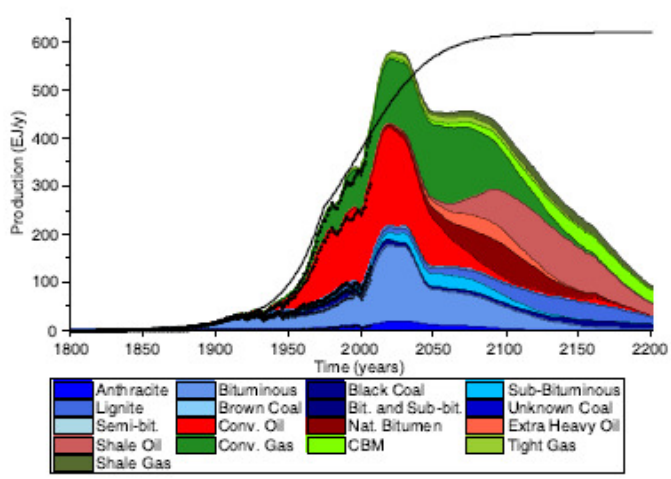

D CASE 2 DYNAMIC

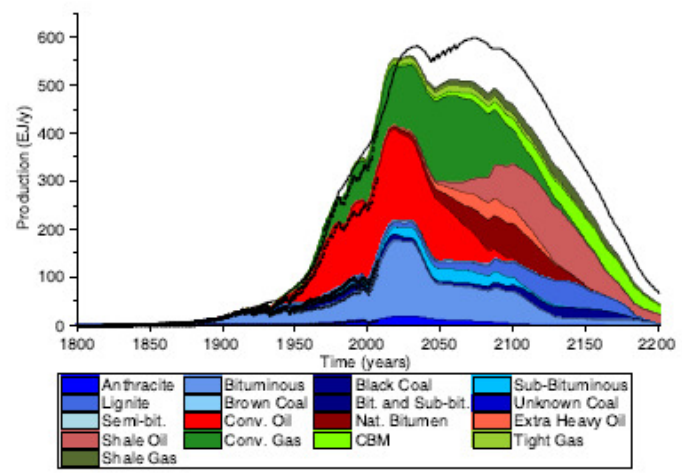

E CASE 3 STATIC

F CASE 3 DYNAMIC

In comparison, renewable energy excluding that derived from biomass, totalled 15 EJ/year of global supply in 2007 and have grown at about $0.6 \mathrm{EJ} /$ year on average in the preceding 5 years (Organisation for Economic Cooperation and Development, 2009). Humans already appropriate about 20 - 30\% of global biomass for food, fibre, timber, and fuel, limiting the scope of further appropriation for fuel, without further undermining ecosystem services (Haberl, 2006; Haberl et al., 2007). For comparative 
purposes, the energy content of the world's agricultural crop production in 2006 was about 72 EJ/year (Johansson et al., 2010), while solid and liquid biomass energy, (mostly wood for heating and cooking) was $46 \mathrm{EJ} / \mathrm{year}$ (Organisation for Economic Cooperation and Development, 2009) (Figure 2-K).

Figure 2-K

Composition of the World's Energy Supply in 2006

Researcher's calculations with data from International Energy Agency (2006); Johansson et al. (2010); and Organisation for Economic Cooperation and Development (2009)

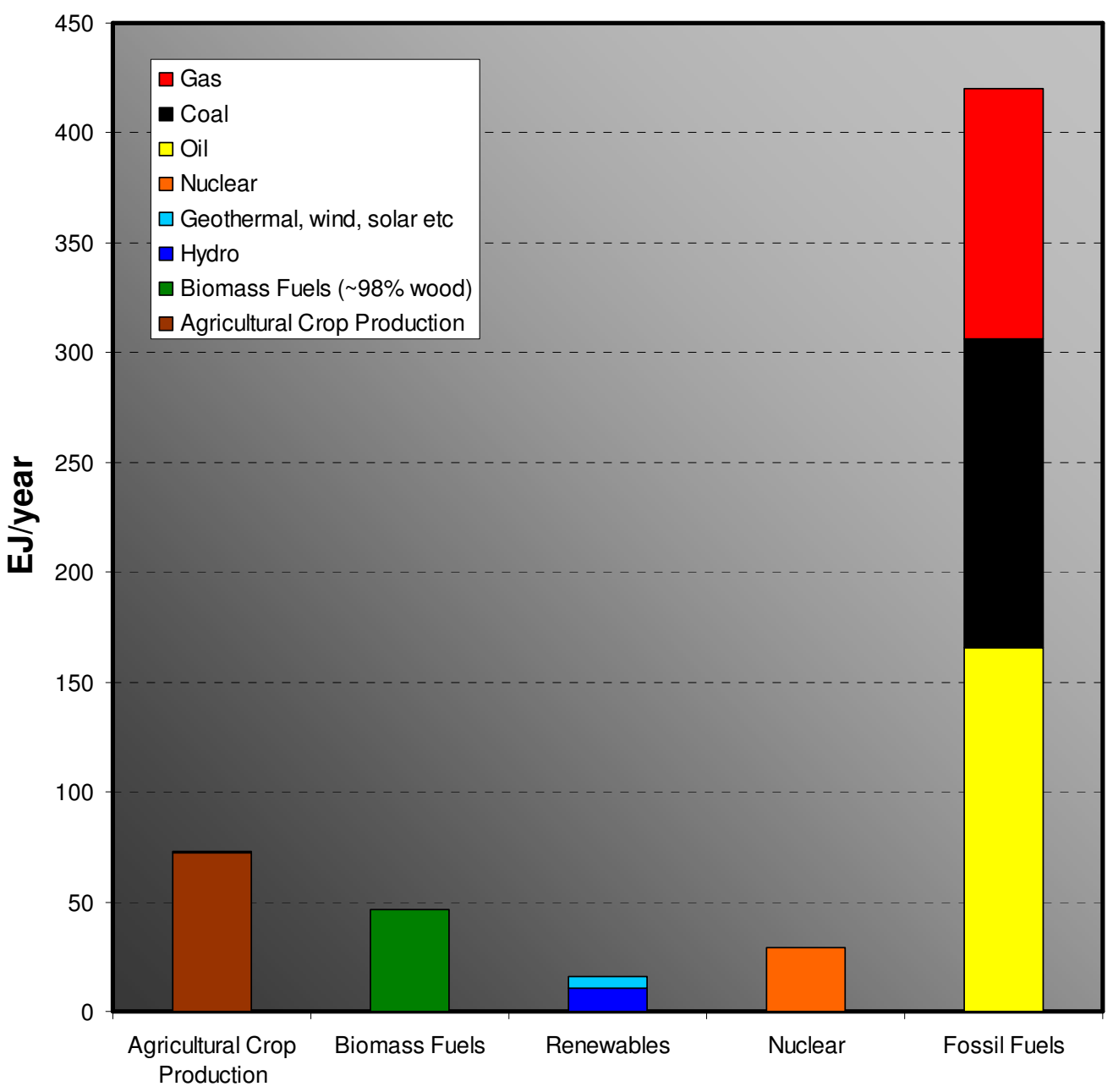


Alternatives require high upfront inputs and additional costs to mitigate intermittency, storage, and waste disposal issues. Analysts who consider the energetic costs and logistics of constructing enough alternatives to power industrial society are much less sanguine than those who do not (Gagnon, 2008; Heinberg, 2009; Hirsch et al., 2005; Kunz, 2009; Lund, 2007; Odum and Odum, 2006; Smil, 2005). A revolutionary energy technology could possibly allow growth to continue but this is highly uncertain and would take decades to become a primary energy source (Smil, 2005).

Declining resource quality and falling rates of resource extraction place hard limits on the growth of resource intensive industries. Logically, if the throughput rate of aggregate energy declines without compensating increases in energy efficiency, the amount of mechanical work will decline with it (Ayres and Warr, 2005). As energy quality declines, more energy must be devoted to finding and extracting energy and manufacturing the capital required to process it, leaving less energy surplus for nonproductive purposes (Hall et al., 2009; Hall et al., 2008). For the householder this will likely mean greater proportional expenditure on resource intensive essential goods and services (food, housing, essential mobility, heating and cooling). Rising non-discretionary costs place further pressure on discretionary spending and the industries that serve it. Declining energy throughput and quality will reorder the economy away from discretionary goods and services towards essentials (AguiarConraria and Wen, 2007; Bassi et al., 2009; Hall et al., 2008).

\subsubsection{Employment}

During the Great Depression of the 1930's, the last global debt de-leveraging period, unemployment levels reached about $25 \%$ in the USA, and stayed above $10 \%$ for 9 years (Figure 2-D). The core economies escaped the Great depression by ramping up manufacturing for the war economy of World War II (Kindleberger, 1973). Keynes $(1930,1)$ commented at the Great Depression's onset, that “...This is a nightmare, which will pass away with the morning. For the resources of nature and men's devices are just as fertile and productive as they were [new emphasis]." The latter 
statement is no longer true for the "resources of nature" 9, and debt ratios are comparable or significantly worse. (see Figure 2-C, and compare to the current debt ratios in Figure 2-F; Figure 2-G; and Figure 2-H). Moreover, in today's globalised economy, an economic shock in one country is rapidly transmitted to others (Walti, 2009).

For employment rates to remain stable, essential goods producing industries must create jobs faster than any jobs lost in the discretionary sectors, and keep up with a growing population ${ }^{10}$. Once economic restructuring has worked through, rising energy costs and falling labour costs may eventually make human labour an economically efficient substitute for exosomatic machine labour (although of course this would involve much lower wages than today). Additionally, radical political interventions such as universal basic income or a reduced working week could maintain employment in a declining economy (Jackson, 2009). This study argues that that there is significant risk that both of these conditions will not be met in the medium term, and that further financial difficulties will compound problems.

Falling employment and material wealth has significant economic, psychosocial, and political implications for society. Poverty, unemployment and financial strain contribute to the prevalence of common mental disorders (Weich and Lewis, 1998). Losses of income or employment will likely result in a decline in perceived socioeconomic status and poorer health outcomes (Hayo and Seifert, 2003). Low socioeconomic status is associated with greater chronic stress (Sapolsky, 2004).

Of concern, studies have found a connection between economic decline and political extremism (Bruckner and Gruner, 2010; International Monetary Fund - International Labor Organisation, 2010) The following sections argue that community gardens could potentially mitigate negative outcomes by providing a social, political, economic, and educational base for communities.

\footnotetext{
${ }^{9}$ From a biophysical economics perspective "Men's devices" do not produce economic goods and services, merely transform existing resources, and ecosystem services (Ayres and Warr, 2005)

${ }^{10}$ Globally, 440 million new jobs are required in the next ten years to absorb new labour market entrants (International Monetary Fund - International Labor Organisation, 2010).
} 


\subsubsection{Benefits of Community Gardening}

A mainstream perspective may consider 'political action' to involve influencing the state, large businesses, or global institutions either directly through political lobbying and protest, or indirectly through manipulating public opinion. Gardening is none of these things but that does not mean we should consider it apolitical. Breines (1980) labels the former kind of politics "instrumental" contrasting it with the "prefigurative" politics of new left organisations of the 1960's (see also Rossinow, 1997). Instrumental politics is zero-sum in outlook and seeks to influence, or potentially capture the centres of power. Pre-figurative politics is positive-sum in outlook, seeks to found institutions within which one wishes to live, and directs the balance of efforts towards civil society (e.g. Dryzek, 1996). Instrumentalists often accuse prefigurative activists of irrelevance and an apolitical cynicism or idealism (Kleinman, 2009; e.g. Steffen, 2009).

Lyson (2004) argues that community gardens are part of a pre-figurative civic agriculture movement concerned with food sovereignty and nutrition security. Those concerned with food sovereignty claim that cultivating (or catching) at least some of one's own food is a political act and connects an individual to the environment and their heritage. Those concerned with nutrition security claim that cultivating food by one's own hand is nutritionally superior to industrially produced food. Civic agriculture includes urban community gardening, community supported agriculture, farmers' markets and 'guerrilla gardening' (the cultivation of space one does not own) (ibid.)

Civic agriculturalists resist the dominance of the 'agro-industrial food system', that is, the linked food production, distribution, and preparation systems in industrialised countries from large-scale agribusinesses, through to supermarkets and fast food outlets (Fonte, 2002). Many scholars have criticised this system on a variety of grounds including: environmental and human health, equity, resource use and resilience (Cordell et al., 2009; Gomiero et al., 2008; Khan and Hanjra, 2009; Monsivais and Drewnowski, 2009; Pimentel, 2009; Pimentel et al., 1973; Smil, 2000). 
From an economic rationalist perspective vernacular food gardening is an economically inefficient opportunity cost on one's time. In this line of thought, employment with which to pay for supermarket-provisioned food serves a better use of one's time than attempting to inefficiently produce food oneself (Seeth et al., 1998). This is probably true in many cases and should hold a degree of validity in a post-growth society. However, this argument makes three assumptions: first, that a job in formal economy will be available and will be well-paying enough to incur an opportunity cost; second that the financial system will remain stable; and third that vernacular food production is always less efficient than the industrial agricultural system.

Previous sections 2.2.4 and 2.2.6 have discussed employment and the prospects for financial stability. Lacking formal, and/or well paying economic opportunities, food gardening can offer a degree of economic independence, a feature that Sharashkin (2008) and Orlov (2008) note was relevant for Russians during and after the collapse of the Soviet Union. Moreover, in Argentina's financial collapse of 2001-2002 barter networks sprung up when people could not access their savings' accounts (Pearson, 2003). In such a scenario, a garden stocked with fresh food could hold greater advantage than abstract wealth.

The economic efficiencies of food production systems has been a subject of much debate in the agricultural economics literature (Cornia, 1985). Polycultural farms are known to be more productive per unit of land area and energy, while monocultural industrial farms are more productive per unit of labour (Altieri, 1999). Polycultural (and usually small scale) food cultivation can leverage ecological relationships between plants and livestock and achieve greater resource efficiencies than largescale monocultures (Hoare and Thomas, 2007; Sharashkin, 2008). The orthodox economics focus on labour productivity as the engine of wealth creation (and wellbeing), reflects the high cost of labour in the industrial age, a conceptualisation of the economy as independent of natural resource flows, and Western conceptions of work as a necessary evil (Schumacher, 1973a). Labour productive systems can generate financial wealth as long as resource inputs remain abundant and cheap. Conditions that this study argues will not hold.

Orthodox economics does not engage with questions of class power relations or how wealth, once generated, is distributed. Heterodox economic perspectives have not neglected these questions. Arguably, a labour efficient system that depends on 
capital-intensive machinery, would favour the owners of capital rather than workers, leading to wealth disparities, while a knowledge-intensive polycultural system would result in more equitable wealth distribution (Carson, 2010; Gintis, 1987; Nell, 1987; Schumacher, 1973b). Carson (2010) takes this argument further. In Carson's view the combined impacts of peak oil on the state-subsidised industrial distribution system, and the development of sophisticated, household-scale, and open-source manufacturing technologies make domestic production increasingly competitive (ibid.).

Vernacular food gardening is not necessarily polycultural or efficient, but skilled gardeners can achieve impressive results. Sharashkin $(2008,14)$ notes that Russian households cultivate roughly $90 \%$ of potatoes, $80 \%$ of fruits and vegetables and $50 \%$ of meat produced in Russia, typically on 0.5 ha polycultural plots. In another example, Vitiello and Nairn (2009) conservatively estimate that community gardens in the city of Philadelphia produce \$US4.9 million of vegetables and fruits over a summer season on 33.4 acres of cropped area. Finally, the Dervaes family of Pasadena, California claim to produce 6000 pounds of produce yearly, on $1 / 10^{\text {th }}$ of an acre garden in a suburban lot (Dervaes, 2010).

The key to a successful polycultural systems appears to be ecological knowledge (Borron, 2006; Mollison, 1990). The following section examines how the social context of a community garden group promotes learning and knowledge transfer.

\subsubsection{Role of Communities of Practice}

Lave and Wenger (1991) use the term 'Community of Practice' (CofP) as the key unit or relationship in the situated model of learning. They argue that much authentic learning occurs informally in social settings. In their situated model, learning involves an identity change as the learner understands how to behave (as much as what to know) through observation and interaction with the more knowledgeable. They contrast this model with an established model of learning as the mechanistic transmission and absorption of ideas (Cox, 2005). CofP's are defined as 'mutually engaged' groups of practitioners working on a 'joint enterprise' and developing a 'shared repertoire' of knowledges (Wenger, 1998). Although other works (Wenger et 
al., 2002) use different, and vaguer definitions (Cox, 2005). CofP are a focus of the knowledge management literature. Wenger at al. (2002) argue that informal CofP's are a key ingredient in an organisation's knowledge transfers.

Krasny \& Tidball (2009) suggest that CofP theory applies to practitioners of community gardening. Accordingly, a community garden provides a platform for multiple types of learning including: (a) scientific learning (i.e. botanical and ecological knowledge); (b) innovating and distributing applied knowledge more broadly (the development and sharing of gardening technique with others); and (c) broader social learning beyond direct involvement in the group activities (i.e. enhanced natural resource management and community resilience) (ibid.). These latter aspects contribute to the social and environmental good.

Taking this argument further, through broader social learning mechanisms community gardening potentially has a deeper political influence. In this argument, a community garden serves as an activist base for civic political action. The garden would link activists to their local social networks. Activists could draw on fellow gardeners for support and establish trust and influence in their neighbourhood (Krasny and Tidball, 2008; Wheatley and Freize, 2006).

More obviously, community gardens provide a social context for mutual social support. For many employed people, employment provides opportunities for social inclusion (Evans and Repper, 2000) The social opportunities of community garden's could mitigate opportunities lost through unemployment (Saldivar-Tanaka and Krasny, 2004).

\subsection{Chapter Conclusion: Collapse?}

Historically, resource depletion has often lead to a breakdown of a society's institutions. Some scholars have speculated that various impacts of resource depletion, increasing complexity, climate change, and environmental degradation could precipitate the collapse of industrial society (Beddoe et al., 2009; Costanza et al., 2008; Diamond, 2005; Tainter, 2000). A summary of the collapse literature will not be attempted here, but the ideology of collapse, one's belief in the inherent 
robustness or vulnerability of the status quo, and how this ideology motivates actions is relevant to the research focus. Collapse ideology is briefly discussed below.

Diamond (2005) frames collapse as 'choice to fail or succeed' implying that complex societies faced with predicaments are viable collective decision-making units. This conception, possibly reflects the influence of rationalism, and the assumption of rational choice identified in section 2.1. Hassan (2008) disagrees with Diamond's framing, arguing that distributing wealth is contentious enough in periods of economic growth. During economic decline, the social dynamics of negative-sum resource competition can disrupt the usual mechanisms for consensus building, leading to breakdown.

Colouring the debate, 'collapse' is a highly loaded term. Popular culture, influenced by Christian eschatology, imagines that industrial society will end in an apocalyptic upheaval (Gray, 2007; Greer, 2008). Society goes from a sophisticated high-tech civilisation to a zombie-infested wasteland within the space of a two hour movie. In reality, past collapses proceeded over the course of several decades, if not centuries, and there were significant degrees of continuity (Kolata, 2006), and periods of recovery (Greer, 2005). Arguments that our current society is vulnerable to collapse, or that industrial society is currently in decline have not met widespread acceptance, but that is not surprising when ideologies of unending growth and progress hold sway. Nevertheless, as the following anecdote demonstrates, that some form of collapse will occur (or is occurring), but will go unrecognised for some time, is a possibility that should be included in any risk assessment.

In 66 C.E. much of Rome burnt to the ground in a great fire. The Roman Empire had to fund the reconstruction but did not have enough funds in the treasury to cover costs. During the empire's expansion, Rome had enjoyed periods of great wealth. At that time however, the empire had reached the limits of its expansion and flow of slaves and loot from newly conquered colonies had ceased. Rome had to transition to a low-gain agriculture-based economy subject to depleting soils and frequent crop failures. To fund the rebuilding, the authorities turned to a strategy that future rulers would find all-too tempting. Rome re-minted the silver denarius with less silver content and used the surplus to pay its bills (Figure 2-L). Rome was rebuilt, but of course traders eventually caught on and the value of the denarius dropped. What the citizens of Rome could not have realised was that future historians would mark this 
point as the beginning of the decline and fall of the Roman Empire (Tainter, 1988; Tainter et al., 2003).

Figure 2-L

Debasement of the Silver Denarius

(Tainter, 2000, 21)

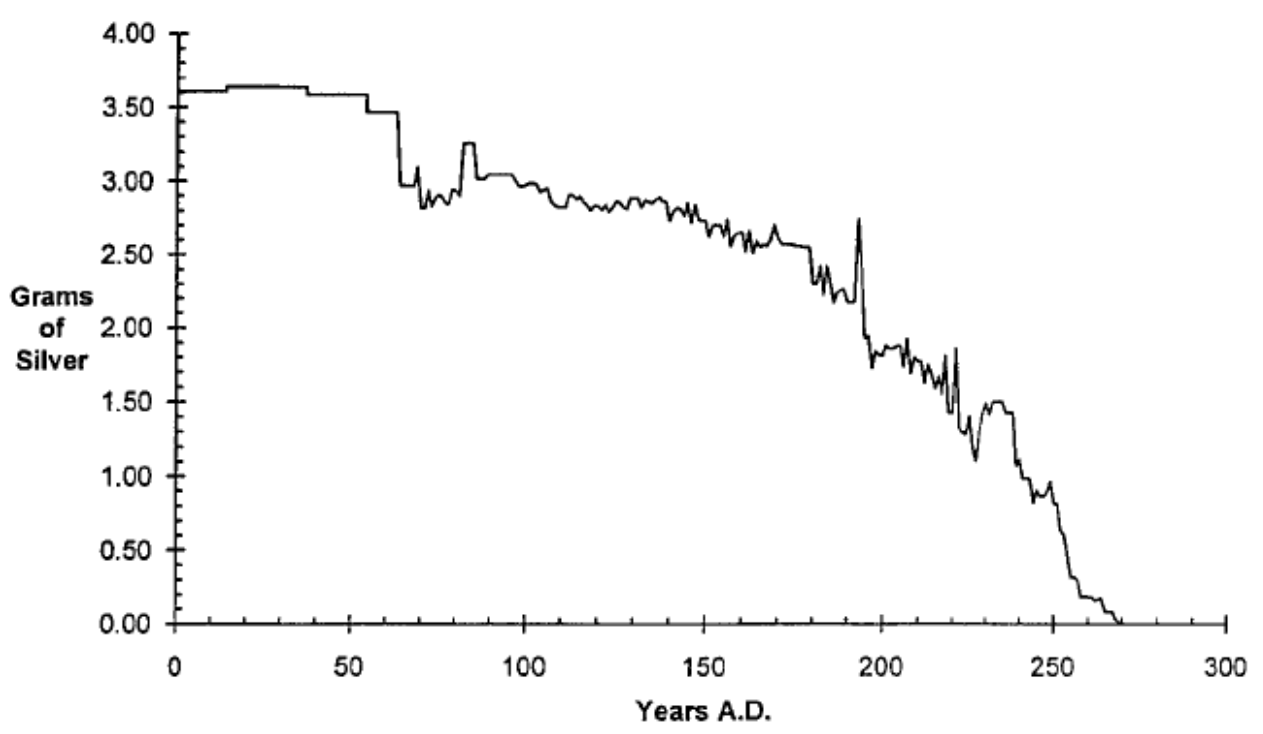

The reader may wish to compare the actions of authorities two thousand years ago to the actions of governments and financial institutions to the GFC today. As industrial society faces the depletion of key resources and a necessary transition to a low-gain energy regime, the authorities seem to have once-again found financial chicanery alltoo tempting.

In the event of collapse, political action can still make a difference to the conduct of authority or the quality of life. Depending on one's preferred definition, a prolonged period of high unemployment brought about by financial disruption or resource depletion as identified in this chapter, may or may not constitute societal collapse. It seems likely that progressivism and rationalism will remain prominent and prevent timely and constructive action from being taken to mitigate this outcome. Simple gardens do not fit within the dominant narratives of progress and techno-institutional centrism. Influenced by these ideologies, decision-makers may neglect of the various political, economic and psychosocial benefits of community gardens. Accordingly, there is a need for activists to develop initiatives themselves. This study argues that activists will find the social, economic, and political base provided by community gardens valuable, but these projects must rely on volunteer efforts and are therefore 
limited by lack of motivation and power. The following chapter reviews the literature on empowerment and motivation as applied to the research focus. 


\section{The Psychology of Empowerment and Participatory Geographic Information Systems}

"Yet a man who uses an imaginary map, thinking that it is a true one, is likely to be worse off than someone with no map at all; for he will fail to inquire whenever he can, to observe every detail on his way, and to search continuously with all his senses and all his intelligence for indications of where he should go."

$\sim$ E. F. Schumacher, Small is beautiful

This chapter reviews the literature on empowerment, PGIS, motivation, and cognitive style. Empowerment is usually categorised as psychological or social (Conger and Kanungo, 1988). Psychological empowerment refers to motivational processes while social empowerment refers to the distribution of political or economic power amongst different groups (Eylon and Bamberger, 2000). The PGIS literature largely discusses social empowerment outcomes rather than psychological empowerment processes (e.g. Corbett and Keller, 2005; Elwood, 2002; Kyem, 2001). Esnard (2007) cites the regular failure of GIS practitioners to convince others of the utility of GIS projects. While community development professionals are sceptical of the value of purely psychological approaches (Breton, 2002). It is possible that in addition to differences in power and skill that can skew participatory projects, cognitive style variation could influence participant's motivation for project activities. It is proposed here that two theories can shed light on how psychological empowerment occurs in community development projects, including PGIS projects, and provide a rationale for differing outcomes. These theories are the SelfDetermination (SD) theory of Deci and Ryan (1985, 2000; Ryan and Deci, 2000), and the Empathiser-Systemiser (E-S) theory of cognitive style developed by Baron- 
Cohen and colleagues (Baron-Cohen, 2002, 2008; Baron-Cohen and Belmonte, 2005; Baron-Cohen et al., 2005; Baron-Cohen et al., 2003)

\subsection{Empowerment}

Empowerment is recent concept first used as a social work construct (Solomon, 1976) and more recently as a management construct. In social and development work it refers to both a process whereby oppressed groups collectively investigate problems and take action; and an outcome whereby an oppressed group achieves greater control over their lives (Carr, 2003). Social work and development researchers have drawn heavily on the work of Brazilian educator Paulo Freire (b. 1921 - d. 1997). Freire argued that mainstream educational practices socialize people to accept roles as objects of the status quo. Friere's methods regard learners as subjects with the ability to change their circumstances. Freire found many nonliterates blamed fate or God's Will for their position and did not consider themselves agents of their circumstances. In one method, Freire would show a group of nonliterates a series of pictures of animals (unable to affect culture) and humans creating and using artefacts (able to affect culture) to spark discussions about human capacities. In another, learners would discuss the political context of a various concepts they had selected themselves as meaningful such as 'shanty-town' or 'wage', before learning how to write the words for these concepts. Freire called this process 'conscientisation' (conscientização), i.e. a critical awareness about one's political circumstances and the means to change it. By such methods non-literates have learnt to read in 30 hours and used their literacy as a political tool (Brown, 1974; Freire, 2000).

The management literature also uses the empowerment concept. Over recent decades management scholars have advocated businesses shift from hierarchical mechanistic organisational structures to flatter, more networked structures (e.g. Scharmer, 2009; Senge, 1990). According to Senge (ibid.), businesses with flatter structures benefit from distributed decision-making and the creative input of subordinates. Here, empowerment is regarded as both a delegative construct whereby managers share decision-making power with subordinates; and as a psychological construct whereby 
subordinates are intrinsically motivated to perform tasks and power sharing is one example of a motivational method amongst others (Conger and Kanungo, 1988).

Both literatures draw a distinction between empowerment that affects the generation or redistribution of political or economic power and empowerment that affects internal psychological processes. The current study will refer to these as social and psychological empowerment respectively. The management literature tends to focus on the psychological empowerment of employees (Spreitzer, 1995; Thomas and Velthouse, 1990). Social work theorists have countered that a focus on psychological empowerment without social empowerment is inadequate (Riger, 1993). As Breton (2002) puts it:

\footnotetext{
"Without exercising the power to act, the awareness of personal strengths and competence may give people a sense of empowerment... and lead them to think and feel that they have more power and are more in control-it does not mean that they have more power and are more in control."
}

A zero-sum model of power underlies the social work perspective (Gutierrez, 1990; Riger, 1993). In this context, zero-sum means that any power acquired by one group necessarily results in the loss of power by another group. Riger (ibid.) argues that such a guiding ideology can create conflict between groups or between an individual and their community. The following sub-sections examine how different disciplines have made use of the empowerment concept.

\subsection{Participatory Geographic Information Systems (PGIS)}

GIS's powerful capabilities of have given GIS-based analyses a high degree of influence in policy settings (Haque, 2001). In reaction, many have criticised the technological and expert orientation of 'traditional GIS', drawing on Foucault's analysis of the indivisibility of knowledge and power (Craig et al., 2002a; Crampton and Elden, 2007; Pickles, 1995b). Harley \& Cosgrove (1988) took up Foucault's themes and applied them to cartography with the particularly influential Maps, 
Knowledge and Power. From these perspectives, researchers have argued that traditional GIS privileges quantitative and spatially relevant information over other informational forms. Further, that GIS entrenches an already dominant rationalist approach to decision-making. The cutting edge use of GIS requires a high degree of technical training and access to expensive software. Non-experts struggle to counter GIS-welding political opponents or are excluded from decision making altogether (Craig et al., 2002; Elwood, 2002; Jankowski, 2008)

In response to these critiques, a number of researchers have developed PGIS and Public Participation GIS (PPGIS) approaches. Typically PPGIS involves participatory planning in industrialised countries while PGIS involves participatory development in non-industrialised countries (Rambaldi et al., 2004). The use of PGIS for community development has usually been accompanied with an ideology of social empowerment. For example, PGIS practitioners seek to include the disadvantaged in local decision-making, and improve the capacity of community members to produce geographic knowledge (Corbett and Keller, 2005; Craig and Elwood, 1998; Elwood, 2002; Kyem, 2001)

\subsection{Empowerment in PGIS}

The PGIS literature largely follows the social work/development perspective of empowerment. PGIS scholars view GIS as a tool for disadvantaged individuals or groups to improve their own capacities and gain or redistribute power. For example, a GIS can communicate the geographic features that the group values to influence political outcomes. Elwood (2002) describes how a neighbourhood association's GIS capabilities lead to greater involvement in local-government decision-making. Elwood (ibid.) Kyem (2001) and Corbett and Keller (2005) use different frameworks to analyze empowerment in a PGIS context. A sketch of these frameworks and the possible correspondences between them is presented in Table 3-A. 
Table 3-A

Approximate Correspondence between PGIS Empowerment Frameworks

\begin{tabular}{|c|c|c|}
\hline Kyem, 2001 & Elwood, 2002 & Corbett and Keller, 2005 \\
\hline Distributive Power & Distributive & \multirow{2}{*}{ Empowerment } \\
\hline Social Change & Procedural & \\
\hline $\begin{array}{l}\text { Building Human Capital } \\
\text { for Collective Action }\end{array}$ & \multirow{2}{*}{ Capacity Building } & \multirow{2}{*}{ Empowerment Capacity } \\
\hline Generative Power & & \\
\hline
\end{tabular}

PGIS empowerment frameworks do not directly address the psychological aspects of GIS construction and use. 'Empowerment Capacity' (Corbett and Keller, 2005) or similar constructs, can include the acquisition of GIS-related skills, and psychological processes. Broader GIS literature makes links between visual information and cognition (e.g. Khatri et al., 2006; MacEachren, 2004; MacEachren and Ganter, 1990), while psychological factors feature prominently in the broader empowerment literature (Eylon and Bamberger, 2000; Kraimer et al., 1999; Spreitzer, 1995; Thomas and Velthouse, 1990; Zimmerman, 1995), the psychological empowerment aspects of PGIS have not been considered. Power relations may be a more pressing focus for the disadvantaged communities in which PGIS projects usually take place. In addition, a zero-sum social empowerment ideology may have influenced researchers to focus on 'hard' outcomes such as changes in power relations. 


\subsection{Empowerment and Motivation Theory}

\subsubsection{Management and Empowerment}

Thomas and Velthouse's (1990) (TV1990) model operationalises empowerment as intrinsic task motivation and has been frequently cited in the management literature (Eylon and Bamberger, 2000; Gagné et al., 1997; Kraimer et al., 1999). The model centres on the individual's learning cycle (Figure 3-B). 'Environmental events' interrupt this cycle providing new data that the individual assesses according to four criteria at two scales ('Global Assessment', i.e. accumulated beliefs; and 'Task Assessment', i.e. specific to the task).

The four criteria are:

1. Impact - Could the task make a difference?

2. Competence - Can I perform the task competently?

3. Meaningfulness - Is the value of the task relevant to my ideals or standards?

4. Choice - Am I a self-determined agent or a pawn of larger forces? 


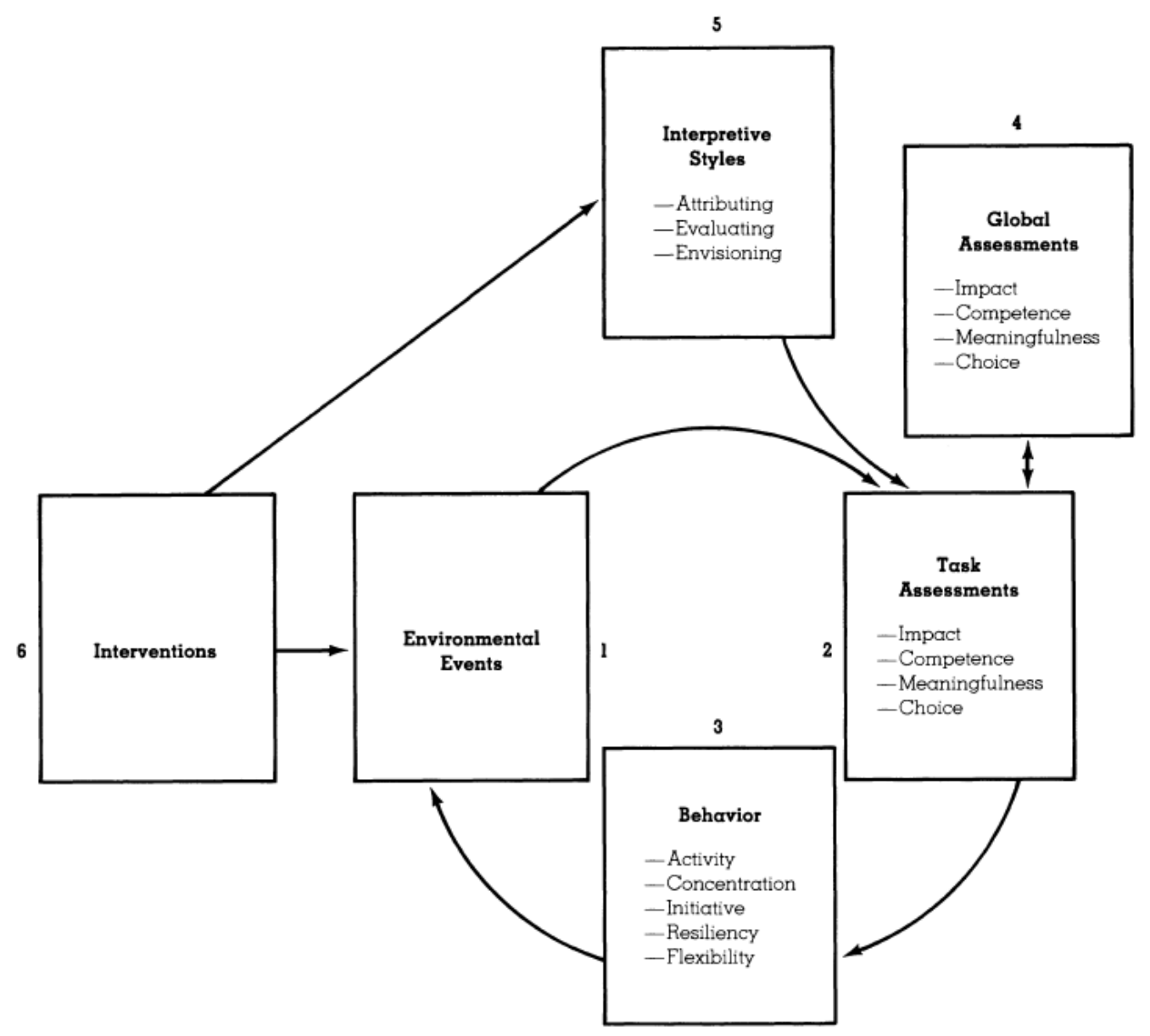

'Impact' refers to the perception of task effectiveness. Tasks perceived as likely to achieve their intended effect are more likely to motivate individuals. Situations where tasks have little impact despite competent performance distinguish 'impact' from 'competence'. 'Competence' refers to the perceived self-efficacy of those performing tasks and draws on Bandura's (2002) social cognitive theory. 'Meaningfulness' refers to how much the subject intrinsically cares about a task. Presumably, an individual with a group identity will be motivated to perform tasks for the benefit of group members and will consider these tasks meaningful, although in this context 'meaningfulness' seems broader than the SD concept 'relatedness'. 'Choice' refers to an internal perceived locus of control and draws on SD theory. In TV1990's model, interventions can influence how a subject interprets events. For 
example, verbal persuasion may influence an individual to re-evaluate their task performance in a more positive light and affect their perceived self-efficacy (i.e. 'competence').

\subsubsection{Social Work and Empowerment}

Despite the different philosophical orientation of social work identified in section 3.1, Parsons, Gutierrez, and Cox's (1998) (PGC1998) frequently cited model of social work empowerment uses similar empowerment constructs to the management literature. The model mixes cognitive components ((1) and (2)) with skills and practices ((3) and (4)):

1. Belief in self-efficacy.

2. Validation through collective experience.

3. Knowledge and skills for critical thinking and action.

4. Reflective action.

PGC1998 use the competence-equivalent concept 'perceived self-efficacy' citing social-cognitive theory (Wood and Bandura, 1989). 'Validation through collective experience' involves establishing social connections to others that motivate prosocial behaviour, analogous to 'relatedness'. 'Knowledge and skills for critical thinking and action' implies that the subject perceives themselves as a selfdetermined agent. 'Reflective action' would also appear to imply self-determination and/or task evaluation, analogous to TV1990's 'Impact' concept.

Similar empowerment constructs from different literatures imply common underlying processes. The following section examines a psychological theory that could illuminate these processes.

\subsubsection{Intrinsic Motivation and Self-Determination (SD) Theory}

A frequent feature of psychological empowerment theory is the concept of intrinsic motivation (Gagné et al., 1997; Lee and Koh, 2001; Thomas and Velthouse, 1990). 
Deci and Ryan's (1985, 2000; Ryan and Deci, 2000) Self-Determination (SD) theory distinguishes between intrinsic and extrinsic motivation. Intrinsic motivation is the incentive to undertake an activity based on the expected enjoyment of the activity itself. Extrinsic motivation is the incentive to undertake a task based on external controls (rewards and punishments). Subjects performing intrinsically motivated tasks demonstrate greater interest, excitement, persistence, creativity, and performance than those performing tasks to comply with external criteria (ibid.). According to SD theory subjects construct intrinsic motivation for the content of a task from evaluating their prior experience of a task's context in satisfying or thwarting innate psychological needs. External regulations can also motivate behaviour, but must be internalised to avoid thwarting needs and diminishing intrinsic motivation (ibid.).

SD theory proposes that human's adaptive capacities include an active pursuit of social connections, task engagement, and a unified sense of self. Deci and Ryan (2000) identify three innate psychological needs essential to well-being, 'selfdetermination', 'competence', and 'relatedness'. ${ }^{11}$ It is important to note that extrinsic and intrinsic exist on a continuum. A subject can internalise the values of the external entity and mitigate conflict between external control and selfdetermination (Figure 1.) However, internalisation of external controls does not result in intrinsic motivation. Deci and Ryan (2000) distinguish four types of extrinsic motivation on the continuum of internalisation: 'external regulation' is wholly external control; 'introjected regulation' refers to regulations that are somewhat internalised such as threats of guilt and shame; 'identification' is when the subject accepts the underlying value of the behaviour but performs it for instrumental reasons, for example, accepting that exercise is beneficial and exercising to become healthier, not because of intrinsic enjoyment; finally, 'integration' where the behaviour becomes integral to their values and identity (Table 3-C)

\footnotetext{
${ }^{11}$ Pink (2009) has recently summarised Deci and Ryan's work and other literature on motivation for a business audience and re-labels these concepts, 'autonomy', 'mastery', and 'purpose' respectfully.
} 
Table 3-C

The External-Internal Motivation Continuum (Deci and Ryan, 2000, 237)

\begin{tabular}{|c|c|c|c|c|c|c|}
\hline Behaviour & $\begin{array}{l}\text { Nonself- } \\
\text { determined }\end{array}$ & \multicolumn{4}{|c|}{$\leftarrow$} & $\begin{array}{c}\text { Self- } \\
\text { determined }\end{array}$ \\
\hline $\begin{array}{c}\text { Type of } \\
\text { Motivation }\end{array}$ & Amotivation & \multicolumn{4}{|c|}{ Extrinsic Motivation } & $\begin{array}{l}\text { Intrinsic } \\
\text { Motivation }\end{array}$ \\
\hline $\begin{array}{c}\text { Type of } \\
\text { egulation }\end{array}$ & $\begin{array}{l}\text { Non- } \\
\text { regulation }\end{array}$ & $\begin{array}{c}\text { External } \\
\text { Regulation }\end{array}$ & $\begin{array}{l}\text { Introjected } \\
\text { Regulation }\end{array}$ & $\begin{array}{l}\text { Identified } \\
\text { Regulation }\end{array}$ & $\begin{array}{l}\text { Integrated } \\
\text { Regulation }\end{array}$ & $\begin{array}{c}\text { Intrinsic } \\
\text { Regulation }\end{array}$ \\
\hline $\begin{array}{l}\text { Locus of } \\
\text { Causality }\end{array}$ & Impersonal & External & $\begin{array}{l}\text { Somewhat } \\
\text { External }\end{array}$ & $\begin{array}{c}\text { Somewhat } \\
\text { Internal }\end{array}$ & Internal & Internal \\
\hline
\end{tabular}

Deci and Ryan (2000) hypothesise that the three needs evolved to facilitate the transmission of culture through social learning. It follows that subjects with a need for relatedness mimic their elders; subjects with a need for competence develop their skills; and subjects with a need for self-determination avoid external controls that may not be in their best interests (see also Inghilleri, 1999).

The need for 'Self-determination' relates to a subject's perceived locus of causality and is a prerequisite for experiencing intrinsic motivation. Deci et al. (1999) demonstrate that rewards and punishments (the proverbial 'carrot and stick'), enhance task performance only when the task is mundane. When the task requires creativity, rewards and punishments shift the perceived locus of causality to an external entity and conflict with the need for self-determination. Many institutions require creative tasks and attempt to motivate members through offering rewards or setting deadlines but this can be counter-productive. When a place of work or a school offers higher pay or better marks in exchange for improved performance or enforces compliance with external criteria the subject perceives this as an external constraint and the intrinsic motivation to perform the task diminishes ${ }^{12}$ (Deci, 1971; Deci and Ryan, 1985).

Interestingly, progressive ideologies grant political actors a large degree of causality. Environmental politics often frame political actions as 'saving the world' Adopting a contrary deterministic perspective of global environmental change, where humans

\footnotetext{
${ }^{12}$ A phenomenon that may be relevant to thesis writing.
} 
have less control over the course of events, would shift the perceived locus of causality away from the individual (and human actors in general) to the environmental systems. This could explain the wide-spread resistance to this perspective and the tendency of discussions of global environmental problems to demotivate (Hopkins, 2008).

The second need, 'Competence' refers to the subject's belief in their abilities to perform tasks. Those with positive self-efficacy beliefs experience greater task satisfaction (Bandura, 2002). While the third need, 'Relatedness' refers to the desire to connect with others. Humans are social animals, happiest when they maintain social connections (Haller and Hadler, 2006).

Importantly, according to SD theory, activities are not necessarily performed for the purpose of satisfying innate needs but can satisfy needs spontaneously. A subject is motivated to perform activities they regard as important or interesting. Their prior experience of an activity in a particular social context influences what they regard as interesting. Sequentially for example, a musician may regard music practice as interesting; play music; experience spontaneous pleasure from satisfying a need for competence; and strengthen their subsequent interest and motivation for music practice. Those with low levels of need satisfaction may also seek out opportunities to directly satisfy needs. A lonely person may seek out opportunities to socialise for example (Deci and Ryan, 2000).

Deci and Ryan (2000) argue that the satisfaction or thwarting of the three needs plays a significant role in wellbeing and the psychosocial ills of modern society. From an evolutionary psychology perspective the three needs were 'fit' for the social context of ancestral hominids, that of life in small hunter-gatherer bands. Evolutionary psychologists call this context that the Environment of Evolutionary Adaptedness (EEA) (Charlton, 1996). When social contexts do not adequately satisfy needs this can have greater impacts other than a simple lack of satisfaction. Liedloff (1986) and Alexander (2008) attribute widespread pathological behaviours such as consumerism, drug addiction and dysfunctional relationships to the fundamental lack of innate satisfaction in industrial society. They argue that a mismatch has developed between human ontology fit for the EEA and the recent (on evolutionary timescales) development of complex societies. Despite myths to the contrary hunter-gatherers did not suffer from inadequate nutrition, and did provide for innate needs (Diamond, 1987; Sahlins, 2004). 
Modern life differs markedly from our evolutionary past. Hierarchical organisation, labour market logics, and long working hours impose a multitude of constraints on behaviour. Morris (1996), in his book The Human Zoo famously compared the pathological behaviour of humans in industrial society to that of caged animals. Prevalent conditions of psychological threat (i.e. feelings of insecurity), appear to influence subjects to focus on extrinsic goal-striving (Sheldon and Kasser, 2008), paradoxically undermining innate need satisfaction and psychosocial wellbeing. A 'viscous cycle' can emerge which subjects may find difficult to break.

Efforts to improve wellbeing must consider the influence of hierarchical capitalist power relations. The potential for formal employment to thwart innate needs has not been factored the orthodox opportunity cost arguments presented in 2.2.7. Falling unemployment may result in falling labour costs and more exploitative work environments. Conversely, if formal employment thwarts self-determination by controlling worker tasks, thwarts competence by providing sub-optimally challenging work, and thwarts relatedness by imposing long-work hours or an unfriendly work environment, then this may represent an unfavourable opportunity cost on one's wellbeing. We should consider the overall costs and benefits of foodgardening versus formal employment, including mental health. 


\title{
3.4.4 Psychological Empowerment Model Summary
}

\author{
Table 3-D \\ Potential Correspondence between Empowerment Models and Self \\ Determination Theory
}

\begin{tabular}{|c|c|c|}
\hline PGC1998 & TV1990 & $\begin{array}{c}\text { Self-Determination Theory. } \\
\text { Deci and Ryan, 2000 }\end{array}$ \\
\cline { 1 - 1 } $\begin{array}{c}\text { (Reflective Action) } \\
\text { Knowledge and skills for } \\
\text { critical thinking and action }\end{array}$ & Choice & Self-Determination \\
\hline Perceived self-efficacy & Competence & Competence \\
\hline Validation through collective & Meaningfulness & Relatedness \\
\hline experience & & \\
\hline (Reflective Action) & Impact & \\
\hline
\end{tabular}

TV1990's and PGC1998's models appear to complement each other and SD theory. Table 3-D shows an approximate correspondence between the various constructs. The terminology of TV1990's model is easily understandable and covers four distinct concepts. PGC1998's model draws on their experiences in group-based social work, but the terminology is somewhat clunky and indistinct. It seems plausible that common underlying empowerment processes could stem from human psychology. The following sections examine another psychological theory that accounts for variation in one's cognitive preferences.

\subsection{Cognitive Style}

An individual's cognitive style is potentially relevant to community development activities and empowerment theory (Cole, 2007). Cognitive style is "a person's typical or habitual mode of problem solving, thinking, perceiving and remembering." (Riding and Cheema, 1991). For example, two well established forms of cognitive style are Wholistic-Analytic and Visual-Verbal. According to these theories an 
individual can express a preference for assimilating information either as big-picture wholes or detailed parts (Wholistic-Analytic); and can prefer to think in pictures or words (Visual-Verbal) (ibid.). These cognitive styles may be relevant to PGIS but have no apparent connection to empowerment theory and are not investigated for reasons of scope. The following section describes a cognitive style that may have a direct connection to SD theory.

\subsubsection{Empathiser-Systemiser Theory of Cognitive Style}

Baron-Cohen and collaborators (Baron-Cohen and Belmonte, 2005; Baron-Cohen et al., 2005; Baron-Cohen et al., 2003; Lawson et al., 2004; Wakabayashi et al., 2007) have developed the Empathiser-Systemiser (E-S) theory of cognitive style to explain patterns of behaviour associated with Autistic Spectrum Conditions ${ }^{13}$. Autistics often have a deficit of empathy but heightened mathematical or spatial abilities. Theorists have proposed that ASC is an extreme version of cognitive sex difference that applies to the general population, the Extreme Male Brain theory of autism (BaronCohen, 2002). Cognitive sex differences have historically focused on spatial and linguistic skills. Baron-Cohen (ibid.) argues that sex differences can be grouped into two dimensions, 'empathising' (typically female) and 'systemising' (typically male). Systemising is the drive to construct and predict the behaviour of systems. Systems can be natural (ecology), abstract (mathematics), or spatial (geographic space) amongst others. Systemising involves analysis of input-output relations to derive rules in order to predict behaviour. Empathising is the drive to understand the mental states of others and respond appropriately. Empathising and systemising can also be viewed as attempts to understand different types of causality. Those with a preference for empathising (empathisers) are driven to understand agent-based causality (other people's thoughts, feelings, motivations etc.) and respond appropriately, while those with a preference for systemising (systemisers) are driven to understand non-agent deterministic causality and make predictions (Baron-Cohen and Belmonte, 2005; Baron-Cohen et al., 2005; Wakabayashi et al., 2007).

\footnotetext{
${ }^{13}$ Asperger's syndrome and autism exist on a spectrum. Autism is largely differentiated by delayed language development.
} 
Unlike other theories of cognitive style, the two impulses are largely independent and individuals can be equally driven to empathise and systemise (balanced); be driven to empathise more than to systemise; or vice-versa. E-S cognitive style is measured through two separate questionnaires, one for empathising quotient (EQ) and one for systemising quotient (SQ). The results are normalised to population averages. The difference between a normalised EQ and SQ determines the cognitive style category. Therefore all combinations of high/low EQ and SQ are possible.

It is possible that systemising correlates with analysing in the W-A cognitive style. However, E-S theory has not been tested for correlation with other styles. BaronCohen and Belmonte (2005) argue that the theories are distinct but can be developmentally unified. Accordingly, systemisers will initially focus on detailorientated analysing. As cognitive abilities mature the systemiser will come to appreciate how complex systems function by testing the component parts of the complex system separately.

\subsection{Application of Motivation and Cognitive Style to Communities of Practice and PGIS}

The two empowerment constructs, 'relatedness' and 'competence' appear to have a connection to E-S theory. Relatedness appears to be the underlying need that motivates empathising. Competence appears to be the need that motivates systemising. CofP's are competence-based and also have collaborative empathising aspects (Wenger et al., 2002). Participants also undertake a variety of activities in PGIS projects. Projects can involve both activities with a high degree of 'empathising' such as consensus decision-making or skill sharing, and 'systemising' such as geographic analysis (Corbett, 2009). The reviewed theories suggest that participants will focus on different aspects of an empowerment project, which in turn satisfy different innate needs, and influence the participants' intrinsic motivation. This process could lead to differing outcomes for participants and influence project success.

For example, maps include conventions that transform 3-D space into 2-D representations, such as scale, orientation and altitude. Map users apply rules to 
transform spatial representations into memory codes of geographic space (BaronCohen, 2002; LLoyd, 2006). According to E-S theory, (spatially aware) systemisers will actively seek out opportunities to construct and manipulate spatial systems. According to SD theory the optimally challenging manipulation of spatial systems will satisfy an innate need for competence. Competence satisfaction contributes to well-being and reinforces the intrinsic motivation to use maps.

Empathisers are motivated to understand other's emotions and thoughts and respond appropriately. According to E-S theory, empathisers will actively seek out opportunities to understand and share others' intentions and experiences. According to SD theory, this practice satisfies the need for relatedness, and influences intrinsic motivation for pro-social behaviour and group formation (Decety and Meyer, 2008; Parsons et al., 1998).

A community development project can involve systemising elements such as mapping or knowledge generation and empathising elements such as collaboration and group formation. Such projects should contain opportunities for empathisers, systemisers and balanced individuals to engage in activities they find intrinsically motivating. A project can engage a participant with intrinsically motivating activities and also extend a participant's skills by exposing them to activities they would not normally pursue. Different projects will contain different degrees of these activities. The balance of participant cognitive styles and the balance of activities contained within a project may affect the project's ultimate success and the motivation of participants to maintain the CofP or PGIS.

The PGIS literature has not addressed the psychological empowerment aspects of PGIS. While the various concepts of motivation, psychological and social empowerment are linked in the literature, the particular relationships between these concepts are not clear. This study explores how E-S cognitive style can influence motivation, and attempts to apply SD theory to empowerment practice to a community gardening case study. 
"To put the world in order, we must first put the nation in order; to put the nation in order, we must put the family in order; to put the family in order, we must cultivate our personal life; and to cultivate our personal life, we must first set our heart"

$\sim$ Confucius

This chapter describes the epistemologies that have informed the research and gives a background information on the community garden group. The method section describes how the research process progressed, and how insights arose. The final section details the collection of data and methods of analysis.

\subsection{Methodological Approach}

\subsubsection{The Problems of Rationalist Research}

Section 2.1 describes the assumptions of rationalism. The rationalist approach to research assumes a consistent relationship between cause and effect exists; a structured methodology can discover this relationship; and that the decision-maker can use this knowledge to predict the outcomes of a course of action. Thomas (1998) has challenged the rationalist approach when applied to complex phenomena such as those involving human actors. Thomas (ibid.) argues that rationalist research has epistemological, pragmatic, and political problems. Using E-S terminology we could say that at times rationalist researchers inappropriately systemise, attempting to derive lawful rules when the phenomenon in question is not lawful system (Lawson et al., 2004; Lawson, 1995). Epistemological problems arise when an identifiable relationship between cause and effect does not exist or is only identifiable in hindsight (Hjorth and Bagheri, 2006; Kurtz and Snowden, 2003; Snowden, 2005). Pragmatic problems arise when rationalist research methodologies produce theoretical knowledge that does not usefully inform practice, but gives an illusion of 
certainty and control (Reason, 2006; Whitehead, 1967). Political problems arise when rationalist research maintains ties to elite institutions and implicitly favours the interests of those institutions over those of the disadvantaged (Levin and Greenwood, 2008). The assumptions of rationalism lead to a planning perspective of human affairs and commissioned research that devalue local context, practical knowledge, and insights generated during practice (Hayek, 1945; Scharmer, 2009; Scott, 1998). Scharmer (2009) proposes an alternative prototyping perspective congruent with action research.

\subsubsection{Action Research}

Researchers credit psychologist Kurt Lewin (1946) with coining 'action research' and developing early action research theory (Masters, 1995). Multiple cycles of reflection and action form the basis of action research methodologies. Figure 4-A depicts the classic action learning cycle as described by Kolb (1973). In addition to multiple action learning cycles, action research involves a planned action to solve a problem (McMahon, 1999).

Figure 4 A

The Learning Cycle (Kolb, 1973, 2)

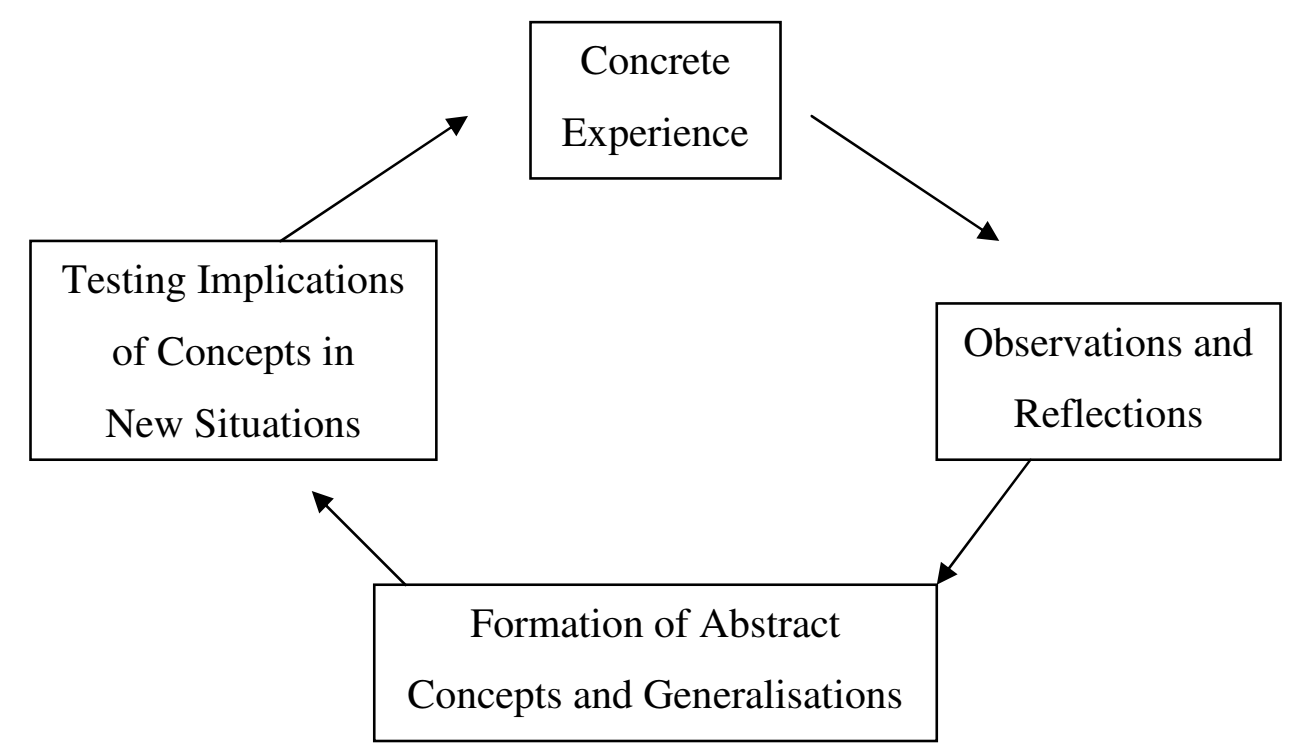


Action research mitigates the three problems described in section 4.1.1. Firstly, action research uses insights generated during practice to inform methodology for subsequent cycles. In doing so, action researchers strengthen methodological relevance but limit knowledge claims. Depending on context, weak knowledge claims do not limit practical usefulness (Foreman-Peck and Murray, 2008). When the trade-off is with 'misplaced concreteness', the reification of abstract ideas, weak knowledge claims may be preferable to strong ones. Secondly, action research binds theory to practice. The focus remains on what to do rather than what is true, ensuring usefulness. Finally, democratic principles of participation and emancipation guide action research aligning the researcher with the disadvantaged (Reason, 2006).

\subsubsection{Participation}

Participatory research differs from conventional methods primarily in the alignment of power in the research process. Cornwall and Jewkes (1995), citing Biggs (1989), describe a continuum from shallow to deep participation, in order: contractual, consultative, collaborative, and collegiate. Theoretically much of what is described as participatory research is situated at the deepest level of participation, collegiate, where participants maintain control over the entire process including co-authorship. However, in practice research rarely reaches this level and participation may slide between different levels at different stages (Cornwall and Jewkes, 1995).

There are number of difficulties with deep participation in PGIS research. High-tech PGIS approaches limit participation by imposing skill and resource costs (Kyem and Saku, 2009; Sieber and Wellen, 2007). Further, PGIS researchers will necessarily have greater control over a PGIS project simply through a cultivated interest and familiarity with PGIS processes and technologies. Researchers may also make an $a$ priori assumption that PGIS (of any technology level) is appropriate to a group's problem area when collegiately participative research would consider PGIS as one of several options. Projects that aim for deep participation must ensure that genuine needs and capacities of the participants drive the project rather than those of the researcher. These issues do not mean that shallowly participative research is invalid 
or that an a priori assumption of the value of PGIS cannot be justified; only that the level of participation should be acknowledged.

This research is largely situated at a collaborative level of participation. The research is influenced by both local priorities and personal, theoretical concerns. The problem identification, data collection and analysis are designed and conducted by the researcher, with opportunities for participant feedback. Running parallel to the research project the researcher acquired and developed scale-maps of KTA's garden sites to support KTA's geographic knowledge management.

\subsection{Area of Concern: Kai o Te Aro}

Aro Valley lies directly to the southwest of Wellington's city centre. Aro St runs east to west along the bottom of the valley between sunny north-facing and often shaded south-facing slopes (Map 1.). Aro Valley is a residential suburb with a small number of businesses concentrated near the Devon street intersection.

Aro Valley residents Charles Barrie and Vorry Mahal began Kai o Te Aro ('the food of Aro') (KTA) in March 2009. A landscape gardener and environmental educator, Barrie had previously organised a tour and series of lectures with a community gardens focus in March 2008. With an email list of interested participants, Barrie started KTA as a working bee network with monthly meetings and working bees for gardeners to exchange ideas and pool labour for large backyard gardening projects. Mahal worked as the Aro Valley community coordinator at Aro Valley Community Centre (AVCC) in Aro St and is well connected in the valley. She had noticed an unused patch of land with access off Aro St and following discussions with the landowner secured an agreement for conversion to a community garden (later named the 'secret garden'). In May KTA received a grant from tool company Fiskars ${ }^{\mathrm{TM}}$ for $\$ 1,200$ worth of tools and $\$ 1,000$ worth of plants. During 2009 negotiations with Victoria University of Wellington (a significant local landowner), and AVCC continued and KTA gained permission to garden on three additional sites. The researcher has been a member of KTA since its inception and developed the research project in parallel. 
KTA is a CofP for gardeners to share experiences, create edible landscapes in Aro Valley and improve food-gardening technique. As a new CofP, the membership and participation is growing and fluctuates with currently around a dozen core members attending most meetings and working bees with perhaps another dozen attending semi-regularly and approximately fifty persons in total on the email list. 

Map 4-B. Kai o Te Aro Garden Sites in Aro Valley

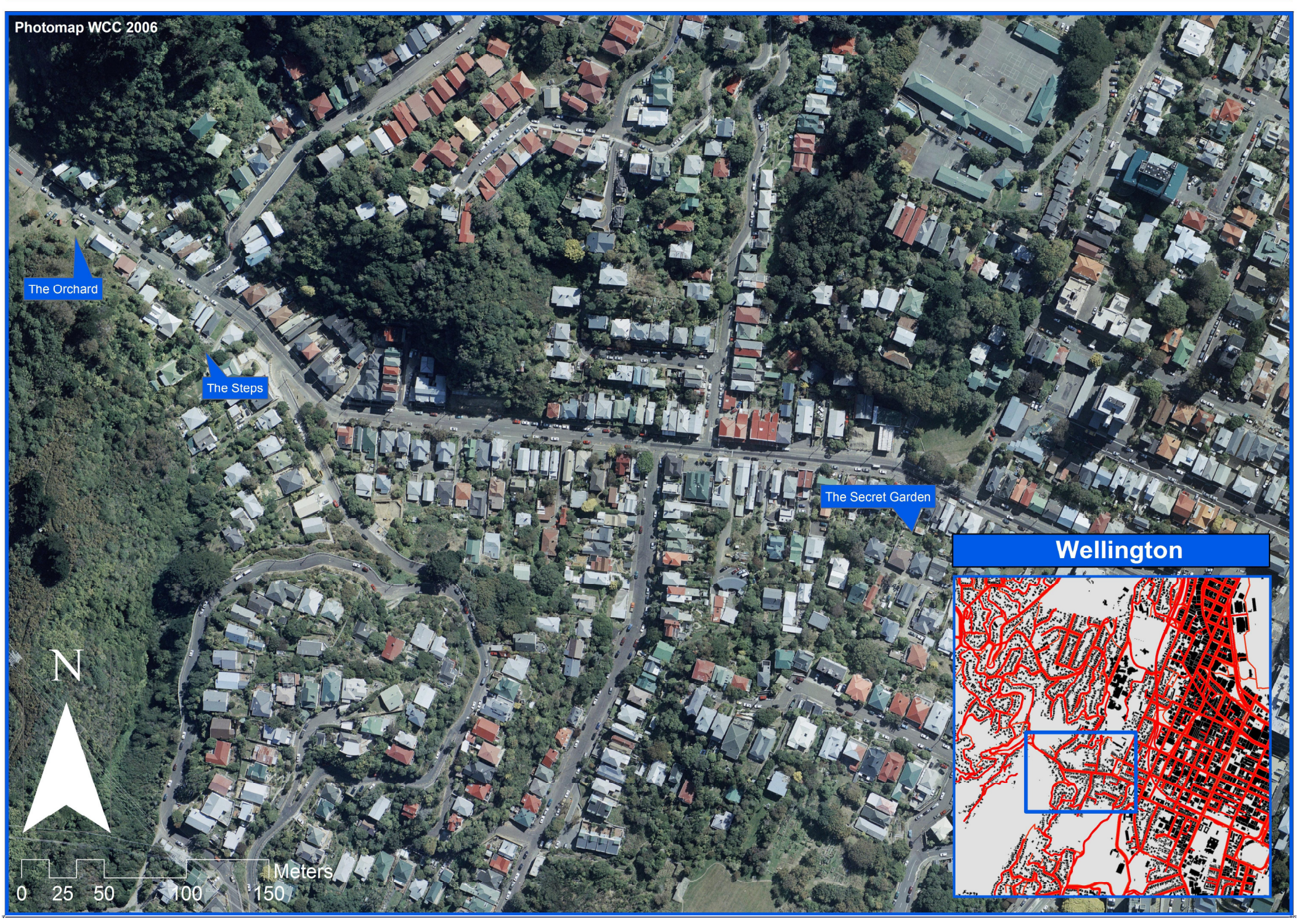




\subsection{Method}

\subsubsection{Method Overview}

Originally, the research project was conceived as an investigation of the psychological empowerment aspects of PGIS and was to approximate the structure of a PGIS project such as described in Craig and Elwood (1998) and Corbett (2009). However, initial mapping interventions and observations indicated that mapping activities were potentially less relevant to some participant's empowerment than KTA itself. The research foci shifted to cognitive variation as an explanation for differing empowerment outcomes and the interplay between intrinsic and extrinsic motivations in KTA. Mapping activities were scaled back to supplement KTA's geographic knowledge management, rather than an extensive community mapping project.

KTA meets monthly at a member's residence on rotating schedule to share food, discuss plans for the monthly working bee and other garden-related business. As a KTA member, the researcher regularly participates in KTA meetings and working bees. During the first half of 2010, three of meetings were audio recorded. Scale maps of the garden sites were introduced into these meetings, along with photomaps of the Aro Valley provided by WCC. Following these meetings, six participants agreed to more in-depth semi-structured interviews and completed E-S questionnaires. Maps were also constructed in collaboration/consultation with a member outside of these meetings. Audio recorded semi-structured interviews followed. At the end of the semi-structured interview participants completed the E-S questionnaire. A research diary was kept to record insights as they arose.

\subsubsection{Action Learning Cycles}

Reason $(2006,190)$ argues that quality in action-research rests “...internally on our ability to see the choices we are making and understand their consequences; and externally on whether we articulate our standpoint and the choices we have made 
transparently to a wider public." In the interest of transparency it is necessary to expose choices made during the research process, and how those choices affected research outcomes. Two learning cycles occurred prior to the analysis of the results. The first cycle lead to insights regarding CofP's and how E-S cognitive style variation could potentially explain differing outcomes for PGIS projects. The second cycle led to the insight that SD theory could illuminate the psychological empowerment process. The two cycles are described below.

\subsubsection{First Learning Cycle: Communities of Practice and Empathiser- Systemiser Theory}

At the project outset, the concept of GIS was introduced to participants with a laptop loaded with ArcView software and projector during a KTA monthly meeting in September 2009. A photomap layer of Aro Valley and surrounds was explored with the researcher driving the software. The layering capabilities of GIS were demonstrated with an insolation layer potentially relevant to garden site selection. The possibilities, purpose, relevance and limitations of GIS were discussed along with the boundaries of the study area. Participant interaction with the GIS was minimal and mediated by the researcher.

In subsequent interactions, KTA members often spoke of the community aspects of KTA as a source of value. Regarding mapping, one participant already used sketchmapping and expressed a desire for more extensive mapping, other participants did not contradict this but may have been less keen or less sure of any value. Cole et al. (2006) note that many participants do not discover the value of participatory modelling processes until the project is almost complete. A similar insight may apply here. Pushing ahead with an extensive mapping project despite a lack of surety may have been fruitful, or it may have proved overly burdensome to KTA members and a distraction from the core foci on food-gardening and community building. It seemed inappropriate to pursue a full-scale PGIS project as described above, when this risked distracting or overburdening participants with activities that they did not find especially empowering. 
These observations and the subsequent literature search revealed two insights. First, that KTA was a CofP. The looser structure of a CofP appears distinct from the typical community groups involved in PGIS projects. CofP formation often involves a shift in the subject's social identity (Lave and Wenger, 1991). Potentially, group identity formation could explain large degrees of empowerment. Second, a literature search revealed that participant's E-S cognitive style could potentially explain the observed variation in sources of empowerment value. In addition, the researcher's E$\mathrm{S}$ quotient was tested and was found to be an extreme systemiser. An irony arises in that according to this test, the researcher is primarily motivated to understand deterministic systems but has taken on non-deterministic qualitative research albeit with a categorical, prediction-based aspect typical of systemising. According to Billington et al.'s (2007) study, physical science students are more likely than humanities students to be systemiser's or extreme systemisers. Based on these results, it is likely that the majority of GIS researchers and professionals are systemisers. Although it is less clear if this applies to PGIS practitioners. A disjunction in cognitive style between researchers and participants could result in communication and participation difficulties in participatory research (Cole, 2007).

These insights led to the inclusion of all KTA-related activities as sources of empowerment; and the inclusion of the E-S cognitive style questionnaire. Mapping activities were scaled back to supplement regular KTA meetings rather than occur in explicit PGIS workshops. This approach is in line with Wenger, McDermott, and Snyder's (2002) recommendations for introducing new elements into a CofP. Mapping is a common form of systemising and relevant to the spatial problemsolving needs of KTA. However, according to E-S theory, empathisers are less likely to show interest in such activities (Baron-Cohen et al., 2005).

By late 2009 KTA had become responsible for developing three new sites and maintaining the secret garden. A regular feature of discussion was the design of new sites. Previously the design of new gardens was developed on site at the working bees and/or with small sketch maps at the meetings (Figure 4-C). In addition to regular business sketch-mapping was complemented by constructing 1:25 to-scale maps of each site using a removable transparent plastic layer upon which nonpermanent or potential features can be sketched with white-board markers. 
Figure 4-C

Example of Sketch Mapping

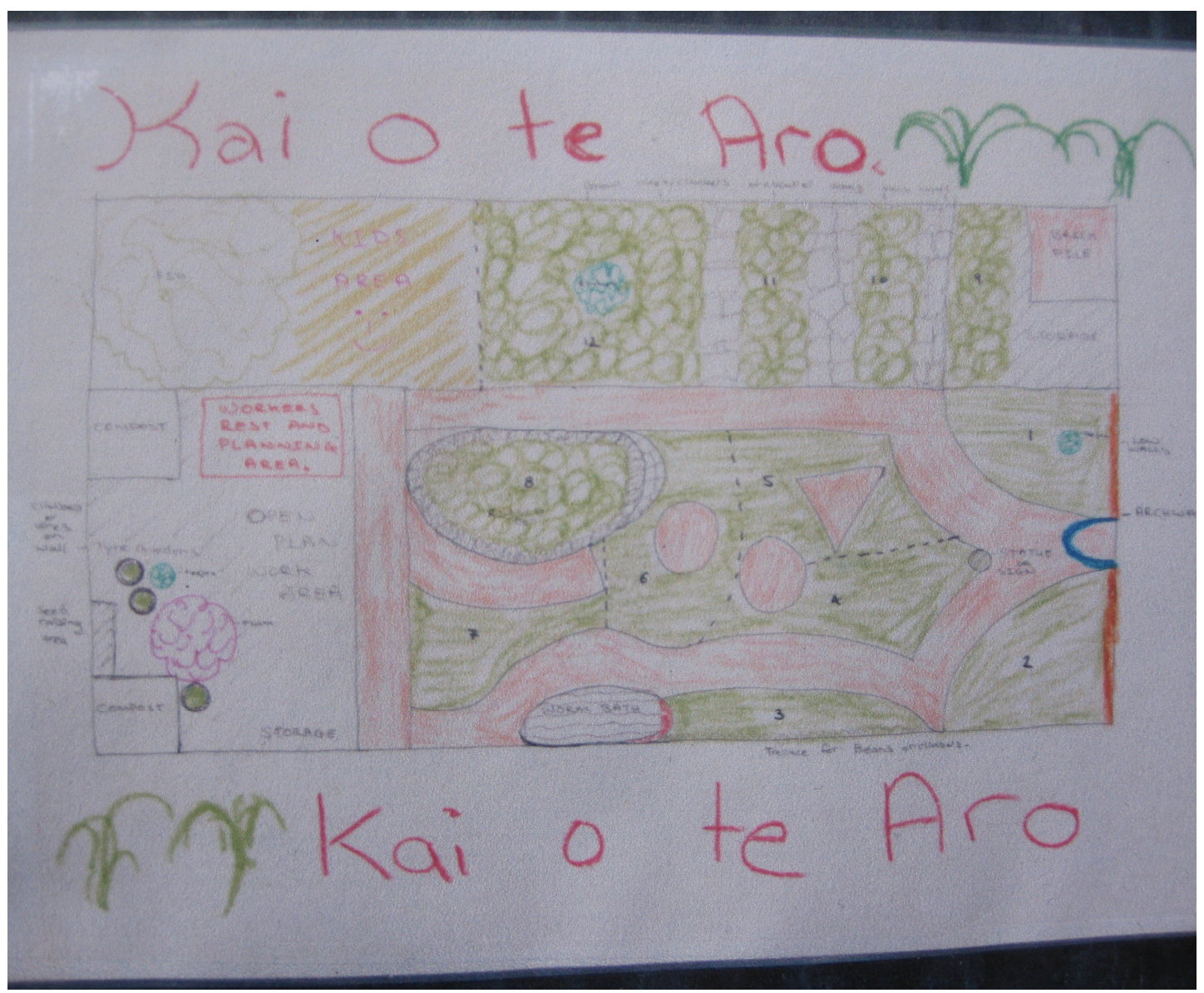

Photomaps of Aro Valley at various scales with street-names, property boundaries and house numbers marked were acquired from WCC. These unmodified maps were used at the KTA stall at the Aro Valley fair for general interest. The maps were introduced as the basis for a modified KTA-generated map and to explain the location of the site to new members. Three monthly meetings were recorded and six participants were interviewed regarding their motivations for involvement in KTA activities. 


\subsubsection{Second Learning Cycle: Self-Determination Theory}

Another insight emerged during the semi-structured interviews and concerned value or ideology internalisation as a source of motivation, and the relevance of SD theory to motivation and empowerment. The researcher has taken an active interest in peak oil and climate change. In the researcher's experience, discussions of these topics tend to be disempowering, but on reflection, have led the researcher to pursue the current study. Three participants also spoke of peak oil and climate change as sources of motivation for their involvement in KTA. These participants believe that peak oil and climate change will disrupt industrial society in ways that make local level community involvement invaluable. Members spoke of a vision of Aro valley where free food was widely available as a source of motivation. However, according to SD theory, beliefs about the future course of events do not motivate people intrinsically, although the actions they take may have intrinsically motivating aspects. A vision may be positive, and activities inspired by it enjoyable, but the vision, as a source of motivation, does not concern the intrinsic qualities of the activity itself. Conversely, one may believe that climate change will almost wipe out humanity (e.g. Lovelock, 2006) and grimly go about one's preparations, but this can hardly be described as intrinsic motivation. TV1990's conception of empowerment as intrinsic task motivation (section 3.4.1), did not fully describe the construction of motivation as it had begun to appear in the results. Further, while links between the study of motivation and empowerment are made in the literature (Lee and Koh, 2001), this is not generally well-developed. Much of the literature displays a general lack of clarity surrounding the various forms of empowerment and the connections between them. These observations and a subsequent literature search revealed the explanatory power of SD theory as discussed in section 3.4.3.

In SD theory terminology, we can regard participant beliefs about a disruptive future as an internalised ideology that regulates appropriate behaviour (e.g. community involvement). Deci and Ryan (2000) label this kind of motivation 'well internalised extrinsic motivation', as distinct from intrinsic motivation. In internalised extrinsic motivation the subject regards the behaviours as 'important' but may or may not find behaviours intrinsically valuable (see Table 3-C, 'Identified Regulation' and 'Integrated Regulation'). At this stage of the research there was not enough time to 
explicitly incorporate SD theory into the methodology. For example, such a methodology may attempt to identify the degree of subject's innate need, in addition to subject's task motivation as this study attempts to do. Despite these shortcomings SD theory informs the analysis of the results and the main theoretical component of Research Question Two.

\subsubsection{Research Questions}

\section{Theoretical Question.}

1. Can E-S theory explain any differences in the intrinsic motivation of KTA members?

\section{Complementary Questions.}

1(a) What activities related to community gardening activities do research participants find motivating?

1(b) What cognitive styles do participants have?

1(c) Do participants find mapping activities intrinsically motivating?

\section{Practical Question}

2. What relevance does ideology and intrinsic motivation have to (a), the participation and motivation of research participants for KTA activities; (b), empowerment theory and practice; and (c), broader theories of social change? 


\subsection{Data Collection and Analysis}

Transcribed audio data from the meetings and semi-structured interviews were coded and analysed with different methods. Meeting data was coded by speech act type and semi-structured interview data were coded by theme. This allowed a comparison of unconscious behaviour and conscious recollections and the triangulation of results (Jick, 1979).

The six interviewed participants varied in the meetings they attended. 'Sam' ${ }^{14}$ and 'Jane' attended all three recorded meetings. 'Warren', 'Penny', and 'Lily' attended the second and third meetings. 'Frank' did not attend any of the meetings. Four other members and the researcher attended the first meeting (total of 7). Seven others and the researcher attended the second recorded meeting (total of 13). Six others and the researcher attended the third meeting (total of 12).

\subsubsection{Kai o Te Aro Meetings}

Audio data from meetings of the six interviewed participants were transcribed and coded by the type of speech act, contrasting relatedness-satisfying and competencesatisfying speech acts. Holmes and Marra (2004) describe 'relational practice' as speech aimed at building relationships, and taking care of interlocutor's emotional needs for intrinsic and instrumental value in an organisational context. Relational practice includes positive humour, approval, sympathy and empathetic questioning etc. Relational practice was used as the basis for coding relatedness-satisfying speech acts. Speech acts where the participant contributed their own insights, clarified points or asked for clarification, or asked technical questions were coded as competencesatisfying speech. If others respond with positive feedback, displaying one's problem-solving abilities through contributing insights could indirectly satisfy competence (Deci and Ryan, 2000). It is argued that seeking to increase one's understanding of the issue through asking technical questions or asking for clarification would contribute to one's perceived efficacy and satisfy competence.

\footnotetext{
${ }^{14}$ Pseudonyms have been used to maintain the anonymity of research participants.
} 
Each of the six participants who completed E-S questionnaires relative prevalence of relatedness- and competence-satisfying speech was compared and a ratio between the two computed.

KTA meetings are not solely for the discussion of garden business but also potlucks hosted at the residence of a KTA member where members bring food to share and make conversation. Meetings tended to follow a format where the host would welcome members and make cups of tea as people arrived. Once most people had arrived members would share a meal, followed by more formal garden business with an agenda. Due to the loose structure of KTA, new members often arrived impromptu. Audio recordings of meetings were only begun once informed consent was obtained. This meant that the recordings missed the initial stages which can be expected to include more relatedness-satisfying activity i.e. the sharing of jokes, emotions, experiences, sympathy, etc. Recordings were largely of garden business focused discussions, which can be expected to include more competence-satisfying activity. This raises two methodological issues. First, it is possible that a participant with a more passive, shy personality will not play an active role, but still find the activity innately satisfying. Audio recordings will not capture these data. Second, with a skew to competence-satisfying context, there will be more examples of active competence-satisfying than active relatedness-satisfying activity in the dataset. The meeting audio data was interpreted with these caveats in mind.

\subsubsection{Semi-structured Interviews}

Semi-structured interviews were conducted with the six participants following the three recorded meetings. Semi-structured interviews collected participant reflections on their motivations and other insights concerning KTA activities. Semi-structured interviews will also collect internal reflections and data from less vocal participants that recorded meetings neglects. Five of the interviewed participants were members of the KTA core group. One participant, Frank, rarely attended and therefore did not take part in most mapping activities. Frank was interviewed to provide a counterpoint to core members. Interview questions concerning participants' motivations were open-ended were directed towards intrinsic motivation but allowed participants to lead the interview as they saw fit (see Appendix A) 
Thematic analysis of semi-structured interview data followed the guide outlined in Braun and Clarke (2006, Table 2, 96). Data were transcribed and coded by theme. Competence- and relatedness-satisfaction are the two themes most relevant to the research questions. Self-determination and other themes related to TV1990's constructs, 'Impact', and 'Meaningfulness' were also present.

The open-ended nature of semi-structured interview questions allowed participants to give ideological, as well as need-satisfying, reasons to describe their motivations. Some participants spoke of the prospect of peak oil and climate change as motivating factors for community involvement. The researcher has interpreted this as wellinternalised extrinsic motivation. In other words, the participant believes that the future will play out in a similar manner as described in Chapter Two, and this ideology has become a part of the subject's identity and psychological frameworks.

Coding was simple when a participant states directly that she enjoys a particular activity, but in other instances the coding relies on greater interpretation and some statements could have conceivably been placed under another theme. 'Community' emerged as a common theme in the semi-structured interviews. It was often unclear if a participant has highlighted 'community' because they believe the idea of community to be important, i.e. they have internalised an ideology that values 'community' or they genuinely constructed community participation, i.e. relatednesssatisfying activity as intrinsically motivating, or some combination of the two. In another example, when a participant reported valuing the consensus decision-making process, this has been interpreted as a conscious awareness of self-determination satisfaction, rather than an extrinsic evaluation of group process (i.e. importance). A large degree of interpretation was involved in coding these results.

\subsubsection{Questionnaire}

At the end of the semi-structured interview participants completed a 115 question questionnaire to assess their E-S cognitive style (Appendix B). The questionnaire has been developed by the Autism Research Centre at Cambridge University by BaronCohen and colleagues to measure the difference between a subject's drive to empathise and systemise (Baron-Cohen, 2002; Baron-Cohen et al., 2003). 
Respondents are asked if they agree or disagree with statements related to systemising or empathising on a 4 point Likert scale.

The questionnaire has typically been used in large sample surveys where the researcher does not know the respondents personally. The questionnaire includes questions where there is a social norm to respond in a certain way. For example, respondents are asked to agree or disagree with the statement "When I was a child, I enjoyed cutting up worms to see what would happen." To avoid biasing responses and causing discomfort for participants each questionnaire was assigned a number and sealed in an envelope at the interview by the participant. A third party scored the questionnaire without knowing the name or other details of the participant and noted the score along with the questionnaire's number. Scores were later matched with participant names by the researcher without learning the responses to particular questions. E-S questionnaire scores were converted into E-S quotients according to formulae and standards found in Wheelwright et al. (2006). Participants were categorised as one of the following options: extreme empathiser, empathiser, balanced, systemiser, and extreme systemiser.

\subsubsection{Overall Analysis}

The prevalence of relatedness- and competence-satisfying speech acts from recorded meetings, and the motivational themes from semi-structured interviews should reveal which activities participants find motivating -Research Question 1(a), "What activities related to community gardening activities do research participants find motivating?" Participants are asked to report on any intrinsic value of mapping activities -Research Question 1(c), "Do participants find mapping activities intrinsically motivating?" Participant E-S quotients are computed -Research Question 1(b), "What cognitive styles do participants have?" and compared to any motivational preferences to determine if E-S theory has explanatory power, and if an intrinsic motivation is connected to E-S cognitive style -Research Question 1, "Can E-S theory explain any differences in the intrinsic motivation of KTA members? Finally, researcher observations, and participant reflections on their motivations may lead to insights into empowerment theory and the role of participant's ideologies in their involvement with KTA -Research Question 2, "What relevance does ideology 
have to (a), the participation and motivation of research participants for KTA activities; (b), empowerment theory and practice; and (c), broader theories of social change?" 
"There's the literature, and then there's doing it."

'Sam', research participant

This chapter divides into two parts. In the first part the results of the investigations are presented and discussed in reference to the case study context. In the second part the results are discussed in reference to the research questions.

\subsection{Results and Discussion: Kai o Te Aro}

\subsubsection{Empathiser-Systemiser Cognitive Style Questionnaires}

Six participants, three female and three male, were interviewed and completed E-S cognitive style questionnaires. The results classified the three male participants as systemisers (Sam, Warren, and Frank), two of the female participants were classified as balanced (Jane and Lily), and one female as an empathiser (Penny). These results are not unusual in regards to the typical distribution of cognitive styles in the general population (Wheelwright et al., 2006).

\subsubsection{Audio Recordings of Kai o Te Aro Meetings}

Recorded meeting data were of the garden-business aspects of meetings (rather than the potluck), and in general competence-satisfying speech exceeds relatednesssatisfying as expected (Figure 5-A). Most of the relatedness-speech was positive feedback, "good idea", "yeah" (positive tone), "awesome" etc., but also includes jokes and expressions of sympathy. Most of the competence-satisfying speech acts are the posing of potential solutions to problems (including spatial problems). For example, in the first recorded meeting, Sam discusses the design of the garden beds that were to be made from macrocarpa sleepers: 
“"'and we cut each them into, each one into, two metres and one metre. It means that we can make them into rectangles...[drawing]...and then if we notch them out, and we can slide them together like that." (2010, pers. comm., $7^{\text {th }}$ April)

Sam's facilitation role ${ }^{15}$, and attendance at all three meetings, partially explains the greater overall number of speech acts. Sam and Warren, two systemisers, engaged in competence-satisfying speech acts more than twice as frequently as relatednesssatisfying speech. Jane tested as balanced and demonstrates a similarly high competence to relational practice but was not as vocal as the other members and a much smaller sample size was recorded. Lily also tested as balanced and her speech acts were more evenly balanced. Penny the only empathiser of the tested participants, made half again as many competence-satisfying acts as relatedness acts and was relatively more vocal than the others (excepting Sam, the facilitator).

\footnotetext{
${ }^{15}$ Meeting facilitation now rotates amongst members.
} 
Figure 5-A

Frequency of Competence- and Relatedness-Satisfying Speech Acts in Kai o Te Aro Meetings (March - May, 2010)

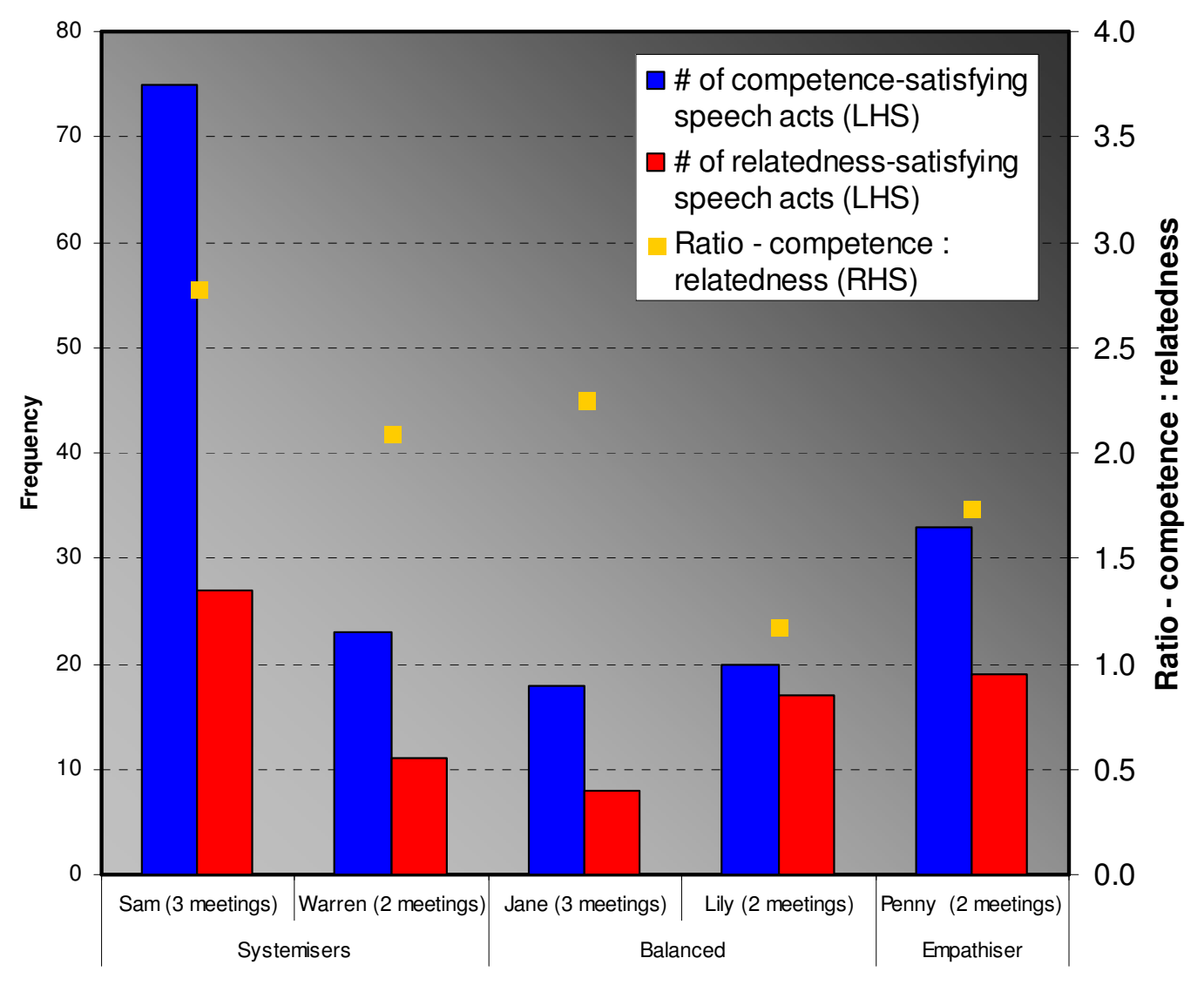

\subsubsection{Discussion of Meeting Data}

No firm conclusions can be drawn from such a small dataset in regards to the influence of cognitive style on group conversational style. However, the results demonstrate a marked distinction in different group interaction styles with some participants playing a much more active role than others. It is possible that such distinctions could cause tension. Systemisers could become bored with an overemphasis on relational practice or vice versa for empathisers. There was no evidence that this was a problem in KTA.

The most obvious result is the systemisers' generally higher ratio of competencesatisfying acts to relatedness-satisfying acts. This may reflect a greater need for competence and would be consistent with E-S cognitive style as reflective of variation in innate needs. On the other hand, Penny, the empathiser, demonstrates an 
elevated competence to relatedness ratio relative to one of the balanced participants, but not as high as the systemisers, suggesting a more complex picture. In the semistructured interview, Penny spoke of her enjoyment of group interactions and collaborative decision-making (2010 pers. comm., $7^{\text {th }}$ June). It appears that Penny has constructed group interactions as intrinsically motivating, and that this drives her more active engagement. Engaging in group process could also be simultaneously competence-, and relatedness satisfying. Considering that recordings are of discussions focused on problem-solving, Penny's disposition towards more active engagement would mean more technical questions and solution-posing in that context, rather than relational practice.

\subsubsection{Semi-Structured Interviews}

All participants demonstrated variation in their source of motivation in the data drawn from semi-structured interviews. Motivations were organised into five themes. Three themes were intrinsic motivations corresponding to innate needs 'competence', 'self-determination' and 'relatedness' and two were extrinsic themes 'impact' (i.e. making a measurable difference) and 'importance' (i.e. affirming of a value system or ideology). Figure 5-B shows the amount of times these themes occurred in the interview data. Core members of KTA (the five participants excluding Frank) all reported greater degrees of intrinsic relative to extrinsic motivation, although the ratio varied widely. Frank reported a greater degree of extrinsic motivation. To Frank, community gardens are "the way of the future" but as he does not live in Aro Valley he did not feel especially motivated to also attend potlucks (2010 pers. comm., 20 $0^{\text {th }}$ June). Much of Frank's reported motivation comes from regarding community gardens as important to future wellbeing rather than having integrated KTA into his identity. 
Figure 5-B

Raw Incidences of Reported Motivation Constructs in the Semi-structured Interview Data: Intrinsic vs. Extrinsic

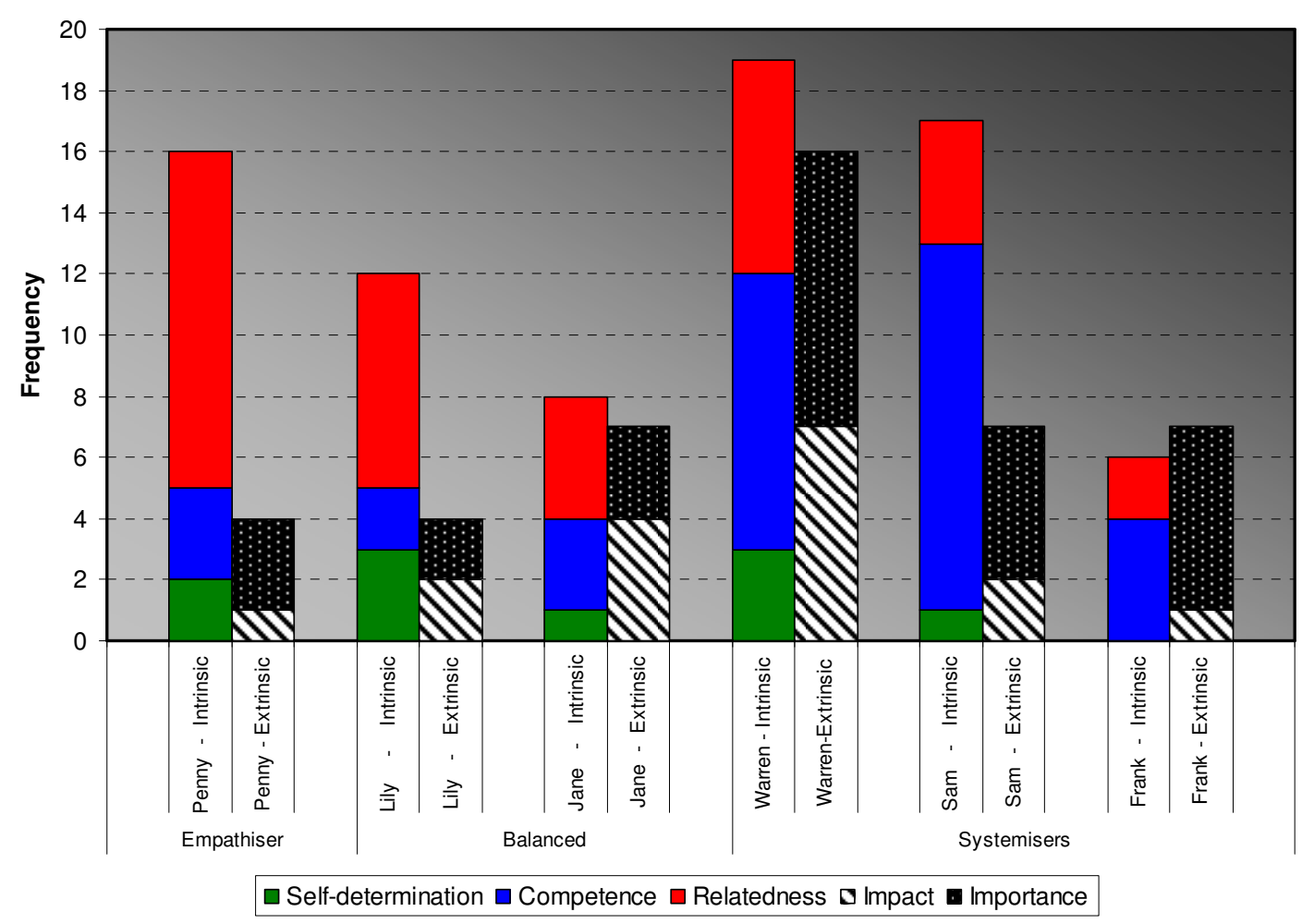

The results show a tendency for those who tested as systemisers to report higher relative degrees of the enjoyment of competence-satisfying activity as a source of motivation. Penny, the empathiser, reported the highest degree of enjoyment of relatedness-satisfying activity as a source of motivation (Figure 5-C). 
Figure 5-A

Distribution of Participant Motivation Constructs in Semi-structured Interviews

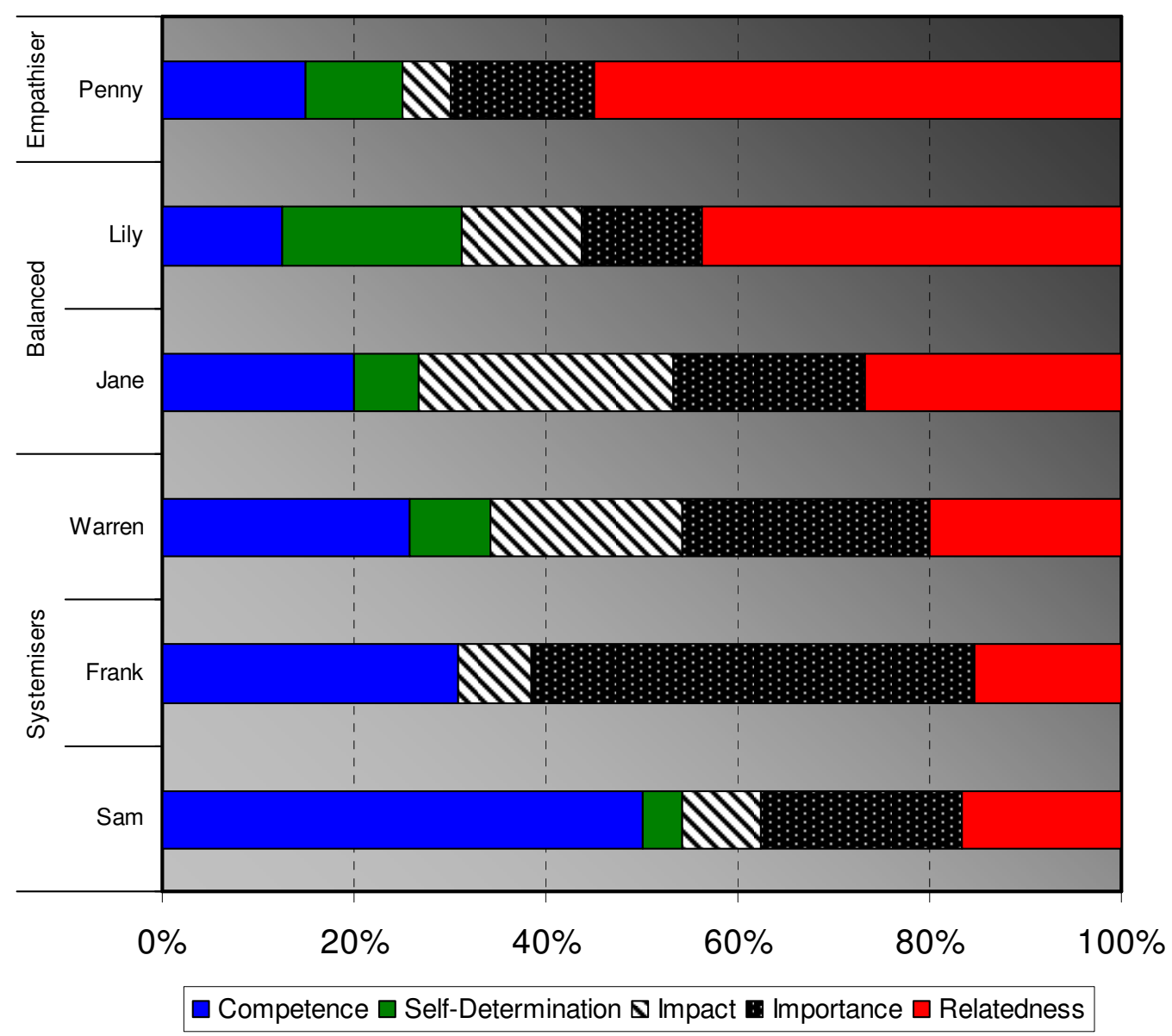

Salient excerpts from the semi-structured interviews are given below to illustrate participants' responses and how responses were coded \{in curly brackets $\}$.

Penny (empathiser):

"I enjoy group dynamics. I enjoy how groups work, how they form, and who does what in them. I am quite an assertive person that is quite happy join a new group." \{Relatedness $\}$

"Over the past year my interest in gardening has really blossomed. Now I would say that it's one of the things I really enjoy, a special hobby..." \{Competence\} (2010 pers. comm., $7^{\text {th }}$ June) 
Lily (balanced):

"It's really balanced in the way we operate. People don't feel afraid to say; actually I think it should be done this way. Or to say 'what does everyone think about this?' I think that's really our strength." \{Self-determination $\}$

"...I guess part of that is that I just really like the people and we always have a good laugh." $\{$ Relatedness $\}$ (2010 pers. comm., $25^{\text {th }}$ June)

Jane (balanced):

"But...it raises quite interesting questions about what is the purpose of the garden. It's been really effective at creating this cohesive group. People getting to know each other. Has it been effective getting people gardening, and learning about gardening. Maybe, but only maybe, y'know, not as strongly." \{Impact $\}$

"I think there's a lot a value in [connecting with one's neighbours], even just in terms of peak oil and climate change." \{Importance (2010 pers. comm., $8^{\text {th }}$ July)

Warren (systemiser):

"Focusing on the plants is quite interesting, things I've read and on youtube." $\{$ Competence $\}$

"I feel kind of a like a duty...I feel that a lot of the solutions [to global predicaments] lie at the level of individuals and communities." $\{$ Importance $\}$ 
“Making things happen.” $\{$ Impact $\}$ (2010 pers. comm., $7^{\text {th }}$ June)

Sam (systemiser):

“...like innovation as well. Like us coming up with our own unique solution to something, and that makes me quite excited." \{Competence\}

"I like...being involved in significant changes, like building things." \{Impact\} (2010 pers. comm., 27 $7^{\text {th }}$ May)

Frank (systemiser):

"I enjoy reading about stuff that other people might find boring...like dirt." \{Competence $\}$

"Modern culture is misguided. People are living further and further away from where their food is grown. We're going to run out of oil and it will be useful to have food around." \{Importance $\}$ (2010 pers. comm., $20^{\text {th }}$ June)

Reported extrinsic motivations include a long-term vision for widely available healthy food; the value of getting to know one's neighbours; general interest in sustainability and the importance of community resilience for peak oil and climate change.

Figure 5-D breaks down the 'Important' construct into four values expressed by participants. 
Figure 5-D

Prevalence of Reported Extrinsic Motivation vs. Overall Motivations in Semistructured Interviews

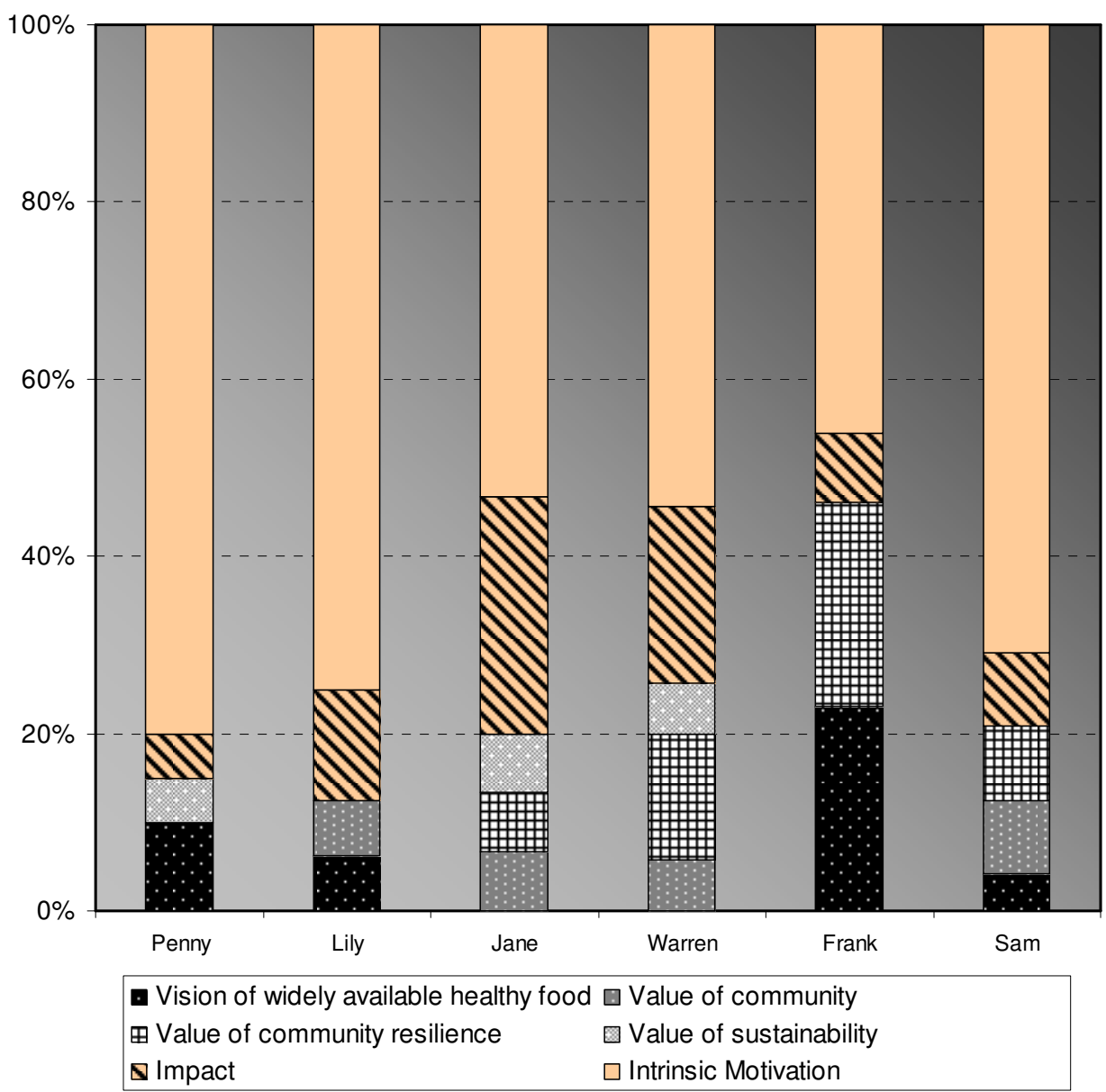




\subsubsection{Intrinsic Value of Mapping}

All participants reported an intrinsic value of maps and mapping activities but there does not appear to be a discernable relationship to E-S cognitive style in the collected data. Sam, a systemiser who uses maps and sketch mapping regularly in his work, reported a high degree of intrinsic mapping value, going so far as "I love maps." (2010 pers. comm., $27^{\text {th }}$ May). Similarly, Warren, another systemiser also reported that: "I love maps actually, they're quite beautiful things." (2010 pers. comm., $7^{\text {th }}$ June). However, Penny, the empathiser, also reported a high degree of intrinsic value for mapping. Penny discussed how people at the Aro Valley fair were drawn to identify their homes on the photomaps available at KTA's stall and how she could relate to that feeling: "We seem to have this kind of urge, to see something that we're so familiar with represented in a different form." (2010 pers. comm., $7^{\text {th }}$ June). Frank, who tested as a systemiser, was not involved in any KTA mapping activities and reported that: "its kinda cheesy but [using maps] is like a treasure map, kind of exciting to go on a bit of a mission to go and find stuff." Frank's response possibly reflects the law-testing orientation of systemisers. Part of the intrinsic value of map usage could come from the use of spatial laws that govern maps to make predictions about the geographical location of objects. Jane, who tested as balanced, reported that she enjoyed using maps because "Everything's organised and kinda neat and where it should be." Finally Lily, balanced, reported to "like seeing how things fit together." (2010 pers. comm., $25^{\text {th }}$ June).

\subsection{Summary of Key Findings}

The pattern of difference between the motivations of participants in the speech acts dataset and the semi-structured interviews are broadly similar. The speech act data rely on the participant's confidence in group situations while the semi-structure interview data rely on participant's conscious awareness of their own motivations. A broadly similar pattern of systemising correlating with high levels of competence motivated behaviour appears in both datasets. Sam demonstrates a marked skew to competence-satisfaction in both datasets. Warren and Jane both have a competence : 
relatedness ratio just above 2 in the speech acts dataset and similar balance between competence and relatedness in the semi-structured interview dataset. Lily has the lowest competence to relatedness ratio (1.2) in the speech acts dataset and reports large amounts of relatedness satisfaction in the semi-structure interview. Penny, the empathiser, expressed a high degree of enjoyment of group collaboration, a result consistent the proposal that E-S cognitive style can influence motivation. Penny's motivation to actively engage may have influenced her speech act data and competence to relatedness ratio (1.7) as discussed previously in section 5.1.2. However, the speech act data are somewhat ambiguous and cannot be statistically validated.

The semi-structured interview data indicate that participants have a diverse range of reported intrinsic and extrinsic motivations for KTA-related activity. Concerning intrinsic motivations, systemisers expressed a greater enjoyment of competencesatisfying activity relative to other intrinsic motivations and relative to other cognitive styles. These results suggest that systemisers have a tendency to focus on competence-satisfying activity, and empathisers have a tendency to focus on relatedness-satisfying activity. All participants reported enjoying mapping activities intrinsically, but there was no apparent relationship to cognitive style.

The five core members who regularly attended meetings (excluding Frank) reported relatively greater intrinsic motivation in the semi-structure interviews, perhaps reflecting their engagement in the monthly potlucks. Extrinsic rationales include valuing community involvement, a vision of freely available healthy food, and preparing for peak oil and climate change. Four of the participants reported concern about future disruptions, consistent with the analysis presented in Chapter 2, as a source of ideological motivation.

The interviewed participants showed a skew to systemising with three of the interviewed participants classified as systemisers and only one classified as an empathiser. It is unknown if the skew is reflective of KTA (and gardening groups in general) or merely of the small sample. 


\subsection{Discussion of Research Questions}

The research design revealed E-S and SD theories as potentially useful for empowerment theory applications but does not allow a definitive answer to the first research question: Can E-S theory explain any differences in the intrinsic motivation of KTA members? Further research could explicitly test for E-S cognitive style and participant motivation and/or innate needs with a much larger sample. Research results, Participant insights and observations indicate the necessity of balancing competence-satisfying and relatedness-satisfying activities within a project, and intrinsic and extrinsic criteria. The following sections discuss the results in reference to the research questions.

\subsubsection{Discussion of Psychological Theory}

\section{Research Question 1:}

Can E-S theory explain any differences in the intrinsic motivation of KTA members?

E-S theory describes a biologically determined drive to perform certain cognitive and affective activities. SD theory describes how subjects construct intrinsic motivation of the content of an activity from a prior context-situated experience and its satisfaction of innate needs. Deci and Ryan (2000) hypothesise that the strength of self-determination, competence and relatedness can vary in the population but have not pursued this avenue of study, preferring to address the social contexts that satisfy or thwart needs. Results of this study indicate the plausibility of E-S theory describing variation in the need for relatedness and competence in the population. The two systemisers present at meetings showed a tendency to adopt a group conversational style consistent with competence satisfaction seeking. The three systemisers reported relatively higher degrees of reported enjoyment of competencesatisfying activity. The empathiser reported a relatively higher degree of enjoyment of relatedness-satisfying activity. These results concern observed behaviour and reported motivations and are a step removed from direct measures of innate need. 
If E-S and SD theories are directly connected, empathising would presumably reflect a greater than average need for relatedness and systemising a greater than average need for competence. A relationship between relatedness and empathising seems obvious, but a relationship between systemising and competence is less apparent. Systemising is defined as the drive to determine the lawful behaviour of a system by analysing input/output relationships in order to make predictions. Making successful predictions could engender feelings of competence. If systemising reflects greater innate need for competence then systemisers will also display a more general drive to master skills. An obvious aspect is a third cognitive style that reflects a more pronounced need for self-determination. Presumably this would interact with the other two types, giving a more complex overall picture.

While all six participants reported they found intrinsic value in mapping, this does not appear to be strongly related to E-S cognitive style. It is possible that visual cognitive styles would have an additional and/or stronger influence on any preference.

\subsubsection{Discussion of Empowerment Theory and Practice}

\subsubsection{Motivation Construction}

\section{Research Question 2(a)}

What relevance does ideology and intrinsic motivation have to the participation and motivation of participants for KTA activities?

Ideology appears to serve as the seed for joining KTA for four of the six interviewed participants, although other motivations are present. Once a participant joined KTA, the intrinsic motivation associated with the innately satisfying contexts provide a means of sustaining motivation.

SD theory describes how need satisfaction occurs prior to the construction of motivation. Here, 'motivation construction' refers to an evaluation of the activity and one's previous experiences of that activity (i.e. 'task evaluation' TV1990). According to SD theory, when an activity is freely performed, and optimally 
challenging, the subject experiences competence-satisfaction (Figure 5-E, (1)). Subsequently the subject is likely to evaluate an activity as interesting or enjoyable (2). This evaluation could lead the subject to seek out more opportunities to perform the activity (3), and experience more satisfaction. Hence, a cycle forms which reinforces the subject's motivation (or amotivation).

Figure 5-E

Motivation Construction

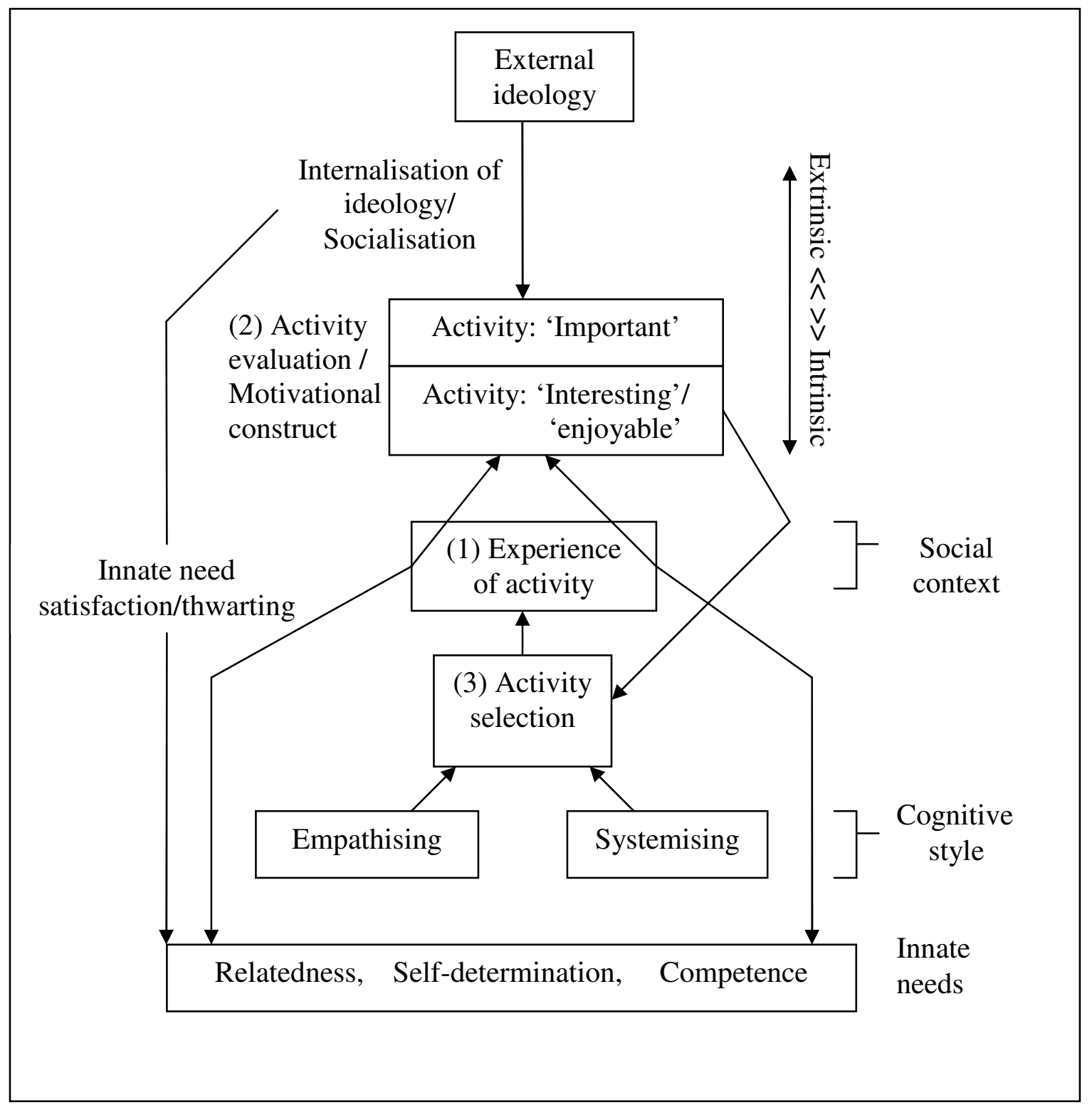


We can consider three 'pathways' that could initiate this cycle although these may occur simultaneously: internalisation-initiated, need-initiated, and associationinitiated.

In an internalisation-initiated cycle, a subject internalises the extrinsic value of an activity first, and subsequently finds the activity innately satisfying. For example, a subject may convert to a religion and internalize the values of that religion including the importance of regular churchgoing. The subject attends church which spontaneously satisfies the person's need for relatedness. Internalisation is supported by need satisfying contexts (Figure 5-E, far left arrow). The positive experience of innate satisfaction influences the churchgoer to additionally construct churchgoing as 'socially satisfying', reinforcing the behaviour (Deci and Ryan, 2000). In KTA, four of the participants (Frank, Sam, Jane and Warren) reported concern about future social disruptions consistent with the analysis presented in Chapter 2 (2010 pers. comm.., $27^{\text {th }}$ May $-8^{\text {th }}$ July). These participants appear to have also internalised a pro-community value system expressed by some peak oil writers (e.g. Heinberg, 2007; Hopkins, 2008; Rudningen, 2009). This value system seems to have led them to seek out community driven projects like KTA and subsequently experience innate satisfaction from KTA activities. For example, as has already been mentioned Frank was that community gardens were "the way of the future" Warren saw part of the value of KTA as "the early stages of forming a citizens response to peak oil." (2010 pers. comm., $7^{\text {th }}$ June). and Sam emphasised his vision of a "benevolent, egalitarian, cooperative society" as an alternative "oil poverty and climate disruption." (2010 pers. comm., $27^{\text {th }}$ May). Jane mentioned peak oil and climate change as rationale for community involvement, but this did not come across as strongly as with the male participants (2010 pers. comm., $8^{\text {th }}$ July). This possibly reflects a gender divide where males are more likely to adopt an explicit peak oil focused ideology. For example according a readership survey, The Oil Drum, a popular peak oil focused website, has about an $80 \%$ a male readership (Hagens, 2009). The other main ideological construct was a vision of widely available healthy food (Figure 5-D).

In a need-initiated cycle, a need deficit or a greater than average need (perhaps one's cognitive style) leads a subject to specifically select an activity to satisfy the need. Participants did not directly report a lack of satisfaction as a driving force behind 
their involvement in KTA. This probably reflects a social norm not to appear needy and/or a lack of conscious awareness of one's innate needs.

In an association-initiated cycle, the subject experiences innate satisfaction from an activity associated with a primary activity. The subject may not have deliberately sought out the associated activity, or extrinsically value it, but the two activities are bundled. For example, a subject may join a sports club seeking opportunities to satisfy competence through sports activity, but also find the club's social aspects innately satisfying, initiating a relatedness satisfying loop around sports club social events. In KTA, Penny joined KTA primarily seeking opportunities to meet people in the neighbourhood. Later, Penny developed an interest in plant propagation (2010, pers. comm., 7th June). Perhaps not an activity that Penny would have initiated without KTA as an intermediary.

\subsubsection{Empowerment Theory and Practice}

\section{Research Question 2(b)}

What relevance does ideology and intrinsic motivation have to empowerment theory and practice?

While ideology may serve as a seed for a project, empowerment practitioners should not neglect the intrinsic value of activities. If ideological criteria have already been established, move to ensure that social contexts are innately satisfying. Cognitive style may be relevant factor for fine-tuning a project to participants. Conversely if the project is founded on the intrinsic value of a practice, once established, move to develop external criteria (i.e. 'impact' or 'importance') that matches participant values. The CofP model and wider literature could be especially relevant (Lave and Wenger, 1991; Wenger, 1998; Wenger et al., 2002; Wheatley and Freize, 2006).

Lee and Koh (2001) argue that empowerment and other constructs such as motivation cannot be equated. Empowered subjects are motivated but motivated subjects are not necessarily empowered. The results of this research suggest a way of fitting these concepts together in reference to SD theory. Participants revealed ideological rationales for their involvement in KTA and evaluated KTA activities in 
ways which recalled two of TV1990's constructs, 'Impact' and 'Meaningfulness'. For example, Sam and Warren were motivated by significant structural changes in the gardens. KTA efforts had transformed vacant overgrown sites into pleasant, productive gardens testifying to the 'impact' of activities. Additionally, activities validated participant's pro-environmental ideologies. Hence, in the context of their ideologies participants evaluated activities as 'important'. TV1990's construct 'Meaningful' is similar but could potentially be construed as relatedness satisfying. The construct 'Important' more clearly signifies extrinsic qualities. However, while these constructs could be a major source of motivation they do not concern the intrinsic qualities of the activity itself so cannot be regarded as intrinsic motivation. In practice, activities have multiple, and interacting intrinsic and extrinsic motivations. The researcher proposes that empowerment be understood as four different processes that can influence each other. (Figure 5-F)

At the base of the model are the three innate needs and need satisfaction. In the second level, the prior experience of need satisfaction influences subsequent construction of intrinsic motivation for an activity. At the third level, subjects evaluate activities according to extrinsic ideological criteria. Is the activity making a tangible difference (i.e. 'impact'); or does the activity validate the subject's ideology (i.e. 'important')? Activities that match these criteria and those of the lower level can additionally be considered psychologically empowering. In the uppermost level, political or economic activities can further social empowerment. These may or may not be psychologically empowering or intrinsically motivating. A political campaign may include boring activities such as letter-stuffing for example. In turn, social empowerment outcomes can satisfy extrinsic criteria, contributing to subject's psychological empowerment. If the balance of all activities experienced by activists meets lower level criteria, social empowerment efforts have a much greater chance of success. In the alternative, activists burn-out after suffering need thwarting and/or drift away from 'soft' projects that fail to meet external criteria. The model suggests that empowerment practitioners take care to build social empowerment on a firm psychological base and develop external criteria for success. 
Figure 5-F

Four Layers of Empowerment

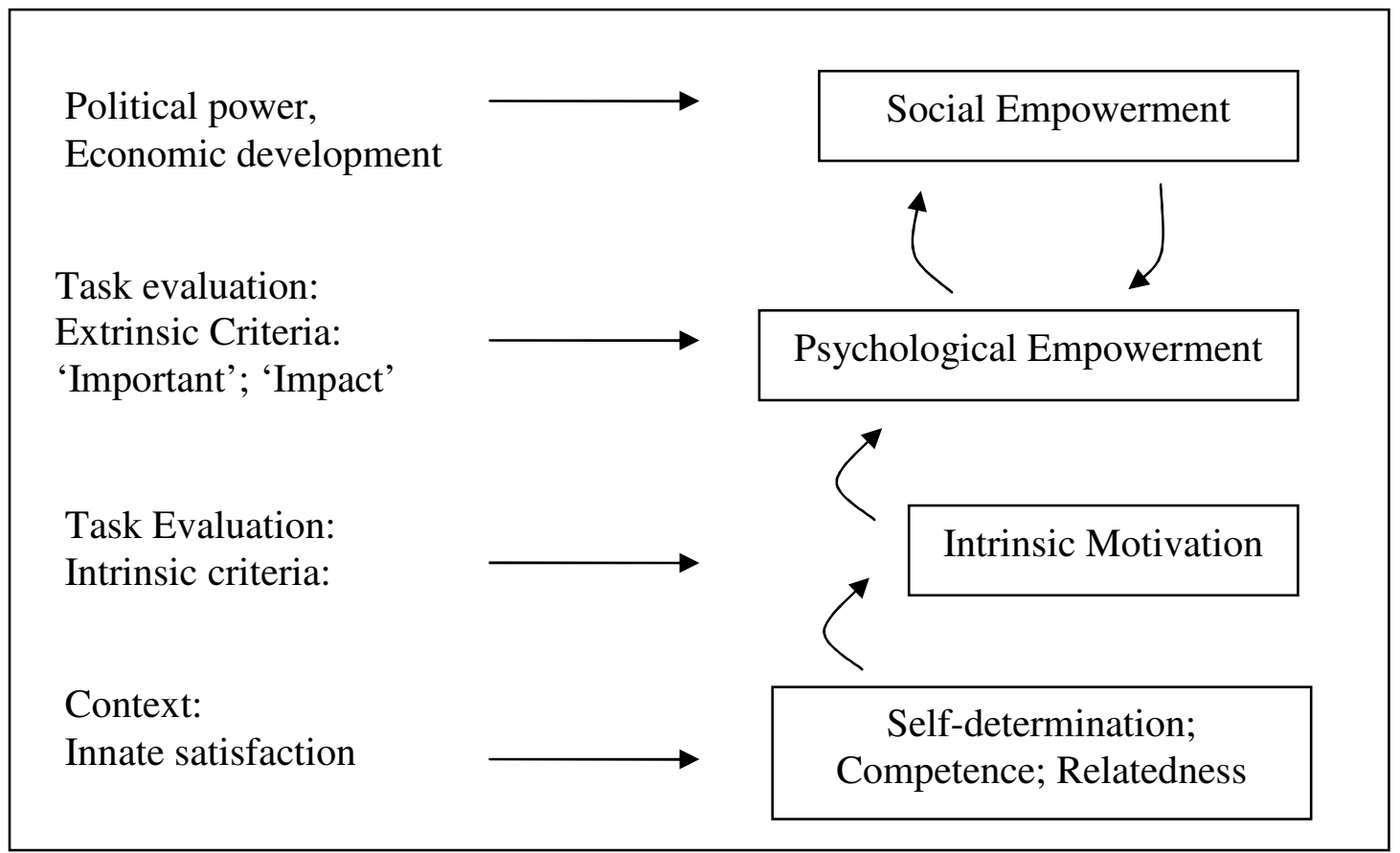

\subsubsection{Implications for PGIS and Community Development}

Practitioners have largely focused on PGIS as a means of social empowerment. A focus on social empowerment may be appropriate In PGIS projects that work with disadvantaged groups. However, if community members are to take ownership of a PGIS, then projects may benefit from acknowledging psychological and motivational aspects. A PGIS will more likely be sustainable and provide longer-term opportunities for social empowerment if community members find PGIS activities intrinsically motivating as well as psychologically empowering. This research has attempted to understand how subjects construct motivation for activities including activities related to mapping and group participation.

Participatory GIS methodologies should facilitate self-determination satisfaction (Corbett, 2009). The PGIS literature is less clear on the satisfaction of competence and relatedness. Variation in participants' and the PGIS practitioner's cognitive style may influence the kinds of activities that they initially pursue or find intrinsically motivating. For these reasons PGIS practitioners may wish to apply the model in the previous section (Figure 5-F), and explicitly ask themselves the following questions, 
along with social empowerment criteria presented in section 3.3 (Corbett and Keller, 2005; Elwood, 2002; Kyem, 2001):

1. What is my E-S cognitive style?

2. Which PGIS activities do I (the GIS champion) find intrinsically motivating? -Could my intrinsic interest in these activities lead me to emphasise this activity more than others, and is that appropriate considering

3. Are current activities designed to encourage participation by both empathiser and systemiser type participants?

4. How might E-S cognitive styles be distributed amongst the PGIS participants? -Is it worthwhile to test participants with a formal questionnaire? (Appendix B)

5. Does the PGIS provide an appropriate context for participant selfdetermination, competence, and relatedness satisfaction? Is there a bias toward the satisfaction of one need or is there a balance across needs?

6. Are the activities creating tangible results (i.e. 'impact')?

7. What are the participant's values, and are the activities validating these values (i.e. are the activities 'important')?

Knowing the responses to the above questions will allow the PGIS practitioner to actively engage with participants of a dissimilar cognitive style and adjust the PGIS process if needed.

Deci and Ryan (2000) explain that relatedness is more a distal need to the maintenance of intrinsic motivation than self-determination and competence. In projects with tight-knit communities ensuring adequate relatedness satisfaction may be less of concern than competence or self-determination. An awareness of any relatedness deficits may be of particular concern in atomised communities.

Depending on the context, PGIS practitioners may wish to adopt a CofP model for PGIS stewardship. If the goal of the project is to build community capacities, an amateur GIS CofP could be a useful focal point for GIS skills. In this model, once an initial project has run its course PGIS practitioners would attempt to connect participants who show particular aptitude or intrinsic motivation for GIS skills into a GIS CofP (Wheatley and Freize, 2006). For example, one of Wenger et al.'s (2002) 
principles for cultivating CofP's is to design for evolution rather than imposing an organisational structure. Initially, KTA had a very light organisational structure with Barrie handling the majority of the administration. Wenger et al. recommend introducing new elements, a website, new projects etc., one at a time. KTA's successful evolution approximates this approach. Another principle is to invite different levels of participation. More formal organisations may expect members to make a minimum commitment. In KTA, some members attend almost every event and some members come to the occasional working bee. This varying level is not regarded as problematic.

There may be tension between this approach and the full participation of the community. Potentially GIS CofP members would leverage increased access to GIS for personal gain at the expense of the broader community. Ideally a GIS CofP would maintain the community's PGIS, promote community participation and continue to develop skills.

Given the expense and personal time commitment involved in acquiring GIS skills, we can only expect the highly motivated to develop more advanced GIS skills. Realistically, without commercial applications and extrinsic benefits, sustained PGIS stewardship requires intrinsic rewards. The social context of a CofP, and the potential status benefits of belonging to one, could suffice.

\subsubsection{Discussion of Ideology, Environmentalism and Social Change}

\section{Research Question 2(c)}

What relevance does ideology and intrinsic motivation have to broader theories of social change?

Environmentalists have attempted to spread environmental values and beliefs to motivate pro-environmental behaviour. The proposed causal chain in these efforts runs from values to behaviour (Dietz et al., 2005; Stern et al., 1999). SD theory suggests that innate needs limits these efforts and makes subsequent behaviour changes fragile. The research has explored intrinsically motivated practices as an alternative to extrinsic values-motivated sustainable behaviour. Practices are adopted 
directly for tangible benefits and/or for intrinsic qualities, without necessarily internalising a new value system. Ironically, this approach could help spread proenvironmental values. Intrinsic motivation may be factor in societal collapse.

\subsubsection{Implications for Environmentalism and Social Change}

Mackenzie-Mohr and colleagues (1999) have developed a suite of behavioural change techniques labelled 'community-based social marketing'. In one technique, community-based agents signal pro-environmental behaviour, such as recycling, as a social norm through visiting households personally and discussing the benefits of the behaviour (Hopper and McCarlneilson, 1991)

In SD theory terms such a technique works through assisting the internalisation of a value system (e.g. pro-recycling) by switching the social context of the behaviour from differentiation to integration. A behaviour the subject would have previously considered to differentiate them from their social context becomes perceived to integrate them when community-based agents signal the behaviour's normality. However, according to SD theory, the minority status of pro-environmental ideologies and radical pro-environmental behaviours limits the effectiveness of such techniques. Radical behaviours that some argue are necessary, such as refusing air travel (e.g. www.stopflying.org.nz), are still very much in the minority. To adopt an uncommon ideology or behaviour a subject must differentiate from the status quo and their immediate social networks, potentially thwarting their need for relatedness. Status quo conformity offers opportunities for relatedness satisfaction with which a minority ideology may struggle to compete. According to SD theory this would reduce the subject's intrinsic motivation to sustain the behaviour.

Some argue that the correct actions could tip the society into a desired proenvironmental paradigm (e.g. Nyborg et al., 2006; Schumacher, 2009). In this scenario society passes a 'tipping-point', where the pro-environmental behaviours rapidly become the new normal. Using SD theory, we can describe how a tipping point could occur. Once a subject perceives pro-environmental behaviour as 'normal', adopting the behaviour satisfies rather than thwarts relatedness through integration with broader social contexts. When the subject adopts the behaviour it makes it more likely that others in their social networks will perceive the behaviour 
as normal, causing a cascading effect. Whether the tipping point scenario will actually play out is less certain. Increasing numbers have professed a concern for the environment, although this has not necessarily followed through into more prevalent pro-environmental behaviour (McKenzie-Mohr and Smith, 1999). Integration and relatedness-satisfaction are only part of the picture. Self-determination needs can conflict with relatedness needs and that other factors influence broader social contexts. Deci and Ryan (2000) argue that in a collectivist culture, adopting a social norm can meet self-determination and relatedness simultaneously, but in an individualist culture, conformity thwarts self-determination, and autonomy thwarts relatedness. Similarly, Brewer's (1991) optimal distinctiveness theory describes how subjects balance the need to relate to broader social contexts with the need to differentiate (i.e. self-determine). Brewer argues that these needs are often reconciled through identification with minority social identities that satisfy both relatedness and a sense of autonomy. Exercising the choice to belong a minority ideology or identity group offers a more optimal distinctiveness than complete conformity. Environmental ideologies are not only competing with the status quo and material status acquisition but with the plethora of minority social identities. Hence, the triumph of one value system is unlikely as long as the society remains broadly individualist.

Complicating matters, limits to growth could dramatically change broader contexts. Existential threats such as long-term unemployment can foster pro-environmental attitudes, but only to the extent that attitudes are salient as pre-existing social norms (Fritsche et al., 2010). In the California-based study, Kahn and Kotchen (2010), find that expressed concern for the environment diminishes with a rise in unemployment. Value-based environmental politics may struggle as the economy declines.

Wheatley and Freize's (2006) CofP-centred model of social change provides an alternative to value and belief-motivated behaviour change. Wheatley and Freize determine a particular order for actions: first, name the pioneering practitioners and recognise their efforts; second, connect the pioneers into a CofP; third, nourish the CofP until it can self-sustain; and fourth, advertise the CofP's successes (ibid.). Naming and connecting practitioners into a CofP provides a social context that can satisfy relatedness and competence as pioneers share skills and try out new techniques. In contrast to value-based social change, the wider promotion of 
practices only comes after the CofP is well established and can demonstrate tangible results. The CofP's social context may appeal to the empathiser, whilst knowledge systems may appeal to the systemiser, and tangible results can appeal to those motivated by competence and status acquisition. Upon learning of tangible successes, a subject can adopt the practice without necessarily internalising a new value system. CofP members undoubtedly have their ideologies but the focus on practices keeps these below the surface. Ideological discussions or extrinsic rationales for gardening are virtually absent from KTA discussions and these were not the main sources of motivation for core members. Warren did not know if other KTA members shared his concerns about peak oil and wondered if it was part of their motivations (2010 pers. comm., $7^{\text {th }}$ June). Sam expressed a preference for this style of group, stating that:

"I think I am quite good at being grounded on the solution, like having some kind of grass-roots group together to start this ...[is better] than talking about it a lot about why we're doing it." (2010 pers. comm.., 27 May)

Need-initiated or association-initiated motivation pathways do not threaten prospective practitioners with social differentiation. The subject can fit the practice into their own value system. If the practice is adaptive, tangible results will appeal to broader value systems. To give an example, an environmental rationale for a passive solar design would be to minimise the house's environmental impact through reduced energy consumption. Members of a passive solar design CofP may be extrinsically motivated by the environmental rationale for passive solar, but in their CofP they focus on design principles and techniques. A prospective CofP member who does not share the CofP's underlying pro-environmental ideology, but values frugality (and hence saving money on energy bills) can join the CofP, without necessarily adopting environmental rationales. The new practitioner affirms their frugal internalised values through practicing passive solar design. Avoiding the internalisation of a new pro-environmental ideology allows the member to maintain social integration with their presumably pro-frugal, but not necessarily proenvironmental friends and family. 
Of course, joining a group that covertly shares a distinctive ideology, especially a group which provides a context for innate satisfaction, makes the new member more likely to eventually internalise a group's values (Deci and Ryan, 2000), but this is incidental. Here, the causal chain runs from the member's current value system (frugality); through the innate satisfaction reinforcing their motivation; and potentially to the internalisation of pro-environmental values as friendships form, and the new member integrates CofP values into their identity.

To take this approach, practitioners have to maintain the primacy of practice and intrinsic value in their CofP's. Perhaps quite difficult for the committed ideologue. Environmentalists should consider which causal chain is more appropriate: a focus on pro-environmental values, potentially leading to behaviour changes, possibly leading to innate satisfaction; or, the development of practice and social context, leading to innate satisfaction and intrinsic motivation, possibly leading to proenvironmental values integration. This distinction recalls that between instrumental and pre-figurative politics (Breines, 1980). The instrumentalist sees the widespread adoption of their ideology as a means of advancing their political agenda and engages in discourse to achieve this end. The pre-figurativist understands that "you catch more flies with honey, not vinegar' and sets about innovating practice and creating a social context for its own intrinsic value.

Krasny and Tidball $(2008,2009)$ argue that community gardens are not simply about communal food production but can also address multiple goals such as civic political engagement. Jane and Frank, two KTA members with higher degrees of extrinsic motivation, have also been active in instrumental politics. Frank has been a vocal advocate of public fruit trees and petitioned the local council to plant fruit trees in public spaces. In the following extract Jane discusses how Frank's connection to KTA assisted his efforts:

\footnotetext{
"Think of Frank with his fruit trees. That's an actual project that happened. He had a connection to Kai o Te Aro. He wanted to get fruit trees in public places. He reached into that connection to get support." (2010 pers. comm., $8^{\text {th }}$ July)
}

Jane went on to discuss how her KTA membership contributed to her own civic advocacy: 
"I had several quite useful conversations with people...Warren was one of them, I had this quite useful conversation with Penny 'cos she worked at the council, [and knew what is actually involved] when you make a submission to the council and what's effective in that. And what she said was really interesting because she had the insider's perspective, that was totally not to do with gardening, but we were having that conversation as we were digging the garden bed." (2010 pers. comm., $8^{\text {th }}$ July)

In practice, the distinction between instrumental and pre-figurative politics is less acute. What may appear to be pre-figurative (a garden), can have instrumental undercurrents (an activist base). At this stage while members have their own projects, KTA does not appear to be developing as an instrumental political organisation. Apart from the tenure arrangements with a private landowner (verbal contract) and VUW (written contract), there is no explicit social empowerment by the criteria of the models presented in Table 3-A. KTA does have good relationship with the AVCC and, interestingly enough, a number of candidates in the recent local body elections have indicated support for community gardens, although this may not be specifically connected to KTA. 


\subsubsection{The Psychology of Collapse}

It is possible that motivation dynamics described above play a role in societal collapse. Janssen and Scheffer (2004) and Whitehead and Richerson (2009) have highlighted possible psychological aspects of past collapses. In Jansen and Schafer's (2004) view the psychology of the sunk-cost effect leads to an overestimation of the advantages of the status quo. Whitehead and Richerson (2009) argue that conformist social learning contributes to the status quo persistence, whereas parent-to-child social learning allows greater adaptiveness. When the broader environment changes but social institutions do not, the variance can cause the society to collapse (ibid.). Intriguingly, SD theory suggests that those who lack consistent relatedness satisfaction are more likely to conform to general social norms. In other words, conformity may be the only way lonely people can maintain social integration, whereas the innately satisfied are freer to experiment, giving the society more resilience.

SD theory raises another psychological aspect of collapse. A simple lack of motivation could contribute. When controlling social contexts thwart innate needs subjects construct activities as uninteresting. The subsequent loss of productivity could exacerbate the society's predicaments. Tainter et al. (2003) argue that societies become more controlling during transitions from high to low gain resources. The low margins and climatic fluctuations of low gain resources, such as agriculture, force the society to closely regulate energy flows. As an example, after transitioning to a lowgain system, The Roman Empire became increasingly controlling during the $4^{\text {th }}$ century, raising taxes and making occupations hereditary. A development that could have diminished the motivation and loyalty of Rome's subjects (ibid.).

The effects of need thwarting contexts may place a natural limit on the control and longevity of authoritarian societies. Tainter (1988) describes societal collapse as an economising process where actors make strategic decisions to opt for institutions that offer superior benefits and to abandon the status quo.

In the current context, if governments respond to the various energy, economic, and climate crises by increasing control over day to day life, then need thwarting is one 
argument for this strategy's failure. From the evolutionary psychology perspective, where modern institutions are evaluated in terms of fitness to the EEA, complex societies demonstrate marked deficiencies (Alexander, 2008; Charlton, 1996; Liedloff, 1986). It should not be surprising then, that complex societies have suffered periods of instability, when we are not adapted to live in them.

In many respects, a community gardens-based activist strategy can be seen as an attempt to recreate aspects of the EEA within day-to-day life. Peer-participation, skill sharing and development, and group identity formation are aspects familiar to our hunter-gatherer ancestors (Charlton, 1996; Sahlins, 2004) and indeed, to members of KTA. It has been argued here that such a strategy is psychologically sustainable and can play a role in mitigating our society's economic decline. 


\section{6 \\ Conclusion}

\subsection{Findings}

The research revealed that E-S and SD theories can potentially explain how variation participant's cognitive style can influence motivation for activities in community development projects. Systemisers appear to seek out opportunities to satisfy a greater than average need for competence. Similarly, empathisers tendency to learn of other's emotions and respond appropriately may reflect a drive to satisfy a greater than average need for relatedness. Research results, participant insights and observations indicate the necessity of balancing both competence-satisfying and relatedness-satisfying activities, and intrinsic and extrinsic criteria over long-term projects. A neglect of either of these aspects could limit project success.

\subsection{Limitations}

Results depend on the observation of unconscious behaviour and participant's conscious and accurate awareness of their own motivations; and a pen and paper test of participant's cognitive style. The case study size of six participants is too small to make strong knowledge claims. Nevertheless, the marked tendency of systemiser participants to pursue competence-satisfying behaviour relative to other cognitive styles suggest a plausible link between E-S and SD theories.

\subsection{Why is this Important?}

The environmental mainstream assumes that members of complex societies posses the capacities to collectively recognise dangers, determine the best course of action, and forego strategies advantageous to self- and sub-group interest; and will act in these capacities to reform the status quo (e.g. Steffen, 2009). Psychology and history 
suggest that this is naive view (Beratan, 2007; Hassan, 2008; Janssen and Scheffer, 2004; Kurtz and Snowden, 2003; Tainter, 1988; Whitehead and Richerson, 2009).

The prospect of near-term economic decline or even societal collapse is a largely unrecognised risk in mainstream discussions. Influenced by progressivism, limits to growth have been dismissed from polite conversation. Instead, rationalist environmental research has pursued abstract generalizable knowledge that may not be useful in complex situations (Kurtz and Snowden, 2003).

Nevertheless, there are opportunities to adapt to decline that work with human psychology. PGIS projects have the potential to be one such method as they incorporate social and psychological empowerment processes and have intrinsic appeal. Establishing a CofP is another such method that can spur innovative practice and meet the range of psychological needs. These methods require practitioners to balance psychological needs, tangible value, and extrinsic rationales.

\subsection{Recommendations}

Further research of E-S and SD theories as applied to community development or PGIS projects could strengthen or disconfirm the proposition that E-S cognitive style is reflective of variation in the degree of innate psychological need. Researcher's may also wish to investigate whether E-S theory can incorporate a cognitive styles reflecting a greater than average need for self-determination.

Empowerment practitioners, who have struggled with the choice between Power and Love focused approaches, may benefit from the study's exploration of empowerment, psychology and practice. At one level the choice is between extrinsic and intrinsic motivation. Extrinsic goals can only be well internalised in the presence of needsatisfying contexts. Intrinsic goals may not achieve tangible results without external criteria, which can subsequently thwart needs (Deci and Ryan, 2000). At another level, the dilemma concerns the social identity and psychological needs of the subject. Should I accept and submit to group norms and expectations (satisfying relatedness)? Or should I strike out on my own (satisfying self-determination)? At another level the dilemma concerns the group's balance of activities. Pursuing relatedness, through empathising, can leave less time for pursuing competence, 
through systemising, and vice versa. The ideologies and psychologies of group members pull the group in different directions. Surfing this wave and reconciling the two requires practitioners to develop their awareness of psychological needs and motivations. 


\section{References}

Acemoglu, D. 2007: Introduction to Modern Economic Growth. Boston, MA: MIT Press.

Aguiar-Conraria, L. and Wen, Y. 2007: Understanding the Large Negative Impact of Oil Shocks. Journal of Money, Credit and Banking 39, 925-944.

Ajzen, I. 1991: The theory of planned behavior. Organizational Behavior and Human Decision Processes 50, 179-211.

Akerlof, G.A. 2002: Behavioral Macroeconomics and Macroeconomic Behavior. The American Economic Review 92, 411-433.

Aleklett, K., Hook, M., Jakobsson, K., Lardelli, M., Snowden, S. and Soderbergh, B. 2009: The Peak of the Oil Age: Analyzing the world oil production Reference Scenario in World Energy Outlook 2008. Energy Policy in press, 28.

Alexander, B. 2008: The Globalisation of Addiction: A study of the poverty of spirit. Oxford: Oxford University Press.

Allison, I., Blindoff, N.L., Bindschadler, R.A. and Cox, P.M. 2009: The Copenhagen Diagnosis: Updating the world on the latest climate science. Sydney: The University of New South Wales Climate Change Research Centre, 64.

Altieri, M.A. 1999: Applying Agroecology to Enhance the Productivity of Peasant Farming Systems in Latin America. Environment, Development and Sustainability 1, 197-217.

Ayres, R.U. 2006: Turning point: The end of exponential growth? Technological Forecasting and Social Change 73, 1188-1203.

Ayres, R.U., Turton, H. and Casten, T. 2007: Energy efficiency, sustainability and economic growth. Energy 32, 634-648.

Ayres, R.U. and van den Bergh, J.C.J.M. 2005: A theory of economic growth with material/energy resources and dematerialization: Interaction of three growth mechanisms. Ecological Economics 55, 96-118.

Ayres, R.U. and Warr, B. 2005: Accounting for growth: the role of physical work. Structural Change and Economic Dynamics 16, 181-209.

Bandura, A. 2002: Social Foundations of Thought and Action. In Marks, D., editor, The Health Psychology Reader, London: SAGE Publications, 94-106.

Bardi, U. 2005: The mineral economy: a model for the shape of oil production curves. Energy Policy 33, 53-61. 
Baron-Cohen, S. 2002: The extreme male brain theory of autism. Trends in Cognitive Sciences 6, 248-254.

Baron-Cohen, S. 2008: Autism, hypersystemizing, and truth. The Quarterly Journal of Experimental Psychology 61, 64 - 75.

Baron-Cohen, S. and Belmonte, M.K. 2005: Autism: A Window Onto the Development of the Social and the Analytic Brain. Annual Review of Neuroscience 28, 109-126.

Baron-Cohen, S., Knickmeyer, R.C. and Belmonte, M.K. 2005: Sex Differences in the Brain: Implications for Explaining Autism. Science 310, 819-823.

Baron-Cohen, S., Richler, J., Bisarya, D., Gurunathan, N. and Wheelwright, S. 2003: The systemizing quotient: an investigation of adults with Asperger syndrome or highâ€"functioning autism, and normal sex differences. Philosophical Transactions of the Royal Society of London. Series B: Biological Sciences 358, 361-374.

Barr, S. and Gilg, A. 2006: Sustainable lifestyles: Framing environmental action in and around the home. Geoforum 37, 906-920.

Bassi, A.M., Powers, R. and Schoenberg, W. 2009: An integrated approach to energy prospects for North America and the rest of the world. Energy Economics In Press, Corrected Proof.

Beddoe, R., Costanza, R., Farley, J., Garza, E., Kent, J., Kubiszewski, I., Martinez, L., McCowen, T., Murphy, K., Myers, N., Ogden, Z., Stapleton, K. and Woodward, J. 2009: Overcoming systemic roadblocks to sustainability: The evolutionary redesign of worldviews, institutions, and technologies. Proceedings of the National Academy of Sciences 106, 2483-2489.

Bently, R. 2009: An Explanation of Oil Peaking. ASPO 2009 International Peak Oil Conference, Denver, CO: Association for the Study of Peak Oil and Gas -USA, 72.

Beratan, K.K. 2007: A Cognition-based View of Decision Processes in Complex Social Ecological Systems. Ecology and Society 12, 27.

Bernanke, B. 1995: The Macroeconomics of the Great Depression: A comparative approach. Journal of Money, Credit and Banking 27, 1-28.

Biggs, S. 1989: Resource-poor Farmer Participation in Research: a synthesis of experiences from nine national agricultural research systems., The Hague:

International Service for National Agricultural Research.

Billington, J., Baron-Cohen, S. and Wheelwright, S. 2007: Cognitive style predicts entry into physical sciences and humanities: Questionnaire and performance tests of empathy and systemizing. Learning and Individual Differences 17, 260-268.

Borron, S. 2006: Building Resilience for an Unpredictable Future: How organic agriculture can help farmers adapt to climate change. Rome: Food and Agriculture Organisation of the United Nations. 
Braun, V. and Clarke, V. 2006: Using Thematic Analysis in Psychology. Qualitative Research in Psychology 3, 77-101.

Breines, W. 1980: Community and Organization: The New Left and Michels' "Iron Law". Social Problems 27, 419-429.

Brenner, R. 2009: What is Good for Goldman Sachs is Good for America: The origins of the current crisis. Los Angeles, CA: Center for Social Theory and Comparative History, UCLA.

Breton, M. 2002: Empowerment Practice in Canada and the United States. The Social Policy Journal 1, 19-34.

Brewer, M.B. 1991: The Social Self: On Being the Same and Different at the Same Time. Personality and Social Psychology Bulletin 17, 475-482.

Brown, C. 1974: Literacy in thirty hours: Paulo Freire's process. The Urban Review 7, 245-256.

Brown Weiss, E. 1992-1993: In Fairness to Future Generations and Sustainable Development. American University Journal of International Law and Policy 8, 1926.

Bruckner, M. and Gruner, H.P. 2010: Economic Growth and the Rise of Political Extremism: Theory and Evidence. London: Centre for Economic Policy Research.

Brundtland, G.H. and Khalid, M. 1987: Our Common Future. Oxford, UK: World Commision on Environment and Development.

Campbell, C.J. and Laherrere, J.H. 1998: The end of cheap oil. Scientific American 278, 78 .

Carr, E.S. 2003: Rethinking Empowerment Theory Using a Feminist Lens: The Importance of Process. Affilia 18, 8-20.

Carson, K. 2010: The Homebrew Industrial Revolution: A low overhead manifesto: Booksurge.

Charlton, B.G. 1996: What is the Ultimate Cause of Socio-economic Inequalities in Health? An Explanation in Terms of Evolutionary Psychology. Journal of the Royal Society of Medecine 89, 3-8.

Cleveland, C.J., Costanza, R., Hall, C.A.S. and Kaufmann, R. 1984: Energy and the U.S. Economy: A Biophysical Perspective. Science 225, 890-897.

Cole, A. 2007: Mediated Modelling, Strong Transdisciplinarity and Sustainable Resource Management in the Motueka Catchment of New Zealand. International Journal of Sustainable Development 10, 345-364.

Cole, A., Allen, W., Kilvington, M., Fenemor, A. and Bowden, B. 2006:

Understanding Whole-of-System Sustainability in the Motueka Catchment: 
Particpatory modelling with an influence matrix. Palmerston North, NZ: Landcare Research 31.

Conger, J.A. and Kanungo, R.N. 1988: The Empowerment Process: Integrating Theory and Practice. The Academy of Management Review 13, 471-482.

Corbett, J.M. 2009: Good Practices in Participatory Mapping: A review prepared for the International Fund for Agricultural Development (IFAD). IFAD, 59.

Corbett, J.M. and Keller, C.P. 2005: An Analytical Framework to Examine Empowerment Associated with Participatory Geographic Information Systems (PGIS). Cartographica: The International Journal for Geographic Information and Geovisualization 40, 91-102.

Cordell, D., Drangert, J.-O. and White, S. 2009: The story of phosphorus: Global food security and food for thought. Global Environmental Change In Press, Corrected Proof.

Cornia, G.A. 1985: Farm size, land yields and the agricultural production function: An analysis for fifteen developing countries. World Development 13, 513-534.

Cornwall, A. and Jewkes, R. 1995: What is participatory research? Social Science \& Medicine 41, 1667-1676.

Costanza, R., Graumlich, L. and Steffen, W.L. 2008: Sustainability or Collapse: an integrated history and future of people on earth. Boston: MIT Press in cooperation with Dahlem University Press.

Cox, A. 2005: What are communities of practice? A comparative review of four seminal works. Journal of Information Science 31, 527-540.

Craig, W.J. and Elwood, S. 1999: How and Why Community Groups Use Maps and Geographic Information. Neighbourhood Planning for Community Revitalisation, Minneapolis, MN Centre for Urban and Regional Affairs, University of Minnesota.

Craig, W.J., Harris, T.M. and Weiner, D. 2002a: Community Participation and Geographic Information Systems. Abingdon, UK: Taylor \& Francis Group.

Craig, W.J., Trevor, H. and Weiner, D., editors 2002b: Community Participation and Geographic Information Systems. New York: Taylor and Francis.

Crampton, J.W. and Elden, S. 2007: Space, Knowledge and Power. Surrey, UK: Ashgate Publishing.

Czech, B. 2009: The neoclassical production function as a relic of anti-George politics: Implications for ecological economics. Ecological Economics 68, 2193 2197.

Daly, H.E. 1980a: The Economic Thought of Frederick Soddy. History of Political Economy 12, 469-488. 
Daly, H.E. 1980b: Growth Economics and the Fallacy of Misplaced Concreteness: Some Embarrassing Anomalies and an Emerging Steady-State Paradigm. American Behavioral Scientist 24, 79-105.

Day, J.W. and Hall, C. 2009: Revisiting the Limits to Growth After Peak Oil. American Scientist 97, 230-237.

Decety, J. and Meyer, M. 2008: From emotion resonance to empathic understanding: A social developmental neuroscience account. Development and Psychopathology 20, 1053-1080.

Deci, E. 1971: Effects of Externally motivated Rewards on Intrinsic Motivation. Journal of Personality and Social Psychology 18, 105-115.

Deci, E. and Ryan, R. 1985: Intrinsic Motivation and Self-Determination in Human Behaviour. New York: Plenum Press.

Deci, E. and Ryan, R. 2000: The "What" and "Why" of Goal Pursuits: Human Needs and the Self-Determination of Behavior. Psychological Inquiry: An International Journal for the Advancement of Psychological Theory 11, 227 - 268.

Deci, E.L., Koestner, R. and Ryan, R. 1999: A Meta-Analytic Review of Experiments Examining the Effects of Extrinsis Rewards on Intrinsic Motivation. Psychological Bulletin 125, 627-668.

Deffeyes, K.S. 2005: Beyond Oil: the view from Hubbert's Peak. New York: Hill and Wang.

Dervaes, J. 2010: The 10 Eelements of Our Urban Homestead.

Diamond, J. 1987: The Worst Mistake in the History of the Human Race. Discover, 64-66.

Diamond, J. 2005: Collapse: How societies choose to fail or succeed. New York: Viking.

Dietz, T., Fitzgerald, A. and Shwom, R. 2005: Environmental Values. Annual Review of Environment and Resources 30, 335-372.

Doyle, R. and Krasny, M. 2003: Particpatory Rural Appraisal as an Approach to Environmental Education in Urban Community Gardens. Environmenal Education Research 9, 91115.

Dryzek, J.S. 1996: Political Inclusion and the Dynamics of Democratization. The American Political Science Review 90, 475-487.

Easterly, W. and Levine, R. 2001: What have we learned from a decade of empirical research on growth? It's Not Factor Accumulation: Stylized Facts and Growth Models. World Bank Econ Rev 15, 177-219.

Elwood, S.A. 2002: GIS in Community Planning: A multidimensional analysis of empowerment Environment and Planning 34, 905-922. 
Energy Information Administration (EIA) 2006: International Energy Annual.

Esnard, A.-M. 2007: Institutional and Organizational Barriers to Effective Use of GIS by Community-Based Organizations. Journal of the Urban and Regional Information Systems Association 19, 13-22.

Evans, J. and Repper, J. 2000: Employment, social inclusion and mental health. Journal of Psychiatric and Mental Health Nursing 7, 15-24.

Eylon, D. and Bamberger, P. 2000: Empowerment Cognitions and Empowerment Acts: Recognizing the Importance of Gender. Group Organization Management 25, 354-372.

Farrell, D., Lund, S., Skau, O., Atkins, C., Mengeringhaus, J.P. and Pierce, M.S. 2008: Mapping Global Capital Markets: Fifth annual report. McKinsey Global Institute.

Ferreira, J.-A.L. 2007: An Unorthodox Account of Failure and Success in Environmental Education. Griffith University. School of Arts.

Fisher, I. 1933: The Debt-Deflation Theory of Great Depressions. Econometrica 1, 337-357.

Fonte, M. 2002: Food Systems, Consumption Models and Risk Perception in Late Modernity. International Journal of Sociology of Agriculture and Food 10, 13-21.

Foreman-Peck, L. and Murray, J. 2008: Action Research and Policy. Journal of Philosophy of Education 42, 145-163.

Foster, J.B. 2008: The Financialization of Capital and the Crisis. Monthly Review 59.

Freire, P. 2000: Pedagogy of the Oppressed. New York: The Continuum International Publishing Group.

Fritsche, I., Jonas, E., Kayser, D.N. and Koranyi, N. 2010: Existential threat and compliance with pro-environmental norms. Journal of Environmental Psychology 30, 67-79.

Gagné, M., Senécal, C.B. and Koestner, R. 1997: Proximal Job Characteristics, Feelings of Empowerment, and Intrinsic Motivation: A Multidimensional Model1. Journal of Applied Social Psychology 27, 1222-1240.

Gagnon, L. 2008: Civilisation and energy payback. Energy Policy 36, 3317-3322.

Galbraith, J.K. 1990: A Short History of Financial Euphoria. Knoxville TN: Whittle Direct Books.

Gintis, H. 1987: The Nature of Labor Exchange and the Theory of Capitalist Production. In Albelda, R., Gunn, C. and Waller, W., editors, Alternatives to Economc Orthodoxy: A reader in political economy, Armonk, NY: M. E. Sharpe, 6888. 
Grauwe, D. 2009: Keynes's Savings Pardox, Fisher's Debt Deflation and the Banking Crisis. University of Leuven, Belgium, 20.

Gray, J. 2007: Black Mass: Apocalyptic religion and the death of utopia. London: Allen Lane.

Greco, T.H. 2009: The End of Money and the Future of Civilisation. White River Junction: Chelsea Green

Greer, J.M. 2005: How Civilizations Fall: A theory of catabolic collapse.

Greer, J.M. 2008: The Long Descent: A user's guide to the deindustrial future. Gabriola Island, BC, Canada: New Society Publishers.

Gutierrez, L.M. 1990: Working with Women of Color: An empowerment perspective. Social Work 35, 149.

Haberl, H. 2001: The Energetic Metabolism of Societies: Part II: Empirical Examples. Journal of Industrial Ecology 5, 71-88.

Haberl, H. 2006: The global socioeconomic energetic metabolism as a sustainability problem. Energy 31, 87-99.

Haberl, H., Erb, K.H., Krausmann, F., Gaube, V., Bondeau, A., Plutzar, C., Gingrich, S., Lucht, W. and Fischer-Kowalski, M. 2007: Quantifying and mapping the human appropriation of net primary production in earth's terrestrial ecosystems. Proceedings of the National Academy of Sciences 104, 12942-12947.

Haberl, H., Fischer-Kowalski, M., Krausmann, F., Martinez-Alier, J. and Winiwarter, V. 2009: A socio-metabolic transition towards sustainability? Challenges for another Great Transformation. John Wiley \& Sons, Ltd., n/a-n/a.

Hagens, N.J. 2009: The Oil Drum Demographic/Opinion Survey Results.

Hall, C., Balogh, S. and Murphy, D. 2009: What is the Minimum EROI that a Sustainable Society Must Have? Energies 2, 25-47.

Hall, C., Powers, R. and Schoenberg, W. 2008: Peak Oil, EROI, Investments and the Economy in an Uncertain Future. Biofuels, Solar and Wind as Renewable Energy Systems, 109-132.

Haller, M. and Hadler, M. 2006: How Social Relations and Structures can Produce Happiness and Unhappiness: An International Comparative Analysis. Social Indicators Research 75, 169-216.

Haque, A. 2001: GIS, Public Service, and the Issue of Democratic Governance. Public Administration Review 61, 259-265.

Harley, J.B. and Cosgrove, D.B. 1988: Maps, Knowledge and Power. Cambridge, UK: Cambridge University Press. 
Hassan, F.A. 2008: The Lie of History: Nation-states and the contradictions of complex societies. In Costanza, R., Graumlich, L. and Steffen, W.L., editors, Sustainability or Collapse?: An integrated history and future of people on earth, Cambridge, MA: MIT Press in cooperation with Dahlem University Press, 169-196.

Hayek, F.A. 1945: The Use of Knowledge in Society. The American Economic Review 35, 519-530.

Hayo, B. and Seifert, W. 2003: Subjective economic well-being in Eastern Europe. Journal of Economic Psychology 24, 329-348.

Heinberg, R. 2007: Out of time? Public Policy Research 14, 197-203.

Heinberg, R. 2009: Searching for a Miracle: "Net energy" limits and the fate of industrial society. International Forum on Globalisation and the Post Carbon Institute.

Helliwell, J.F. 1994: Empirical Linkages between Democracy and Economic Growth. British Journal of Political Science 24, 225-248.

Hirsch, R.L., Bezdek, R. and Wendling, R. 2005: Peaking of World Oil Production: Impacts, mitigation, and risk management. Morgantown, WV: Science Applications International Corporation, 91.

Hoare, B. and Thomas, K. 2007: Deep Organics. In Harre, N. and Atkinson, Q.D., editors, Carbon Neutral by 2020, Nelson, NZ: Craig Potton Publishing, 164-184.

Holmes, J. and Marra, M. 2004: Relational Practice in the Workplace: Women's Talk or Gendered Discourse? Language in Society 33, 377-398.

Homer-Dixon 2006: The Upside of Down: Catastrophe, creativity, and the renewal of civilization. Washington, DC: Island Press.

Hopkins, R. 2008: The Transition Handbook: From oil dependency to local resilience. Totnes, UK: Green Books.

Hopper, J. and McCarlneilson, J. 1991: Recycling as Altruistic Behaviour: Normative and behavioural strategies to expand participation in a community recycling program. Environment and Behavior 23.

Hopwood, B., Mellor, M. and O'Brien, G. 2005: Sustainable development: mapping different approaches. Sustainable Development 13, 38-52.

Imam, A., Startzman, R.A. and Barrufet, M.A. 2004: Multicyclic Hubbert Model Shows Global Conventional Gas Output Peaking in 2019. Oil \& Gas Journal 102, 20-27.

Industry Task Force on Peak Oil and Energy Security 2010: The Oil Crunch: A wake-up call for the UK economy. In Roberts, S., editor, London.

Inghilleri, P. 1999: From subjective experience to cultural change. New York: Cambridge University Press. 
International Energy Agency 2006: World Energy Outlook. Paris.

International Monetary Fund - International Labor Organisation 2010: The Challenges of Growth, Employment and Social Cohesion. Joint ILO-IMF Conference in Cooperation with the Office of the Prime Minister of Norway, Oslo, Norway.

International Monetary Fund 2010: World Economic Outlook -Rebalancing Growth.

Jackson, T. 2009: Prosperity Without Growth: Economics for a finite planet. London: Earthscan.

Jankowski, P. 2009: Towards participatory geographic information systems for community-based environmental decision making. Journal of Environmental Management 90, 1966-1971.

Janssen, M.A. and Scheffer, M. 2004: Overexploitation of Renewable Resources by Ancient Societies and the Role of Sunk-Cost Effects. Ecology and Society 9.

Jick, T.D. 1979: Mixing Qualitative and Quantitative Methods: Triangulation in Action. Administrative Science Quarterly 24, 602-611.

Johansson, K., Liljequist, K., Ohlander, L. and Aleklett, K. 2010: Agriculture as Provider of Both Food and Fuel. AMBIO: A Journal of the Human Environment 39, 91-99.

Kahane, A. 2010: Power and Love: A theory and practice of social change. San Franciso, CA: Berret-Koehler Publishers Inc. .

Kahn, M.E. and Kotchen, M.J. 2010: Environmental Concern and the Business Cycle: The chilling effects of Recession. Cambridge, MA: National Bureau of Economic Research.

Keefer, T.S. 2005: Of Hand Mills and Heat Engines: Peak oil, class struggle and the Thermodynamics of Production. Graduate Program in Political Science, Toronto: York University.

Keen, S. 1997: From Stochastics to Complexity in Models of Economic Instability. Nonlinear Dynamics, Psychology, and Life Sciences 1, 151-172.

Keen, S. 2009a: Bailing out the Titanic with a Thimble. Economic Analysis and Policy 39, 3-24.

Keen, S. 2009b: The Confidence Trick. The Australasian Accounting Business \& Finance Journal 3.

Keen, S. 2009c: The Global Financial Crisis, Credit Crunches, and Deleveraging. Journal of Australian Political Economy 64.

Keen, S. 2009d: Household Debt: The Final Stage in an Artificially Extended Ponzi Bubble. Australian Economic Review 42, 347-357. 
Keynes, J.M. 1923: A Tract on Monetary Reform. London.

Keynes, J.M. 1930: The Great Slump of 1930. Nation \& Atheneum London.

Keynes, J.M. 1936: The General Theory of Employment, Interest and Money. London: Macmillan.

Khatri, V., Vessey, I., Ram, S. and Ramesh, V. 2006: Cognitive Fit Between Conceptual Schemas and Internal Problem Representations: The case of geospatiotemporal conceptual schema comprehension. IEEE Transactions on Professional Communication 49, 109-127.

Kindleberger, C. 1973: The World in Depression 1929 - 1939. Berkeley and Los Angeles, CA: University of California Press.

King Jr., M.L. 1967: Where do we go from here? , Souther Christian Leadership Conference, Atlanta, Georgia.

Kleinman, J. 2009: Local Food and the Problem of Public Authority. Technology and Culture 50, 399-417.

Kolata, A. 2006: Before and After Collapse: Reflections on the regeneration of social complexity. In Schwartz, G.M. and Nichols, J.J., editors, After Collapse: The regeneration of complex societies, Tucson, AZ: University of Arizona Press, 208221.

Kolb, D. 1973: On management and the learning process. Working Paper, Boston: Alfred P. Sloan School of Managment, 70.

Kraimer, M.L., Seibert, S.E. and Liden, R.C. 1999: Psychological Empowerment as a Multidimensional Construct: A Test of Construct Validity. Educational and Psychological Measurement 59, 127-142.

Krasny, M. and Tidball, K. 2008: Systems Theory in Environmental Education: Participation, self-organisation, and community interactions. American Educational Research Association: Cornell University.

Krasny, M. and Tidball, K. 2009: Community Gardens as Contexts for Science, Stewardship, and Civic Action Learning. Cities and the Environment 2, 18.

Kunz, H. 2009: Energy and Globalization: A fairy tale - no happy ending. 2nd International Biophysical Economics Conference, Syracuse, NY.

Kurtz, C.F. and Snowden, D. 2003: The New Dynamics of Strategy: Sense-making in a complex and complicated world. IBM Systems Journal 42, 462-483.

Kydland, F.E. and Prescott, E.C. 1990: Business Cycles: Real facts and a monetary myth. Quarterly Review of the Federa Reserve Bank of Minneapolis 14, 3-18.

Kyem, P. and Saku, J.C. 2009: Web-Based GIS and the Future of Participatory GIS Applications within Local and Indigenous Communities. The Electronic Journal of Information Systems in Developing Countries 38, 1. 
Kyem, P.A.K. 2001: Power, Participation, and Inflexible Institutions: An

Examination of the Challenges to Community Empowerment in Participatory GIS

Applications. Cartographica: The International Journal for Geographic Information and Geovisualization 38, 5-17.

Lave, J. and Wenger, E. 1991: Situated Learning: Legitimate Peripheral Participation. Cambridge, UK: Cambridge University Press.

Lawn, P.A. 2001: Goods and services and the dematerialisation fallacy: implications for sustainable development indicators and policy. International Journal of Services Technology and Management 2, 363-376.

Lawson, J., Baron-Cohen, S. and Wheelwright, S. 2004: Empathising and Systemising in Adults with and without Asperger Syndrome. Journal of Autism and Developmental Disorders 34, 301-310.

Lawson, T. 1995: A Realist Perspective on Contemporary "Economic Theory". Journal of Economic Issues 29, 1-32.

Lawson, T. 1996: Developments in Economics as Realist Social Theory. Review of Social Economy 54, 405 - 422.

Lee, M. and Koh, J. 2001: Is empowerment really a new concept? The International Journal of Human Resource Management 12, 684 - 695.

Levin, M. and Greenwood, D.J. 2008: The Future of Universities: Action Research and the Transformation of Higher Education. In Reason, P. and Bradbury, H., editors, The SAGE Handbook of Action Research: Participative Inquiry and Practice, London, UK: SAGE Publications, 211-251.

Lewin, K. 1946: Action Research and Minority Problems. Journal of Social Issues 2.

Li, J. and Ayres, R. 2008: Economic Growth and Development: Towards a Catchup Model. Environmental and Resource Economics 40, 1-36.

Liedloff, J. 1986: The Contiuum Concept: In search of hapiness lost. New York: Perseus Books.

LLoyd, R. 2006: Understanding and Learning Maps. In Kitchin, R. and Freundschuh, S., editors, Cognitive Mapping: Past, present and future, London: Routledge.

Lovelock, J. 2006: James Lovelock: The Earth is about to catch a morbid fever that may last as long as 100,000 years. The Independent.

Luke, T.W. 1999: Living with Nature: Environmental Politics as Cultural Discourse. Oxford: Oxford University Press.

Luke, T.W. 2009: An Apparatus of Answers? Ecologism as Ideology in the 21st Century. New Political Science 31, 487 - 498.

Lund, P.D. 2007: Upfront resource requirements for large-scale exploitation schemes of new renewable technologies. Renewable Energy 32, 442-458. 
Lyson, T.A. 2004: Civic Agriculture: Reconnecting farm, food, and community. Lebanon, NH: Tufts University Press.

MacEachren, A.M. 2004: How Maps Work: Representation, visualization and design. New York: The Guilford Press.

MacEachren, A.M. and Ganter, J.H. 1990: A Pattern Identification Approach to Cartographic Visualisation. Cartographica: The International Journal for Geographic Information and Geovisualization 27, 64-81.

Massi, P. 1997: IMF Estimates of Potential Output: Theory and Practice. In Fund, T.R.D.o.t.I.M., editor, Staff Studies for the World Economic Outlook, Washington, DC: International Monetary Fund, 40-46.

Masters, J. 1995: The History of Action Research. Action Research Electronic Reader, Sydney: The University of Sydney, 8.

McCall, M.K. and Minang, P.A. 2005: Assessing participatory GIS for communitybased natural resource management: claiming community forests in Cameroon. Geographical Journal 171, 340-356.

McClintlock, N. 2008: From Industrial Garden to Food Desert: Unearthing the root structure of urban agriculture in Oakland, California. ISSC Fellows Working Papers: University of California, Berkeley.

McKenzie-Mohr, D. and Smith, W. 1999: Fostering Sustainable Behaviour: An introduction to community-based social marketing. Gabriola Island, BC, Canada: New Society.

McMahon, T. 1999: Is reflective practice synonymous with action research? Educational Action Research 7, 163-169.

Meadows, D.H., Meadows, D.L., Randers, J. and Behrens, W.W. 1972: The Limits to Growth: A report for the club of Rome's project on the predicament for mankind. New York: Universe Books.

Minsky, H.P. 1992: The Financial Instability Hypothesis. The Jerome Levy Institute of Bard College, 10.

Mohr, S. 2010: Projection of World Fossil Fuel Production with Demand and Supply Interactions. Department of Engineering, Newcastle, Australia: University of Newcastle, 259.

Mohr, S. and Evans, G. 2007: Model Proposed for World Conventional, Unconventional Gas. Oil \& Gas Journal 105, 46 - 51.

Mohr, S. and Evans, G. 2009: Forecasting coal production until 2100. Fuel 88, 20592067.

Mokyr, J., Philippe, A. and Steven, N.D. 2005: Chapter 17 Long-Term Economic Growth and the History of Technology. Handbook of Economic Growth: Elsevier, 1113-1180. 
Mollison, B. 1990: Permaculture: A practical guide for a sustainable future. Washington, DC: Island Press.

Moore, B.J. 1979: The Endogenous Money Stock. Journal of Post Keynesian Economics 2, 49-70.

Morris, D. 1996: The Human Zoo: A zoologist's classic study of the urban animal. New York: Kodansha America Inc.

Mudd, G.M. and Ward, J.D. 2008: Will Sustainability Constraints Cause 'Peak Minerals' ? , 3rd International Conference on Sustainability Engineering and Science: Blueprints for Sustainable Infrastructure, Auckland, NZ, 10.

Nell, E. 1987: Economics: The revival of the political economy. In Albelda, R., Gunn, C. and Waller, W., editors, Alternatives to economic orthodoxy: a reader in political economy, Armonk, NY: M. E. Sharpe, Inc, 89-106.

Nyborg, K., Howarth, R.B. and Brekke, K.A. 2006: Green consumers and public policy: On socially contingent moral motivation. Resource and Energy Economics 28, 351-366.

Oakeshott, M. 1994: Rationalism in Politics. In McKevitt, D. and Lawton, A., editors, Public Sector Management, London, UK: SAGE Publications, 4-10.

Odum, H.T. and Odum, E.C. 2006: The prosperous way down. Energy 31, 21-32.

Organisation for Economic Cooperation and Development 2009: IEA Renewables Information. Renewable Balances: OECD.

Orlov, D. 2008: Reinventing Collapse: The Soviet example and American prospects. Gabriola Island: New Society Publishers.

Oskamp, S. 2000: Psychological Contributions to Achieving an Ecologically Sustainable Future for Humanity. Journal of Social Issues 56, 373-390.

Palley, T. 2007: Financialization: What it is and why it matters. Finance-led Capitalism? Macroeconomic Effects of Changes in the Financial Sector, Berlin: The Levy Economics Institute, 31.

Parsons, R.J., Gutierrez, L.M. and Cox, E.O. 1998: A model for empowerment practice. In Parsons, R.J., Gutierrez, L.M. and Cox, E.O., editors, Empowerment in Social work Practice: A sourcebook, Pacific Grove, CA: Brooks/Cole, 3-23.

Pearce, J.M. 2008: Thermodynamic Limitations to nuclear energy deployment as a greenhouse gas mitigation technology. International Journal of Nuclear Governance, Economy and Ecology 2, 113-127.

Pearson, R. 2003: Argentina's Barter Network: New currency for new times? Bulletin of Latin American Research 22, 214-230.

Pickles, J., editor 1995a: Ground Truth: The social implications of geographic information systems. New York: The Guilford Press. 
Pickles, J. 1995b: Ground Truth: The social implications of geographic information systems. New York: Guilford Press.

Pomeranz, K. 2000: The Great Divergence: China, Europe and the making of the modern world economy. Prineton, NJ: Princeton University Press.

Quigley, C. 1979: The Evolution of Civilizations: An introduction to historical analysis. London: Macmillan.

Rambaldi, G., McCall, M., Weiner, D., Mbile, P. and Kyem, P. 2004: Participatory GIS...? : Integrated Approaches to Participatory Development (IAPAD).

Raskin, P.D. 2000: Bending the Curve: Toward global sustainability. Development 43, 67-74.

Reason, P. 2006: Choice and Quality in Action Research Practice. Journal of Management Inquiry 15, 187-203.

Reinhart, C. and Reinhart, V. 2010: After the Fall. Federal Reserve Bank of Kansas City -Jackson Hole Symposium, Jackson Hole, WY.

Reinhart, C. and Rogoff, K. 2009: This Time is Different: Eight centuries of financial folly. Princeton, NJ: Princeton University Press.

Reynolds, D. 1994: Energy grades and economic growth. Journal of Energy and Development 19, 245-263.

Riding, R. and Cheema, I. 1991: Cognitive styles--an overview and integration. Educational Psychology 11, 193.

Riger, S. 1993: What's wrong with empowerment? American Journal of Community Psychology 21, 279-292.

Rossinow, D. 1997: The New Left in the Counterculture: Hypotheses and Evidence. Radical History Review 1997, 79-120.

Roxburgh, C., Lund, S., Wimmer, T., Amar, E., Atkins, C., Kwek, J.-H., Dobbs, R. and Manyika, J. 2010: Debt and Deleveraging: The global creadit bubble and its economic cosequences. McKinsey Global Institute.

Rudningen, J. 2009: Transition Towns: An intervention method for encouraging proenvironmental behaviour change. Environmental Studies, Wellington, NZ: Victoria, University of Wellington, 144.

Ryan, R. and Deci, E. 2000: Self-Determination Theory and the Facilitation of Intrinsic Motivation, Social Devlopment and Well-Being. American Psychologist 55, 68-78.

Sahlins, M. 2004: Stone Age Economics. London: Routledge. 
Saldivar-Tanaka, L. and Krasny, M.E. 2004: Culturing community development, neighborhood open space, and civic agriculture: The case of Latino community gardens in New York City. Agriculture and Human Values 21, 399-412.

Sapolsky, R.M. 2004: Social Status and Health in Humans and Other Animals. Annual Review of Anthropology 33, 393-418.

Scharmer, C.O. 2009: Theory U. San Francisco, CA: Berret-Koehler Publishers.

Schumacher, E.F. 1973a: Buddhist Economics. In Schumacher, E.F., editor, Small is Beautiful London: Blond \& Briggs, 56-66.

Schumacher, E.F. 1973b: Small is Beautiful: a study of economics as if people mattered. London: Blond and Briggs.

Schumacher, I. 2009: The dynamics of environmentalism and the environment. Ecological Economics 68, 2842-2849.

Scott, J.C. 1998: Seeing Like a State: How certain schemes to improve the human condition have failed. New Haven and London: Yale University Press.

Seeth, H.T., Chachnov, S., Surinov, A. and Von Braun, J. 1998: Russian poverty: Muddling through economic transition with garden plots. World Development 26, 1611-1624.

Senge, P.M. 1990: The Fifth Discipline: The art and practice of the learning organisation. New York: Doubleday.

Sharashkin, L. 2008: The Socioeconomic and Cultural Significance of Food Gardening in the Vladimir Region of Russia. Columbia: University of Missouri, 293.

Sheldon, K. and Kasser, T. 2008: Psychological threat and extrinsic goal striving. Motivation and Emotion 32, 37-45.

Sieber, R. and Wellen, C. 2007: Blending Participatory GIS and Geo-Spatial Ontologies for Indigenous Knowledge Preservation. McGill University.

Simon, J. 1981: The Ultimate Resource. Princeton, NJ: Princeton University Press.

Smil, V. 2005: Energy at the Crossroads: Global perspectives and uncertainties. Boston, MA: MIT Press.

Solomon, B.B. 1976: Black Empowerment: Social work in oppressed communities. New York: Colombia University Press.

Sorrell, S. 2010: Energy, Growth and Sustainability: Five propositions. SPRU Electronic Working Paper, Brighton, UK: University of Sussex, 25.

Spreitzer, G.M. 1995: Psychological Empowerment in the Workplace: Dimensions, Measurement, and Validation. The Academy of Management Journal 38, 1442-1465. 
Steffen, A. 2009: Transition Towns or Bright Green Cities? , Worldchanging, Seattle, WA: Worldchanging.

Stern, D.I., Common, M.S. and Barbier, E.B. 1996: Economic growth and environmental degradation: The environmental Kuznets curve and sustainable development. World Development 24, 1151-1160.

Stern, P.C., Dietz, T., Abel, T., Guagnano, G.A. and Linda, K. 1999: A Value-BeliefNorm Theory of Support for Social Movements: The case of environmentalism. Human Ecology Review 6, 81-97.

Tainter, J.A. 1988: The Collapse of Complex Societies. Cambridge, UK: Cambridge University Press.

Tainter, J.A. 2000: Problem Solving: Complexity, History, Sustainability. Population \& Environment 22, 3-41.

Tainter, J.A., Allen, T.F.H., Little, A. and Hoekstra, T.W. 2003: Resource Transitions and Energy Gain: Contexts of Organisations. Conservation Ecology 7.

Thomas, G. 1998: The Myth of Rational Research. British Educational Research Journal 24, 141 - 161.

Thomas, K. and Velthouse, B. 1990: Cognitive Elements of Empowerment: An "Interpretive" Model of Intrinsic Task Motivation. The Academy of Management Review 15, 666-681.

Vitiello, D. and Nairn, M. 2009: Community Gardening in Philidelphia: 2008 Harvest Report. Penn Planning and Urban Studies, University of Pennsylvania, 68.

Walti, S. 2009: The Myth of Decoupling. Munich: Munich University.

Warr, B. and Ayres, R. 2006: REXS: A forecasting model for assessing the impact of natural resource consumption and technological change on economic growth. Structural Change and Economic Dynamics 17, 329-378.

Weich, S. and Lewis, G. 1998: Poverty, unemployment, and common mental disorders: population based cohort study. BMJ 317, 115-119.

Wenger, E. 1998: Communities of Practice: Learning, meaning and identity. Cambridge, UK: Cambridge University Press.

Wenger, E., McDermott, R. and Snyder, W. 2002: Cultivating Communities of Practice: A guide to managing knowledge. Boston: Havard Business School Press.

Wheatley, M. and Freize, D. 2006: Using Emergence to Take Social Innovations to Scale. The Berkana Institute, 9.

Wheelwright, S., Baron-Cohen, S., Goldenfeld, N., Delaney, J., Fine, D., Smith, R., Weil, L. and Wakabayashi, A. 2006: Predicting Autism Spectrum Quotient (AQ) from the Systemizing Quotient-Revised (SQ-R) and Empathy Quotient (EQ). Brain Research 1079, 47-56. 
Whitehead, A.N. 1967: Science and the Modern World. New York: Simon and Schuster.

Whitehead, H. and Richerson, P.J. 2009: The evolution of conformist social learning can cause population collapse in realistically variable environments. Evolution and Human Behavior 30, 261-273.

Wilson, R.A. 2003: Prometheus Rising. Tempe, AZ: New Falcon Publications.

Wood, R. and Bandura, A. 1989: Social Cognitive Theory of Organizational Management. The Academy of Management Review 14, 361-384.

Zimmerman, M. 1995: Psychological empowerment: Issues and illustrations. American Journal of Community Psychology 23, 581-599.

Zittel, W. and Schindler, J. 2007: Coal: Resources and Future Production. Munich: Ludwig Bölkow Systemtechnik GmbH. 


$\begin{array}{ll}\text { AVCC } & \text { Aro Valley Community Council } \\ \text { CofP } & \text { Community of Practice } \\ \text { EEA } & \text { Environment of Evolutionary Adaptiveness } \\ \text { EIA } & \text { Energy Information Administration } \\ \text { EJ } & \text { Exajoule } \\ \text { EQ } & \text { Empathiser Quotient } \\ \text { EROI } & \text { Energy Return On Invested } \\ \text { E-S } & \text { Empathiser-Systemiser } \\ \text { GDP } & \text { Gross Domestic Product } \\ \text { GFC } & \text { Global Financial Crisis } \\ \text { GI } & \text { Geographic Information } \\ \text { GIS } & \text { Geographic Information Systems } \\ \text { IMF } & \text { International Monetary Fund } \\ \text { KTA } & \text { Kai o Te Aro ('the food of Aro') } \\ \text { Mb/d } & \text { Million barrels per day } \\ \text { PGC1998 } & \text { Parsons Gutierrez and Cox, 1998 } \\ \text { PGIS } & \text { Participatory Geographic Information Systems } \\ \text { PPGIS } & \text { Public Participation Geographic Information Systems } \\ \text { PK } & \text { Post Keynesian } \\ \text { SD } & \text { Self-Determination } \\ \text { SQ } & \text { Systemiser Quotient } \\ \text { TV1990 } & \text { Thomas and Velthouse, 1990 } \\ \text { VUW } & \text { Victoria University of Wellington } \\ \text { WCC } & \text { Wellington City Council } \\ & \end{array}$


1. What street do you live on?

- How far away from the gardens is this?

2. How long have you lived there?

3. What is the Kai o Te Aro initiative as you see it?

How did you become involved in Kai o Te Aro initiative?

4. Do you have a garden yourself?

(if yes) What do you grow?

(if no) Have you ever had a garden?

5. Did you know the others before the project started?

(if yes) Please describe your relationships to the other participants before the project began.

6. What expertise did you bring to the project?

Have you facilitated groups or done project management?

7. Have you used maps in your job or in a hobby?

What about GIS?

8. What motivates you to become involved in Kai o Te Aro (KTA)?

-Has this changed over time?

9. What activities have you participated in?

-Working bees

-Gardening individually on own initiative

-Monthly meetings

10. How often would you say you do those things?

11. Do you enjoy some of these things more than others?

12. What is it about the [things interviewee enjoys] that you like?

13. Have you learnt any skills?

-For example about particular plants or gardening skills

-(If yes) Please tell me how you learnt these things?

For example

-By copying others?

-By trying to understand the principles and testing those principles? 
14. Do you enjoy using maps or not?

(if yes) Could you describe how you use maps and why you enjoy using them?

(if no) What don't you like about maps?

16. We used several maps in the monthly meetings, some of which were requested by members (for example, the scale map of the secret garden). Did you request any? -Why

17. Were the variety of maps I brought to the monthly meetings and working bees and the map we designed useful for you personally or not?

-(if yes)How have they been useful?

-(if no) Do you think others may have found them useful or not?

18. Has your perspective on maps and there uses changed during your involvement with KTA? -(if yes) How?

19. Do you think you have things in common with other members of KTA or not?

(if yes) How do you learn these things about the others?

(if no) What are the differences?

20. Have there been times when you have felt an obligation to the group that has influenced any decisions to contribute to KTA projects?

21. Tell me about times you think we have worked well together and the reasons for that. What about times where we haven't worked well together? -And the reasons for that?

22. Does KTA seem like a cohesive group or not? Should it be more cohesive or like it is now? How might that happen?

23. Has your perspective on involvement in community groups changed as a result of KTA? -(if yes) How?

24. Are there any other things you'd like to talk about or questions you'd like to ask me?

Thank you for taking part in this study. You will have the opportunities to obtain and discuss the results with me individually and as a group with the other participants. Any opinions you have expressed will remain confidential to me and my supervisor. I will be happy to provide written copies of the results and a research summary. 


\section{Appendix B :}

\section{Systemiser Quotient and Empathiser Quotient Questionnaire}

\section{Participant \# .....}

\section{How to fill out the questionnaire}

Below is a list of statements. Please read each statement very carefully and rate how strongly you agree or disagree with it by writing an ' $\mathrm{X}$ ' in the appropriate box. Take special note of whether the statement contains a 'not'. There are no right or wrong answers, or trick questions.

\section{IN ORDER FOR THE SCALE TO BE VALID, YOU MUST ANSWER EVERY QUESTION.}

\section{Examples}

\begin{tabular}{|c|c|c|c|c|c|}
\hline & & $\begin{array}{l}\text { strongly } \\
\text { agree }\end{array}$ & $\begin{array}{l}\text { slightly } \\
\text { agree }\end{array}$ & $\begin{array}{l}\text { slightly } \\
\text { disagree }\end{array}$ & $\begin{array}{l}\text { strongly } \\
\text { disagree }\end{array}$ \\
\hline E1 & I would be very upset if I couldn't listen to music every day. & $\mathrm{X}$ & & & \\
\hline E2 & $\begin{array}{l}\text { I prefer to speak to my friends on the phone rather than } \\
\text { write letters to them. }\end{array}$ & & $\mathrm{X}$ & & \\
\hline E3 & I have no desire to travel to different parts of the world. & & $\mathrm{X}$ & & \\
\hline E4 & I prefer to read than to dance. & & & $\mathrm{X}$ & \\
\hline
\end{tabular}

\begin{tabular}{|l|l|l|l|l|l|}
\hline & & $\begin{array}{l}\text { strongly } \\
\text { agree }\end{array}$ & $\begin{array}{l}\text { slightly } \\
\text { agree }\end{array}$ & $\begin{array}{l}\text { slightly } \\
\text { disagree }\end{array}$ & $\begin{array}{l}\text { strongly } \\
\text { disagree }\end{array}$ \\
\hline 1. & $\begin{array}{l}\text { I find it very easy to use train timetables, even if this } \\
\text { involves several connections. }\end{array}$ & & & \\
\hline
\end{tabular}




\begin{tabular}{|c|c|c|c|c|c|}
\hline 2. & $\begin{array}{l}\text { I like music or book shops because they are clearly } \\
\text { organised. }\end{array}$ & & & & \\
\hline 3. & $\begin{array}{l}\text { I would not enjoy organising events e.g. fundraising } \\
\text { evenings, fetes, conferences. }\end{array}$ & & & & \\
\hline 4. & $\begin{array}{l}\text { When I read something, I always notice whether it is } \\
\text { grammatically correct. }\end{array}$ & & & & \\
\hline 5. & $\begin{array}{l}\text { I find myself categorising people into types (in my own } \\
\text { mind). }\end{array}$ & & & & \\
\hline 6. & I find it difficult to read and understand maps. & & & & \\
\hline 7. & $\begin{array}{l}\text { When I look at a mountain, I think about how precisely } \\
\text { it was formed. }\end{array}$ & & & & \\
\hline & & $\begin{array}{l}\text { strongly } \\
\text { agree }\end{array}$ & $\begin{array}{l}\text { slightly } \\
\text { agree }\end{array}$ & $\begin{array}{l}\text { slightly } \\
\text { disagree }\end{array}$ & $\begin{array}{l}\text { strongly } \\
\text { disagree }\end{array}$ \\
\hline 8. & $\begin{array}{l}\text { I am not interested in the details of exchange rates, } \\
\text { interest rates, stocks and shares. }\end{array}$ & & & & \\
\hline 9. & $\begin{array}{l}\text { If I were buying a car, I would want to obtain specific } \\
\text { information about its engine capacity. }\end{array}$ & & & & \\
\hline 10. & $\begin{array}{l}\text { I find it difficult to learn how to programme video } \\
\text { recorders. }\end{array}$ & & & & \\
\hline 11. & $\begin{array}{l}\text { When I like something I like to collect a lot of different } \\
\text { examples of that type of object, so I can see how they } \\
\text { differ from each other. }\end{array}$ & & & & \\
\hline 12. & $\begin{array}{l}\text { When I learn a language, I become intrigued by its } \\
\text { grammatical rules. }\end{array}$ & & & & \\
\hline 13. & $\begin{array}{l}\text { I like to know how committees are structured in terms } \\
\text { of who the different committee members represent or } \\
\text { what their functions are. }\end{array}$ & & & & \\
\hline 14. & $\begin{array}{l}\text { If I had a collection (e.g. CDs, coins, stamps), it would } \\
\text { be highly organised. }\end{array}$ & & & & \\
\hline
\end{tabular}




\begin{tabular}{|c|c|c|c|c|c|}
\hline 15. & $\begin{array}{l}\text { I find it difficult to understand instruction manuals for } \\
\text { putting appliances together. }\end{array}$ & & & & \\
\hline \begin{tabular}{|l}
16. \\
.
\end{tabular} & $\begin{array}{l}\text { When I look at a building, I am curious about the } \\
\text { precise way it was constructed. }\end{array}$ & & & & \\
\hline \begin{tabular}{|l}
17. \\
\end{tabular} & $\begin{array}{l}\text { I am not interested in understanding how wireless } \\
\text { communication works (e.g. mobile phones). }\end{array}$ & & & & \\
\hline 18. & $\begin{array}{l}\text { When travelling by train, I often wonder exactly how } \\
\text { the rail networks are coordinated. }\end{array}$ & & & & \\
\hline \begin{tabular}{|l}
19. \\
.
\end{tabular} & $\begin{array}{l}\text { I enjoy looking through catalogues of products to see } \\
\text { the details of each product and how it compares to } \\
\text { others. }\end{array}$ & & & & \\
\hline 20. & $\begin{array}{l}\text { Whenever I run out of something at home, I always } \\
\text { add it to a shopping list. }\end{array}$ & & & & \\
\hline 21. & $\begin{array}{l}\text { I know, with reasonable accuracy, how much money } \\
\text { has come in and gone out of my bank account this } \\
\text { month. }\end{array}$ & & & & \\
\hline \begin{tabular}{|l}
22. \\
\end{tabular} & $\begin{array}{l}\text { When I was young I did not enjoy collecting sets of } \\
\text { things e.g. stickers, football cards etc. }\end{array}$ & & & & \\
\hline \begin{tabular}{|l}
23. \\
\end{tabular} & $\begin{array}{l}\text { I am interested in my family tree and in understanding } \\
\text { how everyone is related to each other in the family. }\end{array}$ & & & & \\
\hline 24. & $\begin{array}{l}\text { When I learn about historical events, I do not focus on } \\
\text { exact dates. }\end{array}$ & & & & \\
\hline \begin{tabular}{|l}
25. \\
\end{tabular} & $\begin{array}{l}\text { I find it easy to grasp exactly how odds work in } \\
\text { betting. }\end{array}$ & & & & \\
\hline 26. & $\begin{array}{l}\text { I do not enjoy games that involve a high degree of } \\
\text { strategy (e.g. chess, Risk, Games Workshop). }\end{array}$ & & & & \\
\hline \multirow[t]{2}{*}{27.} & $\begin{array}{l}\text { When I learn about a new category I like to go into } \\
\text { detail to understand the small differences between } \\
\text { different members of that category. }\end{array}$ & & & & \\
\hline & & $\begin{array}{l}\text { strongly } \\
\text { agree }\end{array}$ & $\begin{array}{l}\text { slightly } \\
\text { agree }\end{array}$ & $\begin{array}{l}\text { slightly } \\
\text { disagree }\end{array}$ & $\begin{array}{l}\text { strongly } \\
\text { disagree }\end{array}$ \\
\hline
\end{tabular}




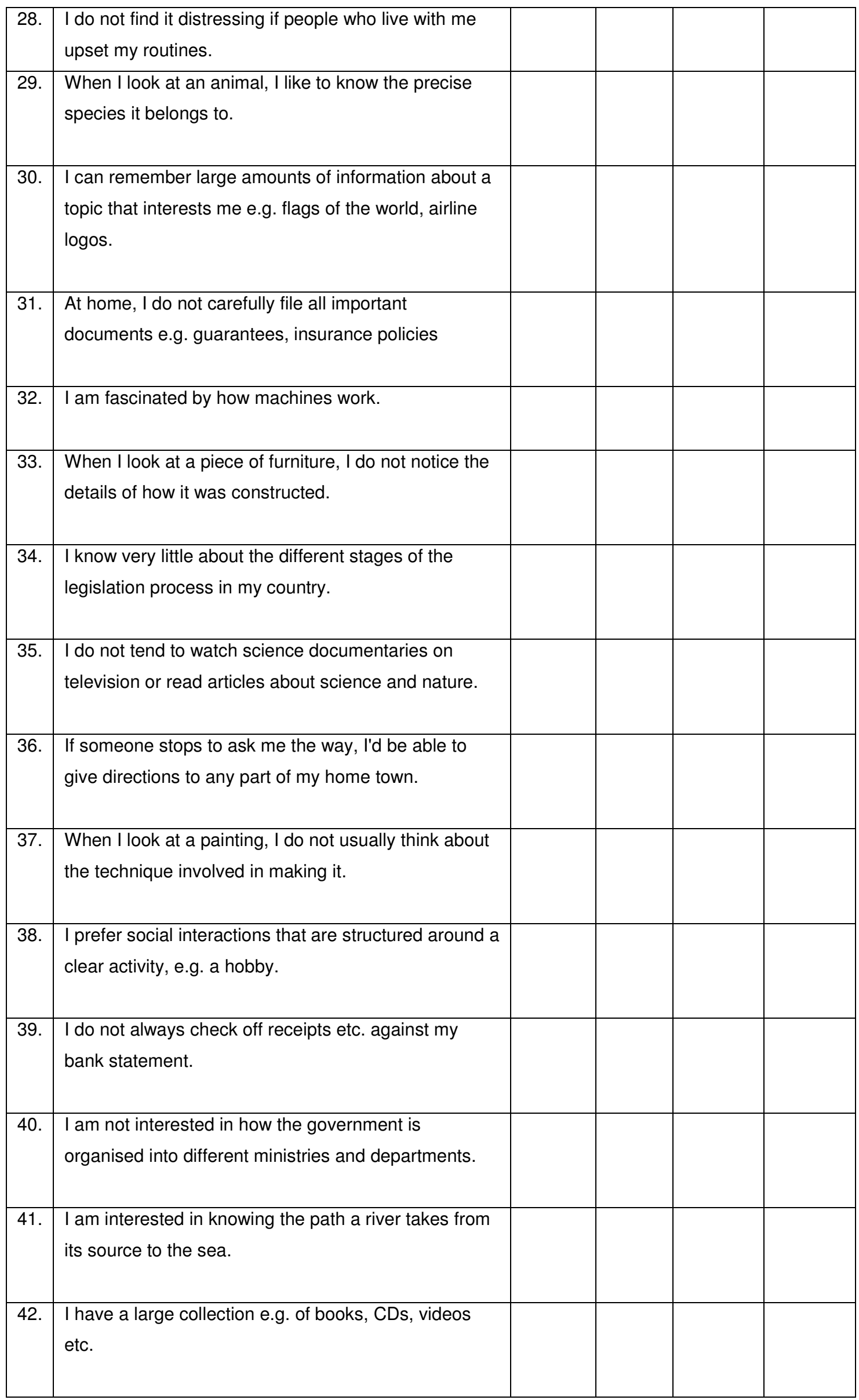




\begin{tabular}{|l|l|l|l|l|l|}
\hline 43. & $\begin{array}{l}\text { If there was a problem with the electrical wiring in my } \\
\text { home, l'd be able to fix it myself. }\end{array}$ & & & & \\
\hline 44. & $\begin{array}{l}\text { My clothes are not carefully organised into different } \\
\text { types in my wardrobe. }\end{array}$ & & & & \\
\hline 45. & $\begin{array}{l}\text { I rarely read articles or webpages about new } \\
\text { technology. }\end{array}$ & $\begin{array}{l}\text { I can easily visualise how the motorways in my region } \\
\text { link up. }\end{array}$ & & & \\
\hline 47. & $\begin{array}{l}\text { When an election is being held, I am not interested in } \\
\text { the results for each constituency. }\end{array}$ & & & & \\
\hline
\end{tabular}

\begin{tabular}{|c|c|c|c|c|c|}
\hline & & $\begin{array}{l}\text { strongly } \\
\text { agree }\end{array}$ & $\begin{array}{l}\text { slightly } \\
\text { agree }\end{array}$ & $\begin{array}{l}\text { slightly } \\
\text { disagree }\end{array}$ & $\begin{array}{l}\text { strongly } \\
\text { disagree }\end{array}$ \\
\hline 48. & $\begin{array}{l}\text { I do not particularly enjoy learning about facts and } \\
\text { figures in history. }\end{array}$ & & & & \\
\hline 49. & $\begin{array}{l}\text { I do not tend to remember people's birthdays (in terms } \\
\text { of which day and month this falls). }\end{array}$ & & & & \\
\hline 50 . & $\begin{array}{l}\text { When I am walking in the country, I am curious about } \\
\text { how the various kinds of trees differ. }\end{array}$ & & & & \\
\hline 51. & $\begin{array}{l}\text { I find it difficult to understand information the bank } \\
\text { sends me on different investment and saving } \\
\text { systems. }\end{array}$ & & & & \\
\hline 52. & $\begin{array}{l}\text { If I were buying a camera, I would not look carefully } \\
\text { into the quality of the lens. }\end{array}$ & & & & \\
\hline 53. & $\begin{array}{l}\text { If I were buying a computer, I would want to know } \\
\text { exact details about its hard drive capacity and } \\
\text { processor speed. }\end{array}$ & & & & \\
\hline
\end{tabular}




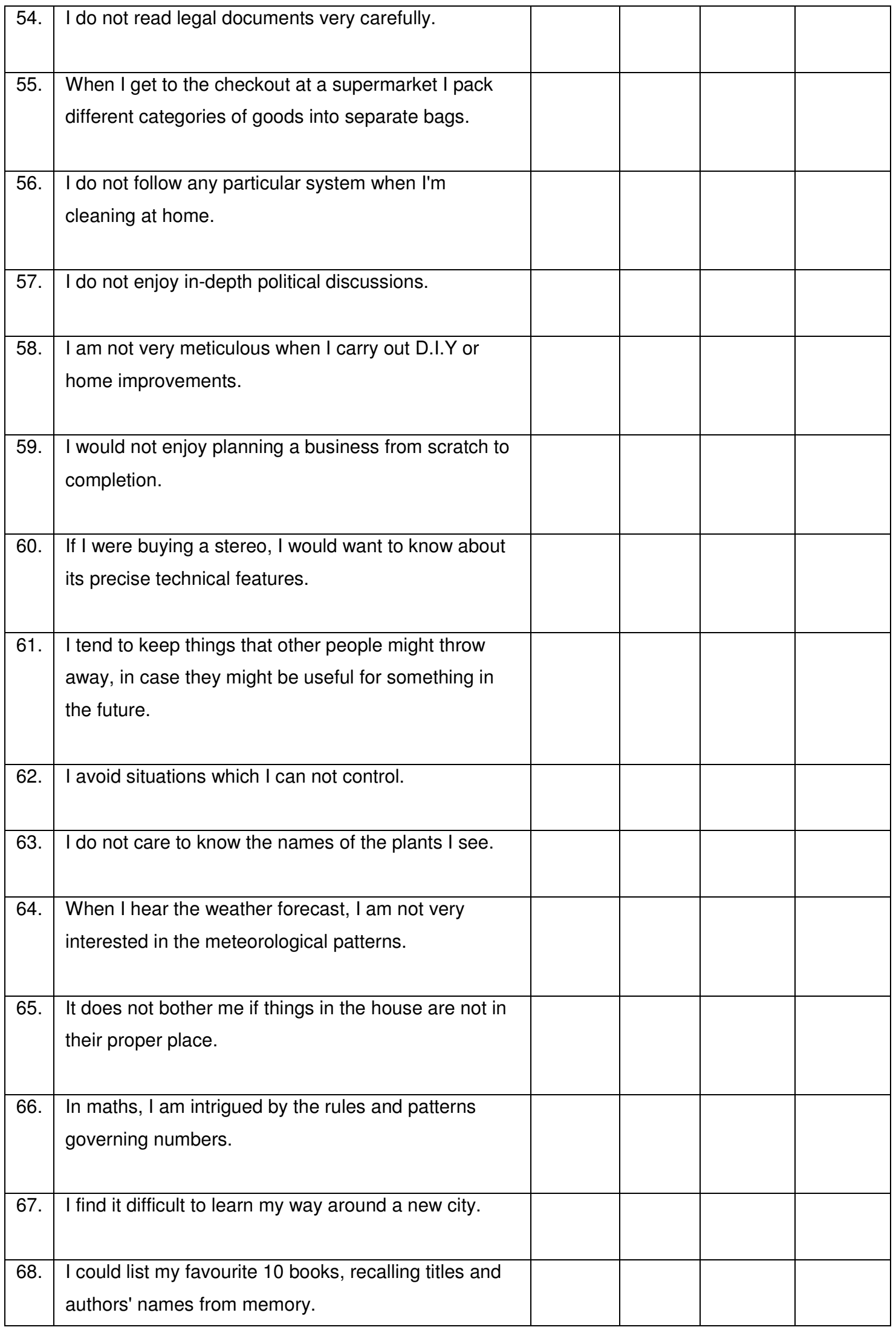

\begin{tabular}{|l|l|l|l|l|l|}
\hline & & strongly & slightly & slightly & strongly \\
\hline
\end{tabular}




\begin{tabular}{|c|c|c|c|c|c|}
\hline & & agree & agree & disagree & disagree \\
\hline 70. & $\begin{array}{l}\text { When I'm in a plane, I do not think about the } \\
\text { aerodynamics. }\end{array}$ & & & & \\
\hline 71. & I do not keep careful records of my household bills. & & & & \\
\hline 72. & $\begin{array}{l}\text { When I have a lot of shopping to do, I like to plan } \\
\text { which shops I am going to visit and in what order. }\end{array}$ & & & & \\
\hline 73. & $\begin{array}{l}\text { When I cook, I do not think about exactly how different } \\
\text { methods and ingredients contribute to the final } \\
\text { product. }\end{array}$ & & & & \\
\hline 74. & $\begin{array}{l}\text { When I listen to a piece of music, I always notice the } \\
\text { way it's structured. }\end{array}$ & & & & \\
\hline 75. & $\begin{array}{l}\text { I could generate a list of my favourite } 10 \text { songs from } \\
\text { memory, including the title and the artist's name who } \\
\text { performed each song. }\end{array}$ & & & & \\
\hline 76. & $\begin{array}{l}\text { I can easily tell if someone else wants to enter a } \\
\text { conversation. }\end{array}$ & & & & \\
\hline 77. & $\begin{array}{l}\text { I find it difficult to explain to others things that I } \\
\text { understand easily, when they don't understand it first } \\
\text { time. }\end{array}$ & & & & \\
\hline 78. & I really enjoy caring for other people. & & & & \\
\hline 79. & I find it hard to know what to do in a social situation. & & & & \\
\hline 80. & $\begin{array}{l}\text { People often tell me that I went too far in driving my } \\
\text { point home in a discussion. }\end{array}$ & & & & \\
\hline 81. & $\begin{array}{l}\text { It doesn't bother me too much if I am late meeting a } \\
\text { friend. }\end{array}$ & & & & \\
\hline 82. & $\begin{array}{l}\text { Friendships and relationships are just too difficult, so I } \\
\text { tend not to bother with them. }\end{array}$ & & & & \\
\hline 83. & I often find it difficult to judge if something is rude or & & & & \\
\hline
\end{tabular}




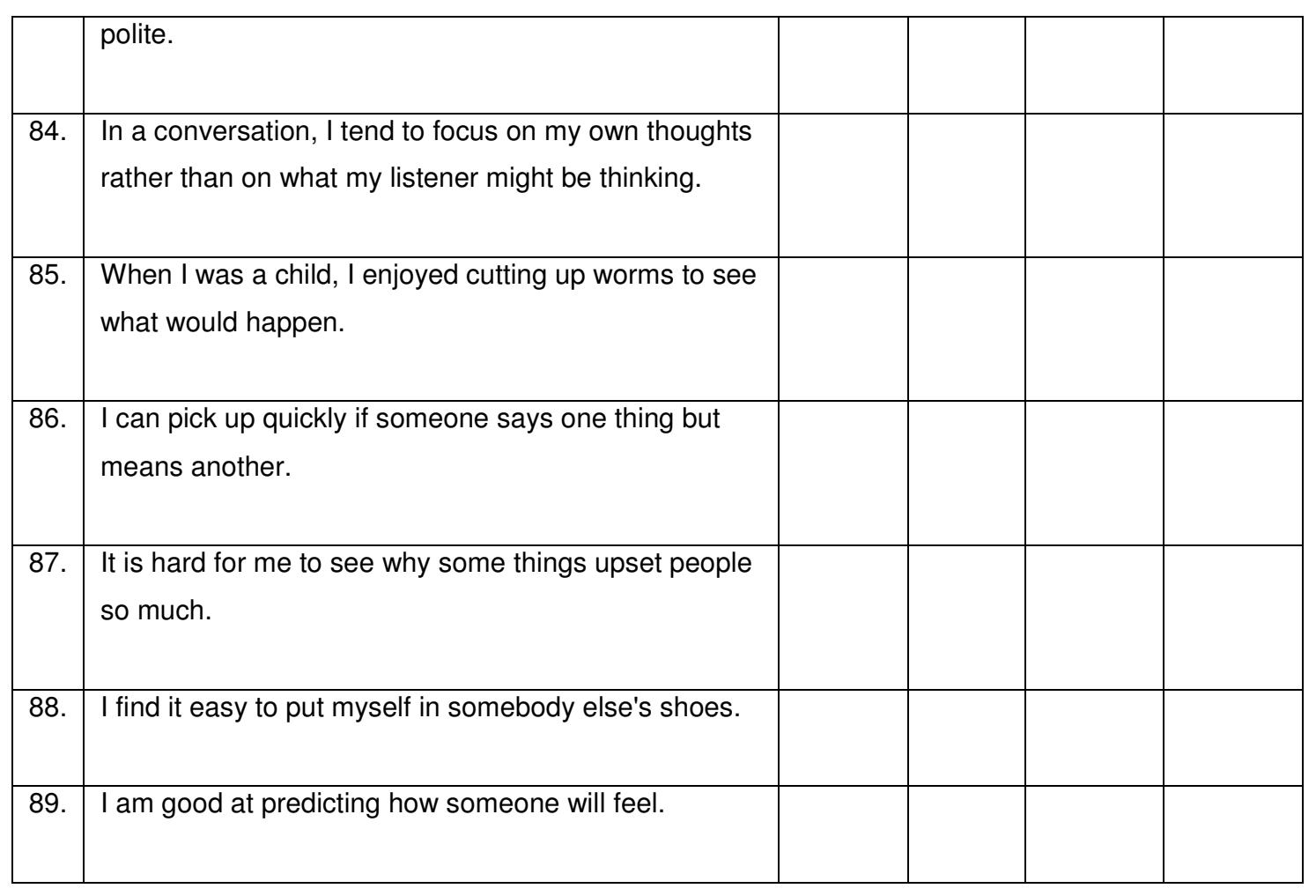

\begin{tabular}{|l|l|l|l|l|l|}
\hline & & $\begin{array}{l}\text { strongly } \\
\text { agree }\end{array}$ & $\begin{array}{l}\text { slightly } \\
\text { agree }\end{array}$ & $\begin{array}{l}\text { slightly } \\
\text { disagree }\end{array}$ & $\begin{array}{l}\text { strongly } \\
\text { disagree }\end{array}$ \\
\hline 90. & $\begin{array}{l}\text { I am quick to spot when someone in a group is } \\
\text { feeling awkward or uncomfortable. }\end{array}$ & & & & \\
\hline 91. & $\begin{array}{l}\text { If I say something that someone else is offended by, } \\
\text { I think that that's their problem, not mine. }\end{array}$ & & & & \\
\hline 92. & $\begin{array}{l}\text { If anyone asked me if I liked their haircut, I would } \\
\text { reply truthfully, even if I didn't like it. }\end{array}$ & & & & \\
\hline 93. & $\begin{array}{l}\text { I can't always see why someone should have felt } \\
\text { offended by a remark. }\end{array}$ & & & & \\
\hline 94. & Seeing people cry doesn't really upset me. & & & & \\
\hline 95. & $\begin{array}{l}\text { I am very blunt, which some people take to be } \\
\text { rudeness, even though this is unintentional. }\end{array}$ & & & & \\
\hline 96. & I don't tend to find social situations confusing. & & & & \\
\hline
\end{tabular}




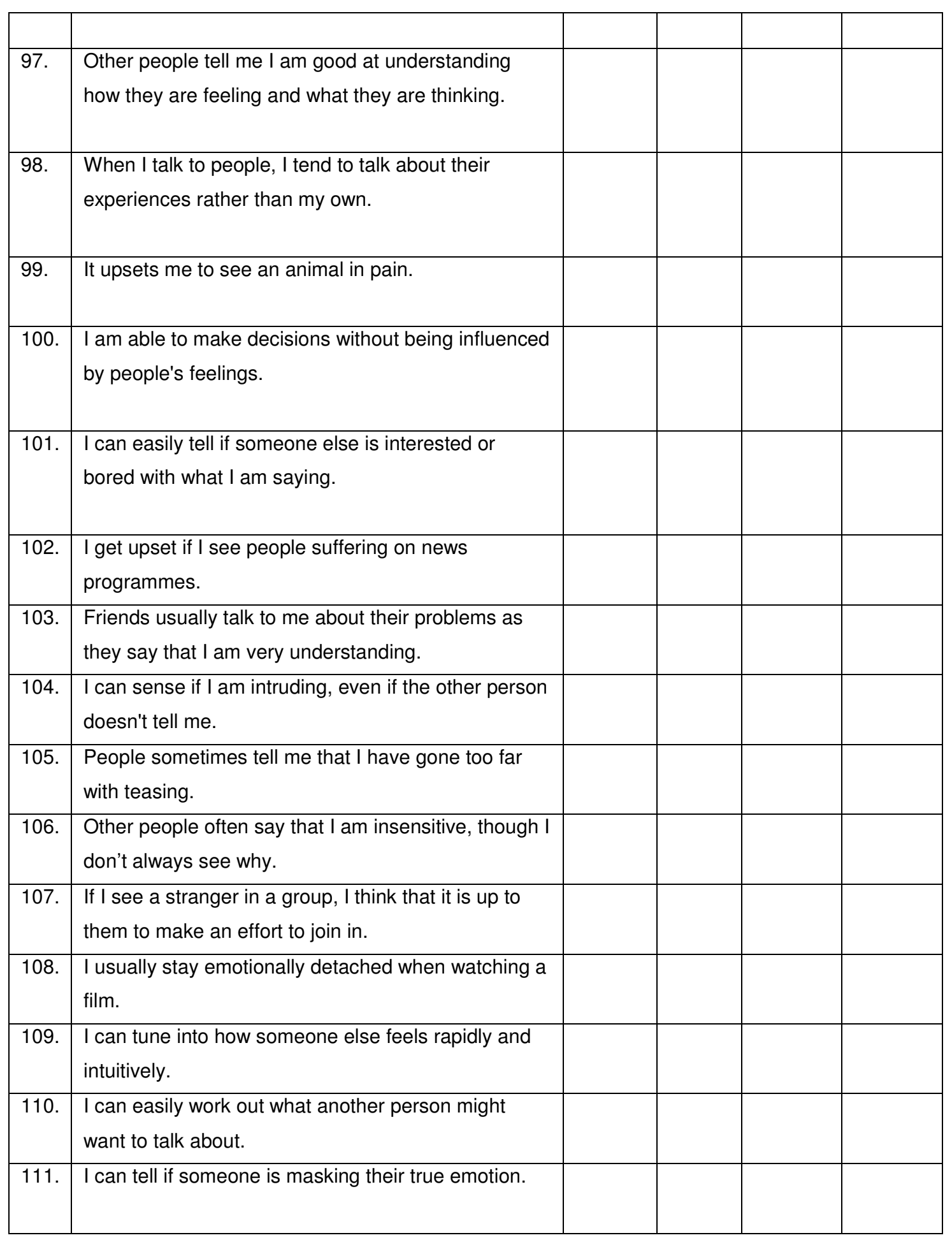




\begin{tabular}{|l|l|l|l|l|l|}
\hline 112. & $\begin{array}{l}\text { strongly } \\
\text { agree } \\
\text { I don't consciously work out the rules of social } \\
\text { situations. }\end{array}$ & $\begin{array}{l}\text { slightly } \\
\text { agree }\end{array}$ & $\begin{array}{l}\text { slightly } \\
\text { disagree }\end{array}$ & $\begin{array}{l}\text { strongly } \\
\text { disagree }\end{array}$ \\
\hline 113. & I am good at predicting what someone will do. & & & & \\
\hline 114. & $\begin{array}{l}\text { I tend to get emotionally involved with a friend's } \\
\text { problems. }\end{array}$ & $\begin{array}{l}\text { I can usually appreciate the other person's } \\
\text { viewpoint, even if I don't agree with it. }\end{array}$ & & & \\
\hline 115. & & & & \\
\hline
\end{tabular}




\section{Appendix C:}

\section{Copy of Participant Information Sheet}

IE WHARE WINANGA O TH CROKO O IE IKA A MAUI

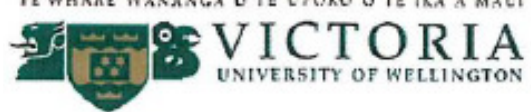

Participant Information Sheet for a Study on Participatory Geographic Information Systems (PGIS) in A ro Valley

Rescarcher: Simon 'Tegg,

Phone: (04) 4639463

Email: simontegg@gmail.com

Supervisor:

Dr Maircad de Roiste

Phone: (04) 4636431

School of Geography, Environment and Farth Sciences,

Victoria University of Wellington.

PO Box 600

Wellington 6100

(04) 4635337

\section{Dear Project Participant,}

I am a Masters student in Environmental Studies at Victoria Lniversity of Wellington. I am undertaking research to investigate the empowerment of community gardeners through a participatory investigation of geographic information and mapping of their local area (the PGIS project). I am inviting people who are involved, or who would like to be involved in the ongoing $\Lambda$ Valley community gardening initiative, Kai o Te Aro to participatc in this stu

Participants will be introduced to Geographic Information Systems (GIS), it: relevant uses and limilations in 30 minute 1 hour focus group. Participant: will be asked to decide on project goals and collaborate with cach other and co-participant researcher in a series of Participatory GIS workshops.

It is anticipated that a varicty of maps will be incorporated into monthly meetings between the months of October, 2009 - May, 2010. Participants wi retain control on the nature and extent of map activities. Participants may be unfamiliar with maps and mapping. Potential uses will be introduced by the researcher. If these uses are decmed relevant to group goals by participants $t$ will be pursued. If not they will not be considered further. Participants will analyze and discuss geographic information; and contribute their own knowledge as a regular part of the meetings. This process will likely product map(s). These maps may be useful in advertising Kai o Te Aro goals or othe documentation purposes. The ownership and management of any map(s) wil remain with participants. Following this project the participants will be aske reflect on their experiences in a semi-structured intervicw which will take between 1 and 2 hours. $\Lambda$ the end of the interview you will be asked to 
reflect on their experiences in a semi-structured interview which will take between 1 and 2 hours. At the end of the interview you will be asked to complete a 15-20 minute questionnaire that measures your cognitive style. According to theories of cognitive style people have a preference for thinking in a particular way and this may influence the kinds of activities they enjoy. This questionnaire has no right or wrong answers. Even so, you may not wish me to know the answers you have given to particular questions. To ensure your answers are anonymous the questionnaire will not detail your name or other means of identifying you. You will assign the questionnaire a number from a list and seal it in an envelope. Another postgraduate student will score the questionnaire without learning your identity. I will match the score to the assigned number without reading your answers to the questions. The results will be strictly confidential and the questionnaire and results will be returned to you at the end of the research.

\section{Purpose of the Research}

Community gardening projects and community mapping projects involve a variety of activities some of which participants may find empowering. Some people may prefer different activities more than others. The research investigates whether a theory of cognitive style can explain these differences and how this affects PGIS (Participatory Geographic Information Systems) projects.

\section{Right of Withdrawal}

Participants are not required to commit to the PGIS project in its entirety. Should any participants feel the need to withdraw from the project, they may do so without question at any time. Just let me know before the final feedback focus group (see below).

\section{Storage and Disposal of Data}

Audio recordings and notes will be made during the focus group, workshops and interviews. I will transcribe and review the audio recordings. These written transcriptions and the results of the questionnaire will form the basis of research. All material collected will be kept confidential. No other person besides me and my supervisor, Dr Mairead de Roiste, will have access to the recordings and transcripts. The answers to the questionnaire will remain anonymous in the manner described above. The thesis will be submitted for marking to the School of Geography, Environment and Earth Sciences and deposited in the University Library. It is intended that one or more articles will be submitted for publication in scholarly journals. Audio recordings and transcripts will be destroyed three years after the end of the project.

\section{Feedback}

Initial results will be presented back to the participants in a focus group and feedback will be requested. Your feedback on the initial findings is integral to the research.

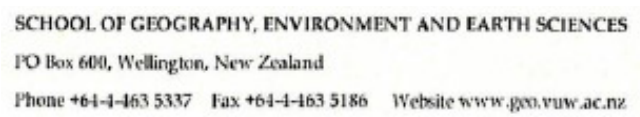




\section{$5=9$ VICTORIA}

If you have any questions about this project, please feel free to ask me now, or contact me, or my supervisor Dr Mairead de Roiste, from the contact details on the first page of the sheet.

Thank you for participating!

Sincerely,

Simon Tegg

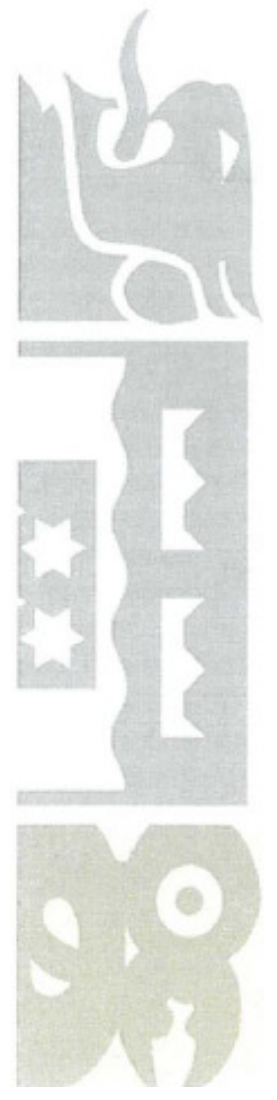




\section{Appendix D:}

\section{Ethics Approval}

TE WHARE WĀNANGA O TE ŪPOKO O TE IKA A MĀUI

MEMORANDUM

Phone $\quad 0-4-4635676$

Fax $\quad 0-4-4635209$

Email_Allison.kirkman@vuw.ac.nz

\begin{tabular}{l|l}
\hline TO & Simon Tegg \\
\hline COPY TO & Dr Mairead de Roiste \\
\hline FROM & Dr Allison Kirkman, Convener, Human Ethics Committee \\
\hline
\end{tabular}

\begin{tabular}{l|l}
\hline DATE & September 28, 2009 \\
\hline PAGES & 1 \\
\hline
\end{tabular}

\begin{tabular}{l|l}
\hline SUBJECT & $\begin{array}{l}\text { Ethics Approval: No } 16856-\text { The Role of Participatory GIS in } \\
\text { seeding food-gardening communities of practice }\end{array}$ \\
\hline
\end{tabular}

Thank you for your application for ethical approval, which has now been considered by the Standing Committee of the Human Ethics Committee.

Your application has been approved from the above date and this approval continues until 01 March 2010. If your data collection is not completed by this date you should apply to the Human Ethics Committee for an extension to this approval.

Best wishes with the research.

Allison Kirkman

Convener

NB: Extension was granted on May 12 2010 
